\title{
Complexity in Inequality
}

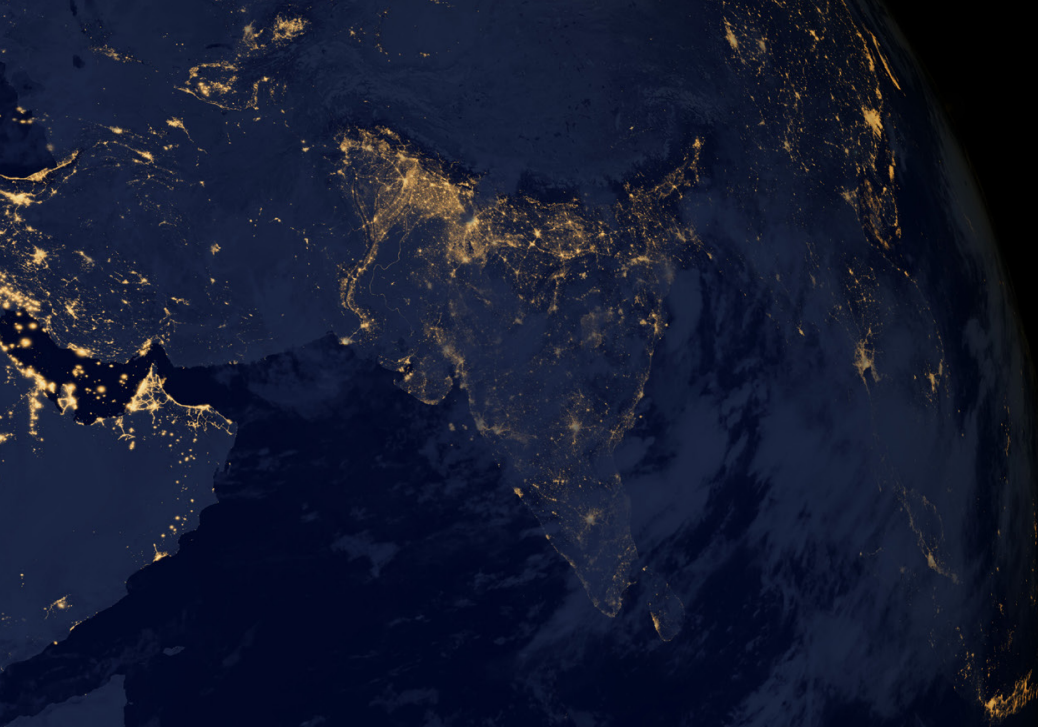





\section{Complexity in Inequality}

M Usman Mirza 


\section{Thesis committee}

\section{Promotor}

Prof Dr Marten Scheffer

Professor of Aquatic Ecology and Water Quality Management|

Wageningen University \& Research

\section{Co-promotors}

Dr Egbert H. van Nes

Researcher, Aquatic Ecology and Water Quality Management

Wageningen University \& Research

Dr Andries P. Richter

Associate Professor, Environmental Economics and Natural Resources

Wageningen University \& Research

\section{Other members}

Prof Dr Tatiana Filatova, University of Twente

Prof Dr Eveline S. van Leeuwen, Wageningen University \& Research

Prof Dr Gert Jan Hofstede, Wageningen University \& Research

Dr Pim de Zwart, Wageningen University \& Research

This research was conducted under the auspices of the Graduate School for SocioEconomic and Natural Sciences of the Environment (SENSE) at Wageningen University, the Netherlands. 


\title{
Complexity in Inequality
}

\author{
M Usman Mirza
}

\section{Thesis}

submitted in fulfilment of the requirements for the degree of doctor at Wageningen University

by the authority of the Rector Magnificus,

Prof. Dr A.P.J. Mol,

in the presence of the

Thesis Committee appointed by the Academic Board

to be defended in public

on Tuesday 4 February 2020

at 1:30 p.m. in the Aula. 
M Usman Mirza

Complexity in Inequality, 130 pages.

$\mathrm{PhD}$ thesis, Wageningen University, Wageningen, the Netherlands (2020) With references and summary in English

ISBN 978-94-6395-185-2

DOI https://doi.org/10.18174/504799 


\section{Table of contents}

$\begin{array}{lll}\text { Chapter 1: } & \text { Introduction } & 1\end{array}$

Chapter 2: $\quad$ Technology driven inequality leads to 10 poverty and resource depletion

Chapter 3: Institutions-inequality interplay shapes 46 the impact of economic growth on biodiversity loss

Chapter 4: Income growth and the structure of inequality

Chapter 5: Global inequality, remotely sensed

$\begin{array}{lll}\text { Chapter 6: } & \text { Synthesis } & 113\end{array}$

$\begin{array}{lll}\text { Chapter 7: } & \text { Summary } & 128\end{array}$ 


\section{Chapter 1}

\section{Introduction: inequality is complex}

"Inequality is widespread and to some extent inevitable...", are the sombre and somewhat tentative words, in which the latest 2018 report on World Inequality begins $^{1}$. While we all harbour strong opinions about rising inequality today, there is little agreement on its nature and drivers. The study of inequality explores a very fundamental and ancient question about the functioning of our societies - why are some individuals or countries rich and others poor? From a normative perspective, inequality can be termed unfair as it violates the basic principles of justice, such as equality of opportunity, but at the same time, neuronal evidence suggests that our brains deem some types of inequality as being fair ${ }^{2}$. Moreover, recent work also suggests that people might actually prefer unequal societies ${ }^{3}$ and in some cases, inequality could even promote beneficial cooperation ${ }^{4}$. On the other hand, there is similarly plenty of evidence on inequality being associated with environmental degradation $^{5}$, social conflict ${ }^{6}$ and loss of economic growth ${ }^{7}$. Moreover, as inequality by its very nature skews the distribution of income, it has negative implications for inclusive growth and the wellbeing of those at the bottom end of the distribution. Inclusive growth here refers to equality of opportunity in the growth process, whereas inequality favours the rich and in the unequal growth process makes them even richer. Malice or opportunity, good or bad, there are still many open questions about how inequality unfolds in the long-run, that we need to understand. How does inequality interact with other economic, social and natural processes in our complex and interconnected world? Do we have the data and empirical evidence to ground our investigation? Do we have a system-wide understanding of inequality and its dynamics in the long run?

Since Kuznets $(1955)^{8}$, we have come a long way in understanding the consequences of inequality. A key turning point, in research methods, was the use of tax data in early $2000 \mathrm{~s}^{9}$, allowing us to capture the elusive top incomes, and shed light into the structural nature of inequality, such as differentiated income growth rates (capital income, labour income etc.) within a heterogeneous population, with the presence of high (entrepreneurs, experienced managers etc.) and low (landowner, farmer etc.) growth types in the population mix ${ }^{10}$. Heterogeneity or a heterogeneous population here is defined as the differentiation based on an individual's capacity, skills, education or access to technology. Armed with this broad-based data, we find large variations in inequality, both across time and between countries, revealing path-dependence on a range of historical and region- 
specific factors. For example, regions such as the Scandinavian countries have historically been equal while Brazil or the Gulf countries have long stayed relatively unequal.

There is no single set of rules which defines the dynamics of inequality. Instead, inequality is complex governed by highly interconnected processes such as technology, globalization, trade and migration. Complexity, of a system or process, is defined as the behaviour that emerges from the interactions, feedbacks and learning of its many heterogeneous sub-elements ${ }^{11}$. These interactions and feedbacks can be highly nonlinear behaviour, causing cyclical dynamics ${ }^{12}$ and/or critical transitions such as tipping points ${ }^{13}$. Similarly, inequality also emerges from the socio-economic interactions of many heterogeneous agents. Inequality as a metric of variation of income might be simple to understand, but how it emerges from the numerous interactions in a society is what makes it complex. For example, high incomes can dominate growth, while restricting gains for the bottom low incomes and/or income growth can be socially determined by interactions with high-income individuals and one's aspirations to match them.

Traditional wisdom, based on the Kuznets curve ${ }^{14}$, hypothesized the relationship between inequality and the stage of development, as measured by economic growth. Here inequality was expected to drop, on average, in the developed world because the countries stabilize after going through the transitionary stages of development, while it was expected to grow in the emerging or developing world, because of initial transitionary growth period. This expected decline in inequality, was consistent with data till the 1980s, after which the sudden rise in incomes of the top $1 \%$, came as a reality check (Fig 1). 


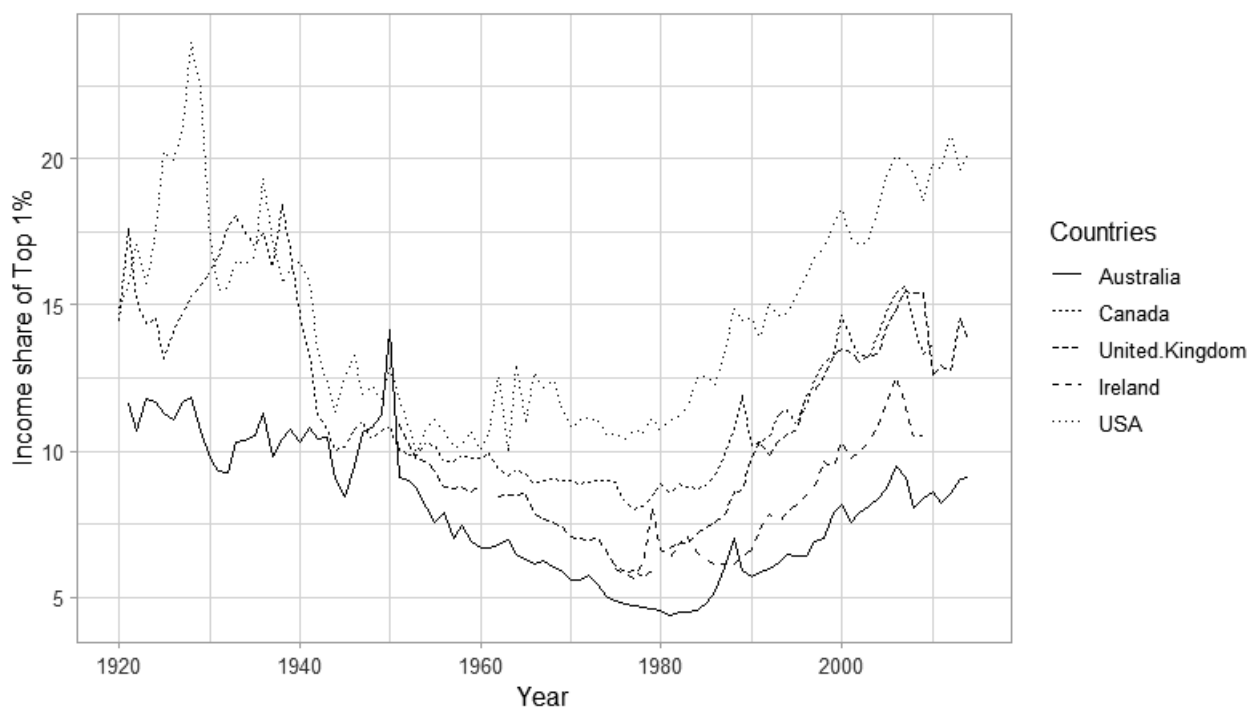

Figure 1: Change in income inequality dynamics post-1980s. Source: WID.world ${ }^{15}$

Post-1980s, top incomes didn't just rise in parts of the developed world, in-fact the trend was global ${ }^{1}$. A look at income growth rates per percentile group shows that the top $1 \%$ is growing much faster than the rest (Fig 2a), capturing more than half of total income over the 1980-2016 period ${ }^{1}$. However this global rise occurs is at very different rates, if we parse by country/region (Fig $2 b$ ). Inequality is highest in the Middle Eastern region and Brazil, while Europe houses the most equal countries. This variation reveals the structural nature of inequality, which is driven by a convolution of complex processes, both global and local, particular to individual countries.

Studies post $1980^{16-20}$, that documented and investigated this worldwide rise of inequality, focused mainly on its micro-foundations. Mostly questioning, what processes at the individual level led to or sustained the unequal distribution of wealth and income. Lobbying power of the rich ${ }^{16}$, credit constraints ${ }^{17}$, skewed education access ${ }^{18}$, distribution of factors of production $^{19}$ and wage differentials ${ }^{20}$ were some of the key highlighted processes. However, a macro perspective into how inequality relates to the aggregate dynamics of the economy was largely missing. These include questions on redistribution mechanisms to make economic growth more inclusive and policy initiatives focusing on intergenerational income mobility so that the wellbeing of those most severely affected by inequality can be preserved. Post-2000 studies by Piketty, Saez, Zucman, Milanovic and others, brought studying distributions back into mainstream macroeconomics ${ }^{12,21-23}$. This 
so-called revolution ${ }^{9}$ in the study of inequality to incorporate a system-wide macro lens was the key motivation behind this thesis, and is what sparked my interest in exploring the 'complexity in inequality'.
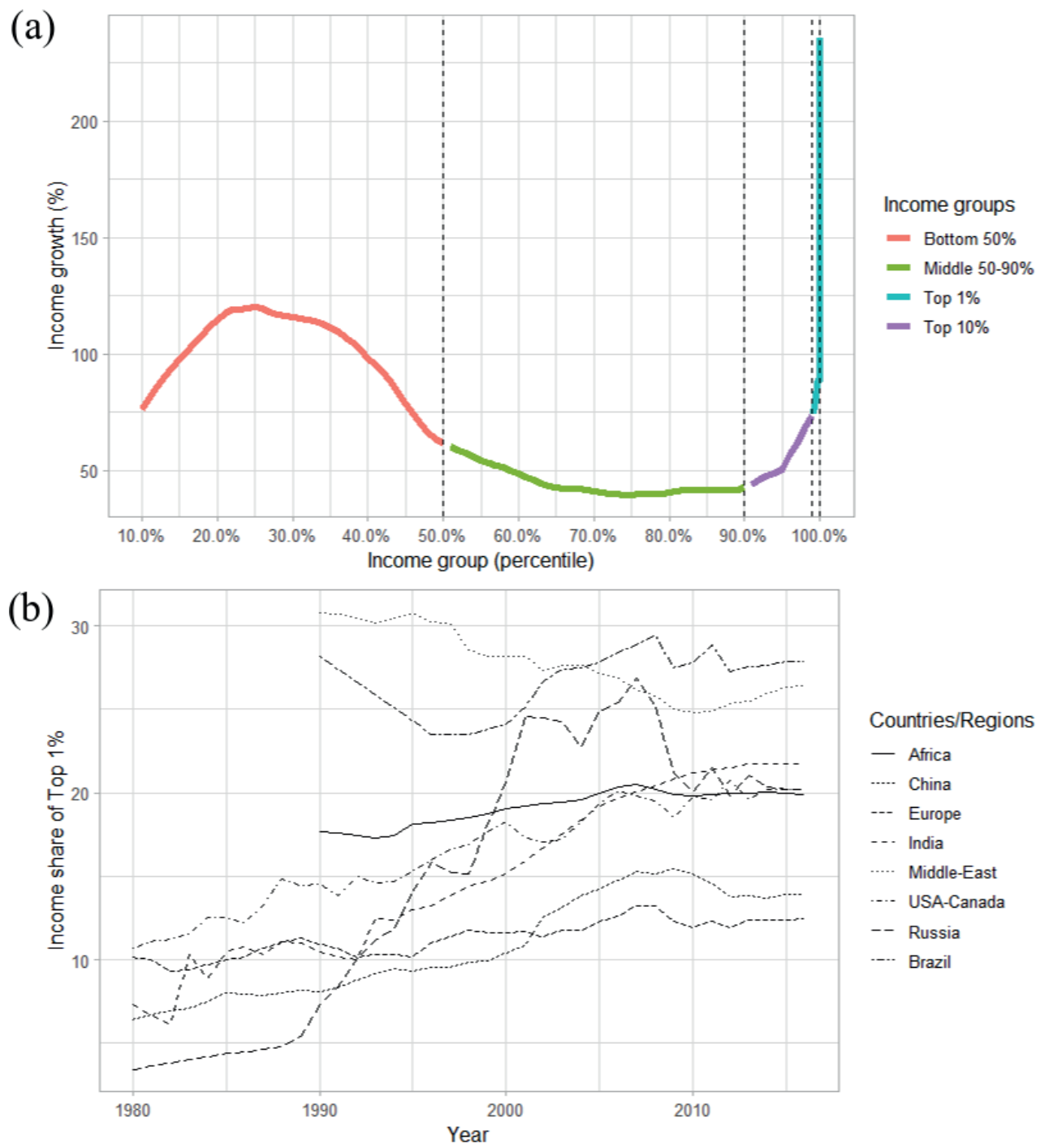

Figure 2: Variation of (a) income growth across income groups and (b) top incomes across countries. Source: WID. world ${ }^{15}$

The current thesis is not a review of all key topics related to inequality (see Atkinson \& Bourguignon (Eds.). (2014) ${ }^{24}$ for a comprehensive review), but rather is motivated by current, novel and policy-relevant avenues in inequality research. 
Understanding the dynamics of inequality in a complex environment, characterized by multifaceted economic, social, technological and ecological dimensions, is at the core of my research interests. Examples include modelling how wealthtechnology feedback allows inequality to emerge and analysing how the interactions between high and low-income growth individuals can reveal the structure of inequality. Work done under this thesis can be classified into two broad categories, theoretic modelling (Chapters 2 and 4) and empirical analysis (Chapters 3 and 5). In modelling inequality, the dynamics are shaped by the interactions of many heterogeneous individuals, as defined by their capacity, skills, access to technology etc. In the data-driven analysis, I use available data to ask whether patterns in income inequality be captured by independent data sources like night lights and how these patterns of inequality interact with environmental variables like biodiversity. Night lights present an interesting avenue to detect inequality as it is remotely sensed and uniform across the globe, as opposed to household surveybased methods of measuring inequality which has problems of comparability and consistency across regions.

This thesis makes three key contributions to current literature. First, it reveals feedbacks and nonlinear interactions, in key variables such as technology and institutions that drive the complex dynamics of inequality. Technology can be thought of as anything that enhances the capacity of individuals to generate income. By institutions, I mean governance effectiveness and rule of law. The idea here is to see how formal rules and regulations limit or control inequality and concentration of economic power. Nonlinearities in the interactions between inequality, technology and institutions help us understand the structural nature of inequality. Second, it uses a non-traditional approach with spatial data on nighttime lights to remotely sense economic inequality and presents the first highresolution global map of light-based inequality and its trends over recent years. Third, it predicts long-term inequality at the country level, using income growth data and a model of the relationship between high and low-income groups. Results for the US, France, China and India are reported. Changes to long-term inequality are also studied with respect to variation in high-income growth rates.

Chapter 2 of this thesis explores how technology-driven income inequality leads to poverty and resource depletion in a developing society. The rapid rise in inequality is often seen to go in-hand with resource overuse. Examples include water extraction in Pakistan, land degradation in Bangladesh, forest harvesting in SubSaharan Africa and industrial fishing in Lake Victoria. Using a coupled dynamic 
economic-ecological model, the aim is to understand feedbacks between system components and key mechanisms that fuel these feedbacks.

Chapter 3 investigates empirically how the strength of national institutions and economic inequality mediates the environmental toll of economic growth.

Evidence suggests that biodiversity loss could make ecosystems more vulnerable to the effects of climate change and other stressors. While economic growth has been identified as a key driver of these biosphere impacts, the size of the impacts depends largely on how society organizes economic activity and distributes its benefits. We find both direct and indirect pathways via which economic growth can affect biodiversity loss. Furthermore, the effectiveness of institutions is conditional on the level of inequality in society, such that biodiversity loss is ameliorated when institutions are strong and inequality low, but in regions with high inequality, institutions tend to lose their efficacy. For example, a country with better institutions and low inequality may be able to effectively enforce conservation regulations such as environmental protected areas or sustainable resource use. However, this might not be the case when inequality is high, as the concentration of power may circumvent the institutional setup. The analysis also uncovers pronounced nonlinearities in inequality-institutions-biodiversity interactions, which are important to investigate further and consider for policy purposes.

Chapter 4 studies the long term structural nature of inequality through modelling the dependence between high- and low-income growths and their respective population sizes. Using income data for the US, France, China and India as case studies, we show that variation in long-run inequality can be explained by the variation in low and high-income growth rates, and the sensitivity of these growth rates to the population size of low incomes. The main contributions of this paper are twofold. First, using dynamic inequality model and income data since 1960, we estimate the long-term stable distribution of income for the US, France, China and India. Our results suggest that inequality is expected to stay around the same level in the US, decline in China and India but increase in France, converging to their respective long-run estimated value. Second, we explore the parameter space with respect to the variation in high and low-income growths for these countries, to understand the long term structure of inequality.

Chapter 5 focuses on the data problem in inequality research. The motivation stemmed from the fact that, though economic inequality is one of the key indicators of social functioning of societies, yet reliable data on income distributions are mostly limited to Northern America and Europe. We aim to address this gap by 
scientifically estimating an independent globally comparable and consistent proxy for economic inequality using remotely sensed geospatial dataset of night-time lights (NTL). The focus here is on light-consumption behaviour, broadly defined, related to residential housing. This includes immediate consumption goods like electricity, house rent etc, and also fixed investments like buying a house. As income rises, a household's light footprint increases in general like more electricity usage, a bigger house, a better neighbourhood with street light etc ${ }^{25}$. Using the consistent tendency for spatial segregation of residential groups to poverty and affluence, we analyse the spatial distribution of light per person as a proxy for variance in economic thriving. The resulting light-based Gini coefficients relate well to existing Gini estimates of net income inequality at the scale of countries globally but also for states within the USA.

Lastly, chapter 6 synthesizes the work done in this thesis, by putting it in the context of existing literature, and also presents a perspective for future research. 


\section{References}

1. Alvaredo, F., Chancel, L., Piketty, T., Saez, E. \& Zucman, G. World Inequality Report 2018. Tijdschr. Geneeskd. (2017). doi:10.2143/TVG.70.09.2001601

2. Cappelen, A. W. et al. Equity theory and fair inequality: A neuroeconomic study. Proc. Natl. Acad. Sci. U. S. A. 111, 15368-15372 (2014).

3. Starmans, C., Sheskin, M. \& Bloom, P. Why people prefer unequal societies. Nature Human Behaviour (2017). doi:10.1038/s41562-017-0082

4. Hauser, O. P., Hilbe, C., Chatterjee, K. \& Nowak, M. A. Social dilemmas among unequals. Nature 572, 524-527 (2019).

5. Boyce, J. K. Inequality as a cause of environmental degradation. Ecol. Econ. 11, 169-178 (1994).

6. Bottero, W. Stratification: Social division and inequality. Stratification: Social Division and Inequality (2004). doi:10.4324/9780203339367

7. Banerjee, A. V. \& Duflo, E. Inequality and growth: What can the data Say? J. Econ. Growth 8, 267-299 (2003).

8. Rubin, A. \& Segal, D. Growth, Expected Growth, and Income Inequality. Am. Econ. Rev. (2013).

9. Jones, C. I. Pareto and Piketty: The macroeconomics of top income and wealth inequality. J. Econ. Perspect. 29, 29-46 (2015).

10. Gabaix, X., Lasry, J.-M., Lions, P.-L. \& Moll, B. The Dynamics of Inequality. Econometrica 84, 2071-2111 (2016).

11. Watkins, N. W. \& Freeman, M. P. Geoscience: Natural complexity. Science 320, 323-324 (2008).

12. Milanovic, B. Income inequality is cyclical. Nature (2016). doi:10.1038/537479a

13. Mirza, M. U., Richter, A., van Nes, E. H. \& Scheffer, M. Technology driven inequality leads to poverty and resource depletion. Ecol. Econ. 160, 215-226 (2019).

14. Kuznets, S. Quantitative Aspects of the Economic Growth of Nations: VIII. Distribution of Income by Size. Econ. Dev. Cult. Change 11, 1-80 (1963).

15. Alvaredo, F., Chancel, L., Piketty, T., Saez, E. \& Zucman, G. World 
inequality database. URL https//wid.world (2018).

16. Alesina, A. \& Rodrik, D. Distributive Politics and Economic Growth. Q. J. Econ. (1994). doi:10.2307/2118470

17. Banerjee, A. V. \& Newman, A. F. Risk-Bearing and the Theory of Income Distribution. Rev. Econ. Stud. 58, 211 (1991).

18. Li, H., Squire, L. \& Zou, H. F. Explaining international and intertemporal variations in income inequality. Econ. J. 108, 26-43 (1998).

19. Deininger, K. \& Squire, L. New ways of looking at old issues: Inequality and growth. J. Dev. Econ. (1998). doi:10.1016/S0304-3878(98)00099-6

20. Juhn, C., Murphy, K. M. \& Pierce, B. Wage inequality and the rise in returns to skill. J. Polit. Econ. 101, 410-442 (1993).

21. Vinet, L. \& Zhedanov, A. A 'missing' family of classical orthogonal polynomials. J. Phys. A Math. Theor. 44, 696 (2011).

22. Saez, E. \& Zucman, G. Wealth in equality in the United States since 1913: Evidence from capitalized income tax data. Q. J. Econ. 131, 519-578 (2016).

23. Alvaredo, F., Atkinson, A. B., Piketty, T. \& Saez, E. The top 1 percent in international and historical perspective. J. Econ. Perspect. 27, 3-20 (2013).

24. Cowell, F., Atkinson, A. \& Bourguignon, F. Handbook of Income Distribution. Handbook of Income Distribution 2, (2000).

25. Henderson, J. V., Storeygard, A. \& Weil, D. N. Measuring economic growth from outer space. American Economic Review 102, 994-1028 (2012). 


\title{
Chapter 2
}

\section{Technology driven inequality leads to poverty and resource depletion}

\author{
M Usman Mirza ${ }^{1,2}$, Andries Richter ${ }^{2}$, Egbert H. van Nes ${ }^{1}$, Marten Scheffer ${ }^{l}$ \\ ${ }^{I}$ Environmental Sciences, Wageningen University, Netherlands \\ ${ }^{2}$ Environmental Economics and Natural Resources Group, Sub-department of \\ Economics, Wageningen University, Netherlands
}

\section{Published as:}

Mirza, M. U., Richter, A., van Nes, E. H., \& Scheffer, M. (2019). Technology driven inequality leads to poverty and resource depletion. Ecological Economics, 160, 215-226. http://doi.org/10.1016/J.ECOLECON.2019.02.015

\begin{abstract}
The rapid rise in inequality is often seen to go in-hand with resource overuse. Examples include water extraction in Pakistan, land degradation in Bangladesh, forest harvesting in Sub-Saharan Africa and industrial fishing in Lake Victoria. While access to ecosystem services provided by common pool resources mitigates poverty, exclusive access to technology by wealthy individuals may fuel excessive resource extraction and deplete the resource, thus widening the wealth gap. We use a stylised social-ecological model, to illustrate how a positive feedback between wealth and technology may fuel local inequality. The resulting rise in local inequality can lead to resource degradation and critical transitions such as ecological resource collapse and an unexpected increase in poverty. Further, we find that societies may evolve towards a stable state of few wealthy and many poor individuals, where the distribution of wealth depends on how access to technology is distributed. Overall, our results illustrate how access to technology may be a mechanism that fuels resource degradation and consequently pushes most vulnerable members of society into a poverty trap.
\end{abstract}

Keywords: Inequality, Technology, Social-ecological systems, Poverty trap 


\section{Introduction}

In growing societies, long-term poverty can be explained by the concept of a "poverty trap" ${ }^{1}$. Here, poverty acts as an attractor where individual wealth dynamics can be trapped in poverty's "basin of attraction". The nature of poverty can be persistent, as individuals trapped in its basin of attraction cannot get out on their own accord ${ }^{2-6}$. At the micro-level, poverty can be conceptualized as a selfreinforcing phenomenon limiting the growth of an individual's wealth ${ }^{7,8}$. Selfreinforcing phenomena emerge from a range of wealth-technology positive feedbacks or frictions causing wealth dynamics to be highly non-linear with local thresholds and increasing returns ${ }^{9-12}$. These include financial factors such as access to low return assets, the set-up cost of high-tech equipment or political economy aspects such as imperfect markets, credit constraints to better technology adaption, differentiated opportunities ${ }^{8,13,14}$. The problem with the persistence of poverty is that it is not only devastating for individuals but can also, over time, lead to persistent inequality within an otherwise growing society.

Different theories attempt to explain the long-run behaviour of inequality. Kuznets in 1955 introduced the hypothesis that inequality rises at first and then drops as gains are distributed more evenly in developing economies, giving rise to an inverted U shaped curve ${ }^{15}$. Recently, Piketty ${ }^{16}$ proposed that in modern capitalistic societies inequality will rise in the absence of government interventions or catastrophic events, such as world wars and the great depression. Milanovic ${ }^{17}$ builds upon both Kuznets and Piketty to propose that inequality moves in cycles the so-called Kuznets waves. Most of existing research on inequality dynamics has focused on macro-level analysis, with little or no focus on local level pathways connecting social-ecological interactions to inequality ${ }^{18}$. Addressing the need to focus on local level interactions, we develop a stylised dynamic model illustrating how key feedbacks and mechanisms can lead to rising inequality in developing societies relying on an ecological resource for livelihood. In studying this stylized model, our contribution to the literature is twofold. First, we unpack complex inequality dynamics by showing how a simple wealth-technology feedback can explain rising local inequality, and second, what pathways allow rising inequality to trigger poverty and resource degradation, considering dynamic socio-ecological interactions.

Indications of a wealth-technology feedback, as a driver of inequality, can be found in both modern and ancient societies. Kohler et al.'s ${ }^{19}$ reconstruction of wealth inequality dynamics in post-Neolithic societies reveals the marked difference between continents. Wealth disparities long remained limited in North America 
and Mesoamerica while in Eurasia inequality rose much more. Evidence suggests that this contrast is due to the availability of large mammals in Eurasia that were domesticated, which is an ancient equivalent to better technology, allowing agricultural extensification ${ }^{19}$. Most likely, only richer households could maintain draft animals allowing them to profit from higher production. Meanwhile in North America and Mesoamerica, such amplification of wealth differences by exclusive access of an elite few to superior productivity was absent.

Similarly, in modern times, numerous case studies illustrate how resource use with technological access to a few can aggravate both inequality and poverty. For example, in Pakistan structural inequality in access to water across regions and between social classes has placed unprecedented stress on water resources ${ }^{20,21}$. The roots of inequality can be traced back to colonial times when land rights were based on patronage exclusive for a few chosen groups of elites ${ }^{22,23}$. Preferential land rights gave birth to big landowners who accumulated wealth and controlled the resource ${ }^{24}$. With modern technology, wealth accumulation took the form of commercial agriculture, where tube wells assisted water overuse ${ }^{25}$, and other lucrative but water-intensive production options like textiles, cement, leather, fertilizers and sugarcane. As a result, small and tenant farmers are pushed-off the resource and forced to migrate ${ }^{26}$.

This and other examples from Amazon rainforest ${ }^{27}$, Bangladesh $^{28}$ and Lake Victoria $^{29}$, show a recurring pattern of increased resource exploitation that goes hand in hand with growing local inequality. Wealth accumulation by elites is achieved by extracting and controlling natural resources, on which the poor population typically also relies, such as commercial agriculture via groundwater exploitation, overfishing for exports and depletion of forests for timber or alternative land use ${ }^{25,27-31}$. As a result, in unequal societies, fast wealth accumulation by the elites may put excessive pressure on key natural resources thus affecting the dependent poor population. Excessive resource use affects dependent livelihoods ${ }^{32-34}$, especially in developing societies where the poor have a primary dependence on ecological or natural resources ${ }^{35-38}$. Thus local inequality can be disastrous for social-ecological resilience and social justice, as wealth accumulation of elites may fuel overexploitation, disregarding sustainable resource use limits ${ }^{39}$ and at the same time disproportionately affecting the poor and most vulnerable members of society.

While equity in distribution is an important aspect of social justice ${ }^{40}$, the ability to access resources is also important for the resilience of the poor ${ }^{41}$. If access to capital, technology and resources are restricted to the elites, wealth accumulation 
and resource extraction for this elite becomes a self-reinforcing phenomenon ${ }^{42-44}$. Wealth wields power to extract resources which in turn generates more wealth, thus mounting pressure on the common natural resource. Left unchecked, this pressure can lead to overexploitation causing environmental degradation or even resource collapse, upon passing certain thresholds ${ }^{45,46}$. Such critical transitions in underlying resources can be sudden, unexpected and in some cases irreversible ${ }^{47}$, with disastrous implications for the dependent population ${ }^{48}$.

There is a need to understand inherent inequality dynamics to determine whether observed patterns described above can be generalized to a much broader set of conditions. In this paper, based on a simple model of local social-ecological interactions in a developing society setting, we argue that resource extraction with a technological advantage exclusive to a few is an important driver of inequality. In particular, we investigate whether rising local inequality leads to reduced resilience of the interdependent social and ecological systems causing critical transitions such as resource collapse and/or poverty traps.

\section{Methods}

We develop a simple coupled social-ecological model to analyse and understand the influence of rising local level inequality on poverty and resource use in an unregulated regime. We begin by outlining key model mechanisms through a conceptual diagram (Fig 1), which is meant to illustrate and aid the actual model description. In the diagram, we see interactions and feedbacks between the social and ecological components of the model through resource extraction and access to technology. Access to technology may give rise to local thresholds (positive wealth-technology feedback) if an increase in the productivity of assets is highly non-linear with respect to increasing assets. For example, a poor farmer may be relatively unproductive because he only owns an ox to plough the fields. A fisherman in a large lake may be limited to smaller radius only due to a small-sized boat. As individuals get richer, they may gain access to technologically better assets with higher productivity. A farmer investing in a tractor may experience a local increase in total and marginal productivity, and the same may be true for a fisher buying a bigger boat. Technology-driven enhanced resource extraction, while stimulating growth of wealth, also negatively affects the growth of resources, which in turn limits the amount of resource available for future extraction (resource-wealth feedback). 
These two feedbacks (wealth-technology and resource-wealth) combined can potentially put exploitative pressure on the resource, which can become depleted or collapse below a certain sustainable threshold.

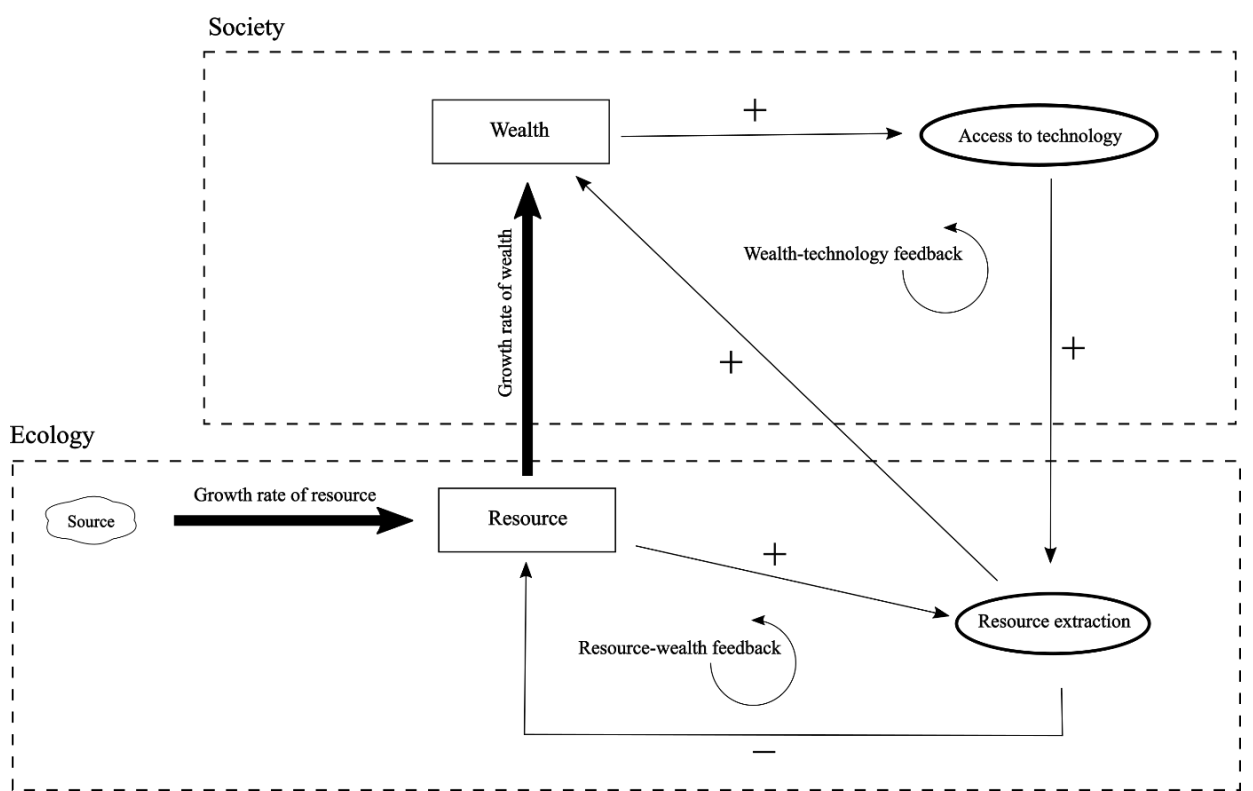

Figure 1: Conceptual sketch of the model structure and interactions showing two feedbacks - wealth-technology and resource-wealth. Boxes and thick arrows and represent state variables and flows between them. Ovals and thinner arrows represent parameters and processes.

\section{Ecological component (resources)}

Resource users have access to a common pool resource $(X)$ that provides services used for earning an income. Resource availability is determined by the dynamics of the ecological resource type in question. We use two examples for ecological resources, portraying a simple abiotic resource (e.g. water) and a more complex biotic resource (e.g. a forest or fish population), building upon earlier approaches ${ }^{48-50}$ in specifying the functional form of those resources. These two types of resources are chosen as two examples of qualitatively different resource dynamics. The simple abiotic resource is assumed to increase with a constant rate (for instance due to precipitation) and to lose as a first-order process (for instance due to transpiration). This results in growth towards an equilibrium with exponential growth limitation ${ }^{51}$ : 
Abiotic: $\quad \frac{d X}{d t}=c\left(1-\frac{X}{X_{\max }}\right)-\sum_{1}^{N} e_{i}\left(\sigma_{i}, a_{i}, X\right)$

$X$ is the total available resource stock, $c$ is the resource inflow, $X_{\text {max }}$ is the maximum resource level, and $\sum_{1}^{N} e_{i}$ is individual resource extraction summed over all individuals, which in turn is a function of technology $\sigma_{i}$, capital assets $a_{i}$ and the resource stock itself $X$. The functional form of $e_{i}$ is provided later in the section.

The biotic resource is motivated by population dynamics examples where a living resource (e.g. fish population) grows logistically but can also collapse if the population is below a critical size, for instance, due to group behaviour or difficulty in finding partners. This well-studied ecological positive feedback is called the Allee effect ${ }^{52-54}$, and the following functional form is widely used for a range of biotic population dynamics ${ }^{55-57}$ :

$$
\text { Biotic: } \quad \begin{aligned}
\frac{d X}{d t} & =\epsilon X\left[X-X_{c}\right]\left[1-\frac{X}{X_{\max }}\right] \\
& -\sum_{1}^{N} e_{i}\left(\sigma_{i}, a_{i}, X\right)
\end{aligned}
$$

where $\epsilon$ is the maximum growth rate of the resource and $X_{c}$ is the critical sustainable resource level.

The abiotic resource model has only one stable equilibrium (Fig. 2a), while the biotic resource model can have three equilibria of which two are stable (Fig. 2b). Resources are used as input in a production process through which individuals generate income and accumulate wealth over time. 
(a) Abiotic resource

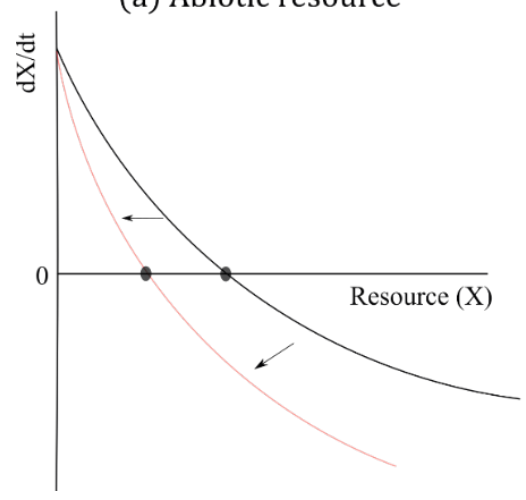

(b) Biotic resource

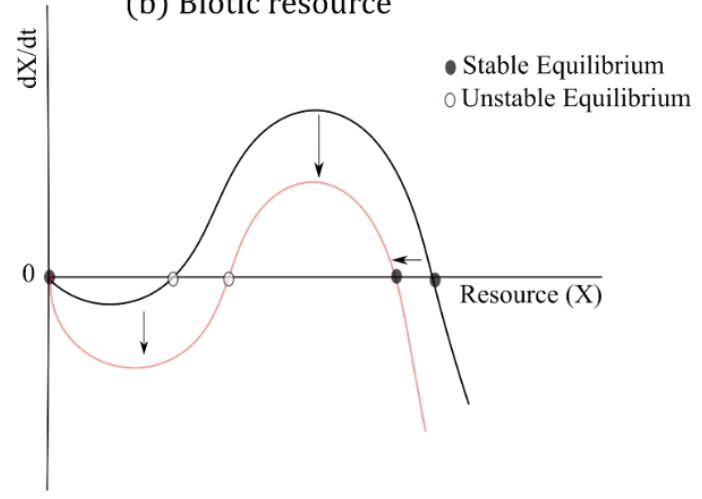

Figure 2: Two models of resources with a constant harvesting pressure: abiotic (a) and biotic resource (b). A shift from a black to red line represents an increase in losses due to resource extraction or harvesting. Note in (b) the distance between the stable (high resource) and unstable equilibrium decreases indicating loss of resilience of the sustainable equilibrium.

\section{Social component (wealth)}

In the model, income $y_{i}$ of individual $i$ is generated using a simplified CobbDouglas production function which uses a combination of natural resources and assets [Eq.(3)]. The function has two inputs - capital assets $a_{i}$ and resource extraction $e_{i}-$ and is given as:

$$
y_{i}=a_{i}^{\alpha} \sigma_{i}\left(a_{i}\right) e_{i}\left(\sigma_{i}, a_{i}, X\right)
$$

where $\sigma_{i}\left(a_{i}\right)$ is the technology function, mapping inputs into output and $\alpha$ is the partial output elasticity of assets. $\alpha<1$ is assumed for marginally decreasing returns on assets.

\subsubsection{Technology}

We assume that above a certain level of assets, individuals get access to advanced technology (Fig. 3). In our model, the parameter $\rho$ determines the strength of this non-linear effect. Thus, an individual's asset level may generate non-convexities with locally increasing marginal returns. In the model, non-convexity is introduced through the technology function $\sigma_{i}$ as follows:

$$
\sigma_{i}=k_{i}\left[(1-\rho)+\frac{\rho a_{i}^{\lambda}}{a_{i}^{\lambda}+\theta^{\lambda}}\right]
$$


$\sigma_{i}$ is specified to range from 0 to maximum $k$, which is a measure of maximum productivity given available access to technology and scaled to 1 . $\lambda$ controls the enhanced wealth generation capacity gained by access to better technology while $\theta$ is the asset level where increasing returns start to set in, determining the presence of these locally increasing returns due to investment in better technology for individuals in a continuum between uniform $(\rho=0)$ to differentiated $(\rho>0)$ access to technology. When $\rho=0$ everyone in the society has access to the same basic technology, giving a standard concave production function with decreasing marginal returns as conventionally assumed in economic models [Fig 3(a) \& (c)]. However, if $\rho>0$, the production function will be non-convex and marginal returns of assets may be locally increasing or decreasing, depending on the asset level [Fig 3(b) \& (d)]. Thus in effect, $\rho$ is actually a control parameter allowing us to switch between a basic null model (diminishing returns when $\rho=0$ ) and a model that includes differentiated access to resources (locally increasing returns when $\rho>$ $0)$.
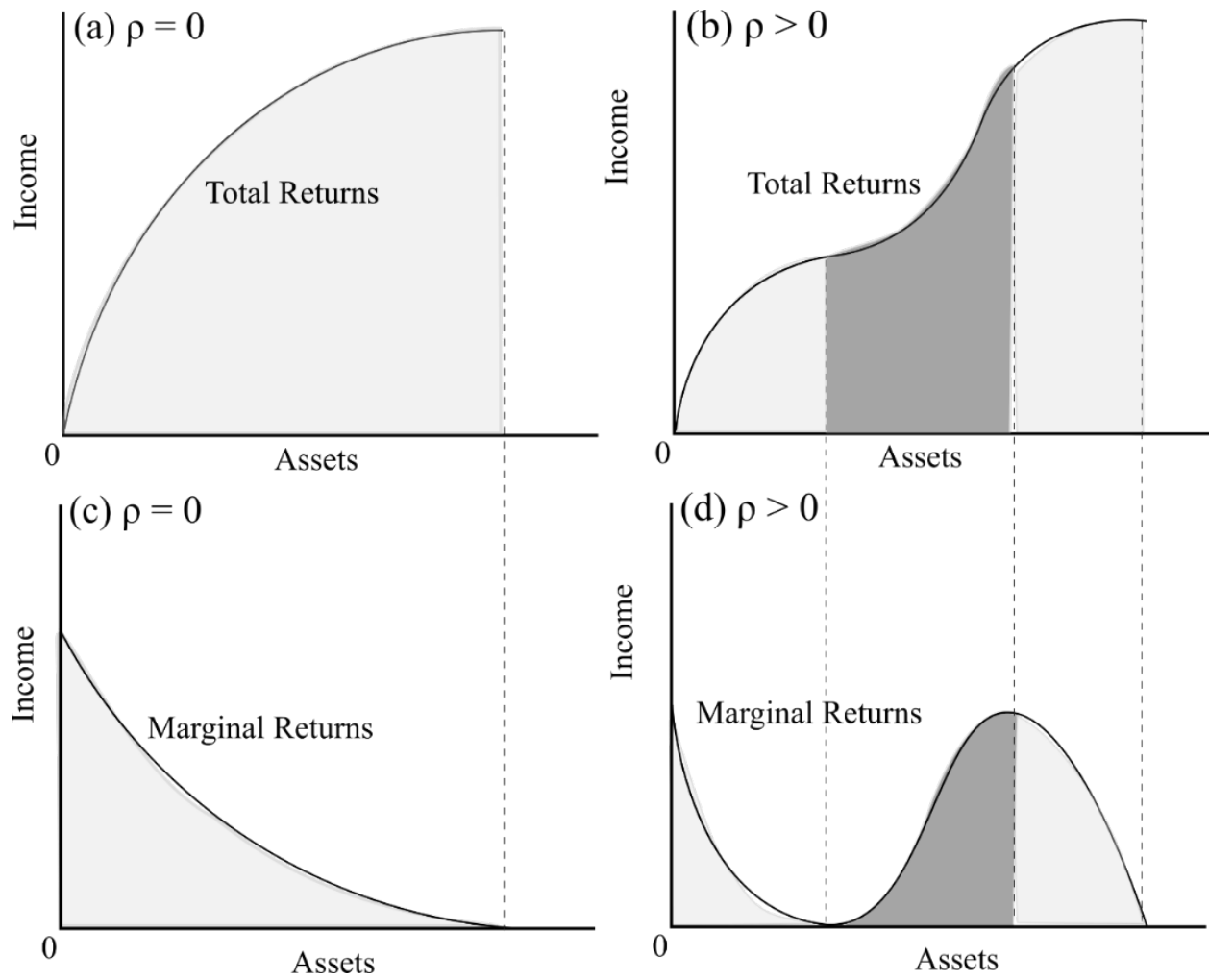

Figure 3: Effect of technology access ( $\rho$ ) on total and marginal returns to assets. Dark grey region denotes increasing returns while light grey denotes decreasing 
returns. (a) \& (c) presents the case with uniform access to technology $(\rho=0)$ where resource productivity diminishes as we deploy more of the same type of assets, while (b) \& (d) represent differentiated technology access options $(\rho>0)$ where resource productivity increases locally when a technological superior asset is deployed. Blue dotted lines delimit areas of decreasing or increasing returns.

\section{Resource extraction}

Individuals as optimizing agents choose resource extraction to maximize profits. Profits $\pi_{i}$ depend on income minus costs of production and are given as:

$$
\pi_{i}=y_{i}\left(\sigma_{i}, a_{i}, e_{i}\right)-C_{i}\left(e_{i}, a_{i}, X\right)
$$

The cost function depends on the assets owned, amount extracted and resource availability. Marginal costs are assumed to depend positively on the extraction level and negatively on both resource abundance and assets owned. The more one extracts, the higher the costs to extract an additional unit of water. Having better assets and abundant water availability makes it cheaper to extract an additional unit of water. With these properties, the cost function for an individual $i$ is specified as follows:

$$
C_{i}=\frac{e_{i}\left(\sigma_{i}, a_{i}, X\right)^{2}}{2 X^{\gamma} a_{i}^{\tau}}
$$

Parameters $\gamma$ and $\tau$ determine the cost-output elasticity of resource abundance and assets respectively where $\gamma, \tau<1$. Substituting income and cost functions gives an expression for the profit function:

$$
\pi_{i}=a_{i}^{\alpha} \sigma_{i}\left(a_{i}\right) e_{i}-\frac{e_{i}^{2}}{2 X^{\gamma} a_{i}^{\tau}}
$$

The institutional regime is described as open access, and therefore discounted longterm profits from the resource cannot be secured. Hence, agents maximize instantaneous profits by setting $\frac{\partial \pi_{i}}{\partial e}=0$ provided our cost function is concave $\left(\frac{\partial C_{i}}{\partial e}>0, \frac{\partial^{2} C_{i}}{\partial e^{2}}>0, \frac{\partial C_{i}}{\partial X}<0, \frac{\partial^{2} C_{i}}{\partial X^{2}}>0, \frac{\partial C_{i}}{\partial a}<0, \frac{\partial^{2} C_{i}}{\partial a^{2}}>0\right)$, which gives us the optimal short-term resource use function as follows:

$$
e_{i}=\sigma_{i}\left(a_{i}\right) X^{\gamma} a_{i}^{\beta}
$$


where $\beta=\tau+\alpha$. Resource use $e_{i}$ depends on the amount of resource available $X$, on an individual's level of assets owned $a_{i}$, as well as a technology function $\sigma_{i}$.

Assets generate wealth, thus endowing the individual's ability to intensify use of resources. Long-term wealth dynamics for each individual $i$ are given by:

$$
\frac{d a_{i}}{d t}=s_{i} y_{i}\left(\sigma_{i}, a_{i}, e_{i}, X\right)-\mu_{i} a_{i}
$$

Here savings rate $s_{i}$ with income $y_{i}$ gives assets inflow while a depreciation loss term $\mu_{i}$ gives assets outflow, thus signalling an individual's wealth accumulation or loss respectively in the long run. From here on, assets and wealth will be used interchangeably based on the similarity of usage and broader meaning. The savings rate is assumed to be constant over time for the sake of simplicity. Note that the amount of wealth accumulated depends critically on the individual's savings rate $(s)$, access to technology $(\rho)$ and maximum productivity $(k)$.

This study was conceived as a theoretical exercise and hence chosen parameters are not motivated by any empirical case(s) but selected to show qualitative changes and different stability regimes in the model. Following Ayres, 1988; Juster, Lupton, Smith, \& Stafford, 2006 and Modigliani, 1986 ${ }^{58-60}$, we focus on technology $(\rho)$, productivity $(k)$ and savings $(s)$ as key parameters in our model, being the most important determinants of wealth creation, analysed systematically to see how the model results change qualitatively. A discussion on other key parameters is provided in the Appendix.

In our analysis, we begin with simulating social-ecological dynamics in the homogeneous case i.e. parameters are the same across individuals. The state space is explored for stable and unstable equilibrium points. While preserving homogeneity, we also vary key parameters - savings rate $(s)$ and access of technology $(\rho)$ - for all individuals in a bifurcation analysis to study the sensitivity and stability of system's equilibrium states. Bifurcation refers to qualitative changes in a dynamic system's behaviour as we change a control parameter to cross a critical value. The critical value or bifurcation point at which this qualitative change occurs is more popularly known as a tipping point and this behaviour more generally as a critical transition. Later we relax the homogeneity assumption to simulate social-ecological dynamics with heterogeneous individuals. Different technology distributions are investigated to study qualitative changes in inequality dynamics. 


\section{Results}

\section{Homogenous society case}

We begin with simulating a society comprising $n=100$ homogenous individuals with both resource types - abiotic and biotic. We analyse the role of differentiated access to technology. If individuals have uniform access to technology $(\rho=0)$, there is no opportunity to increase productivity through wealth. This implies that rich and poor individuals would use the same technology, e.g. a hand pump to access water. With differentiated access to technology $(\rho>0)$, individuals enjoy higher productivity as they possess more assets. For example, individuals with low wealth levels can only afford the hand-pump or small boat while those better-off invest in electric pumps and motorboats.

In our analysis, stable states are defined in a dynamic systems context as points where the state variables stabilize or do not change. These can also be interpreted as equilibrium points in the long run. Phase plane analysis shows four qualitatively different scenarios for the system, based on resource type and access to technology [Fig 4]. For the abiotic resource case with uniform technology access, we get a single stable state $\left(S_{\mathrm{W}}\right)$ [Fig 4(a)]. Since everyone has access to the same technology, all individuals reach the same level of wealth and resource access in the long run. In the case of a biotic resource with uniform technology, we see more complex dynamics [Fig 4(b)]. The potential for the resource to go extinct results in a folded curve with three internal equilibrium points - two stable $\left(S_{\mathrm{C}}\right.$ and $\left.S_{\mathrm{W}}\right)$ and one saddle point $\left(S_{T}\right)$, indicating the threshold between the two stable fixed points. $S_{\text {W }}$ in Fig 4(b) is the positive wealth and resource access level, which is similar to the Fig 4(a)'s $S_{\mathrm{W}}$ for the abiotic case. $S_{\mathrm{C}}$ is the new state we see at the origin depicting social-ecological collapse with the disappearance of the resource and wealth. Such collapse may be triggered by overexploitation, eroding the foundation of resource viability and corresponding economic activity. 
(a) Abiotic resource, $\rho=0$

(b) Biotic resource, $\rho=0$

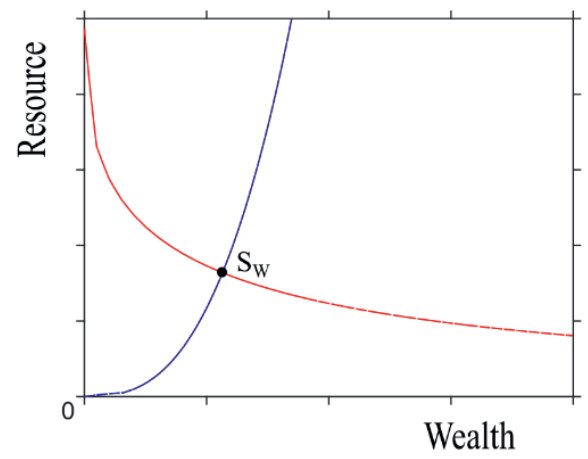

(c) Abiotic resource, $\rho>0$

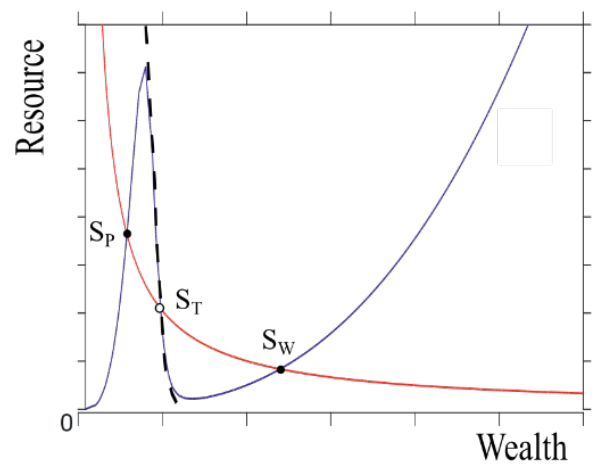

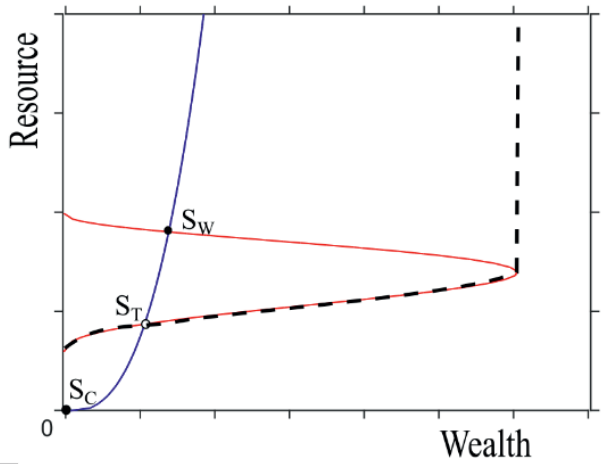

(d) Biotic resource, $\rho>0$

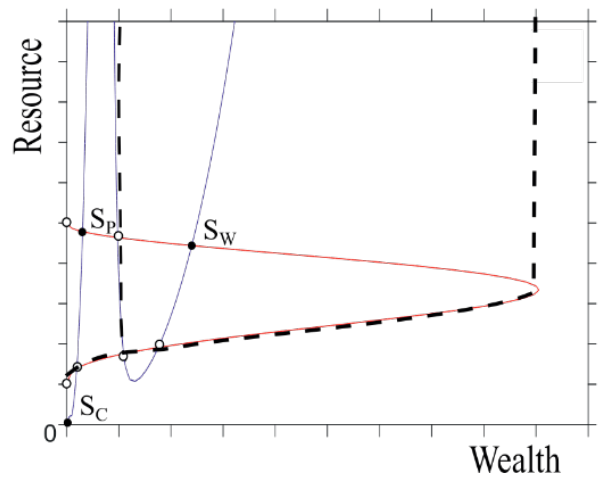

Figure 4: Phase plane for the coupled system for uniform access to technology ( $\rho=$ $0)$ and differentiated access to technology $(\rho>0)$ for the both biotic and abiotic case. Blue lines indicate wealth nullclines $(\mathrm{da} / \mathrm{dt}=0)$ while red lines indicate resource nullclines $(\mathrm{dX} / \mathrm{dt}=0)$. The intersection of nullclines gives equilibrium points of the system. Solid black points are stable equilibriums while hollow points are unstable equilibriums. Dashed black lines are the separatrix delineating the basin of attraction of stable equilibrium points.

With $\rho>0$ individual's access to technology is now differentiated depending on wealth levels [Fig 4(c) \& (d)]. For an abiotic resource case, the system now is bistable with two stable ( $S_{\mathrm{P}}$ and $S_{\mathrm{W}}$ ) equilibrium solutions [Fig 4(c)]. The two stable equilibria correspond to the poor $\left(S_{\mathrm{P}}\right)$ and wealthy $\left(S_{\mathrm{W}}\right)$ states respectively. The dashed line represents the separatrix, separating the set of individuals whose wealth would evolve to one of the stable equilibria in the long run. Depending on one's wealth level, an individual can either accumulate wealth and grow to $S_{\mathrm{W}}$ or get stuck in poverty at $S_{\mathrm{P}}$, also termed as a "poverty trap". Thus both poverty and wealth are stable states, in line with our earlier discussion on poverty traps. For the 
last scenario of a biotic resource, the system now has three stable points $\left(S_{\mathrm{C}}, S_{\mathrm{P}}\right.$ and $S_{\mathrm{W}}$ [Fig 4(d)]. $S_{\mathrm{W}}$ and $S_{\mathrm{P}}$ depict the rich and poor states respectively as before, while $S_{C}$ at the origin represents a case of social-ecological collapse with no resource stock and no assets.

\section{Bifurcation analysis}

Savings rates and access to technology are our key control parameters. We argue that both parameters play a key role when societies move through various development phases and are important drivers for both inequality and resource exploitation. We first analyse the role of savings (Fig.5), where the grey shade signifies region of alternative stable states (bi-stability). Higher savings lead to greater wealth accumulation which in turn allows the individual to invest in enhancing their resource extraction capacity, e.g. using electric pumps. We analyse whether this feedback plays a role in breaking the poverty trap and how this affects the resource at hand.

For the abiotic resource case, we first consider the wealth dynamics [Fig 5(a)]. With low savings $(s<0.14)$ individuals stay poor (branch P). As savings increase, individuals get richer which allows them to use superior technology and after a certain threshold $(s=0.3)$ they have earned enough to break the poverty trap. At higher savings $(s>0.3)$, individuals stay wealthy (branch $\mathrm{W})$ and wealth keeps rising. For $0.14<s<0.3$, the system is bi-stable (grey shaded region), which means that here individuals depending on their initial wealth levels can converge either to the wealthy or the poor state. This is due to the differentiated access to technology which allows higher wealth accumulation to those who are initially wealthy and benefit from access to better technology. For the resource [Fig 5(b)], similar dynamics are seen but in the reverse direction. As rising savings spur wealth accumulation, the resulting resource use puts increasing stress on resource availability. As a result, resource decreases with increasing $s$.

For the biotic resource case, starting with the wealth dynamics [Fig. 5 (c)], individuals stay in the poverty trap for $s<0.13$ (branch P), moving on to alternative stable states for $0.13<s<0.43$ (grey shaded region) and then finally jumping to the wealthy state at $s=0.43$ (branch $\mathrm{W}$ ). However, in contrast to the abiotic case, the wealthy state suddenly becomes unstable again at $s=0.65$, forming a cliff-like figure. With higher savings, as individuals accumulate more wealth and use more resources, the biotic resource collapses below a certain point due to the exploitative pressure. For the resource [Fig. 5 (d)], as the pressure builds up with higher savings, it eventually collapses in this rather catastrophic shift, 
resulting in social-ecological collapse where individuals metaphorically 'fall off the cliff' as the resource disappeared which formed the foundation of society's wealth. The two lower bifurcations in Fig. 5(d) are the fold bifurcations of the two saddle nodes with unstable fixed points. They are not important for dynamics past the tipping point as resource collapses after the stable branch $\mathrm{W}$, irrespective of the two lower bifurcations.

(a) Abiotic resource

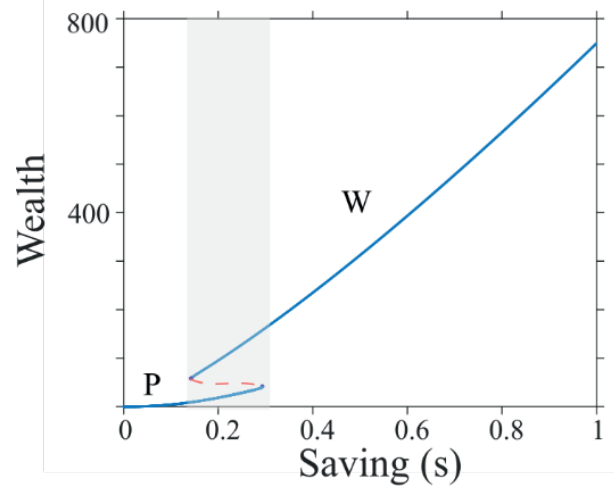

(c) Biotic resource

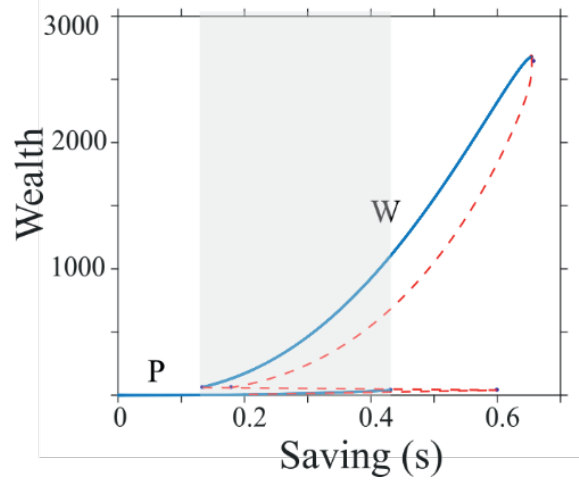

(b) Abiotic resource

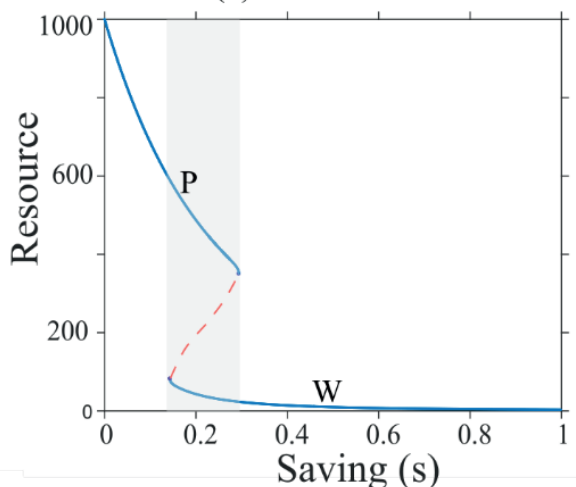

(d) Biotic resource

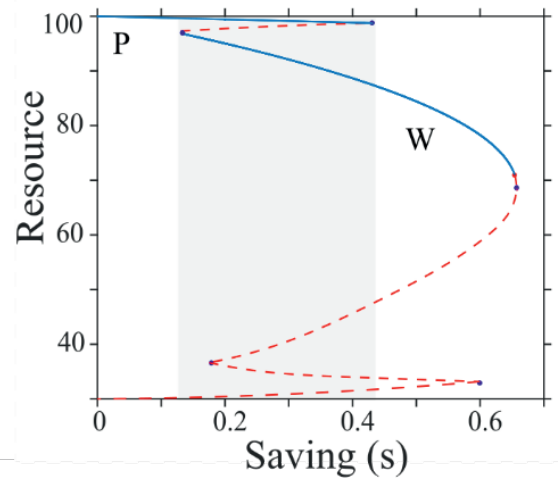

Figure 5: Bifurcation analysis for wealth and resource dynamics with respect to savings rate, in the abiotic resource and biotic resource case. Solid blue lines represent stable branch of the system while dotted red lines represent the unstable branch. Grey shaded region denotes the area of alternative stable states. W and P refer to wealthy and poor stable state respectively.

We now turn to analyse the role of access to technology $(\rho)$ on wealth and the resource stock (Fig 6). While savings allow an individual to increase the rate of wealth generation irrespective of the initial endowment, the effects of access to technology $(\rho)$ depend on individual's current wealth level. So in a differentiated 
technology regime $(\rho>0)$, rich individuals have higher productivity and can increase their wealth accumulation compared to poor individuals.

At low levels of $\rho$ technology is relatively uniform, so initial wealth conditions do not matter, thus there is only one stable state. As we increase technological differentiation, alternative stable states emerge for both $\rho>0.45$ (abiotic resource) and $\rho>0.26$ (biotic resource) respectively. Beginning from a poor state (branch P) and moving from right to left, as we decrease $\rho$ (i.e. making access to technology more uniform for everyone), a saddle-node bifurcation occurs at $\rho=0.45$ for the abiotic resource [Fig 6(a) \& (b)] and $\rho=0.26$ for the biotic resource [Fig 6(c) \& (d)], where the system jumps to the unique stable equilibrium (branch $\mathrm{W}$ where everyone is equally wealthy). As before, the grey shaded area depicts a region of alternative stable states. Interestingly, we find that the more differentiated the technology is (larger $\rho$ ), the lower the wealth levels in the poverty state. Intuitively, this happens because, with an increasing $\rho$, productivity of the poor is lower, reinforcing the poor state, and also affecting the absolute poverty level within that state. Consequently, we see that the resource increases as $\rho$ increases in the poor state, simply because of lacking capacity to extract the resource. 
(a) Abiotic resource

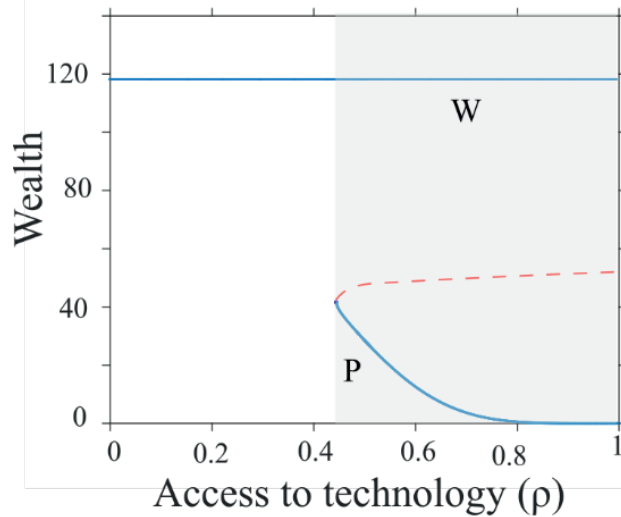

(c) Biotic resource

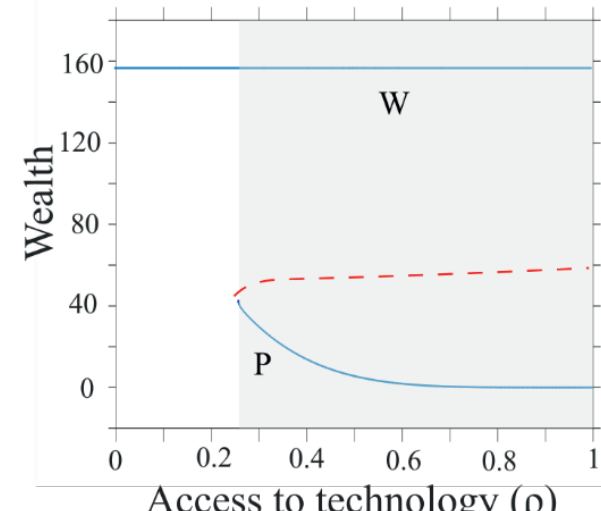

(b) Abiotic resource

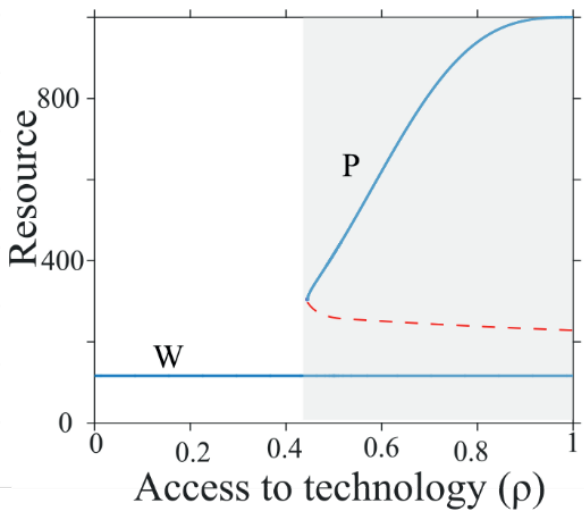

(d) Biotic resource

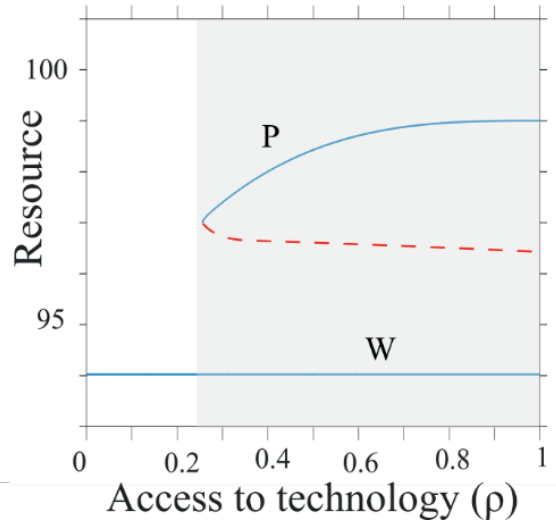

Figure 6: Bifurcation analysis for wealth and resource dynamics with respect to access to technology in the abiotic resource and biotic resource case. Solid blue lines represent stable branch of the system while dotted red lines represent the unstable branch. Grey shaded region denotes the area of alternative stable states. W and $\mathrm{P}$ refer to wealthy and poor stable state respectively.

To analyse how savings rate and access to technology act in concert, we now project bifurcation results in a two-parameter $(s$ and $\rho$ ) space and identify critical transitions [Fig 7]. For the abiotic resource [Fig 7(a)], with low savings (s), the system stays in an exclusive poor state, regardless of access to technology. As savings rate increase, the system transitions from an exclusively poor state to either a region with alternative stable states or a region with the exclusively wealthy state, depending on access to technology $(\rho)$. This V-shaped area of alternative stable 
states, which decreases with increasing savings rate, marks a risky region where the system can potentially flip between poor or wealthy states.

For the biotic resource case [Fig 7(b)], the situation is similar to the abiotic case, except that the system may undergo another transition into a state of socialecological collapse. At high savings rates, the excessive pressure erodes the regenerative capacity of the resource and paving the way to resource extinction. The case where the ecological resource collapses is particular to the biotic resource and the key qualitative difference between the two resource dynamics. However, in both cases, access to technology $(\rho)$ regulates this potentially risky region with alternative stable states, such that at high values of $\rho$, the region expands, while at low values of $\rho$, it vanishes in what is called a cusp point.

(a) Abiotic resource

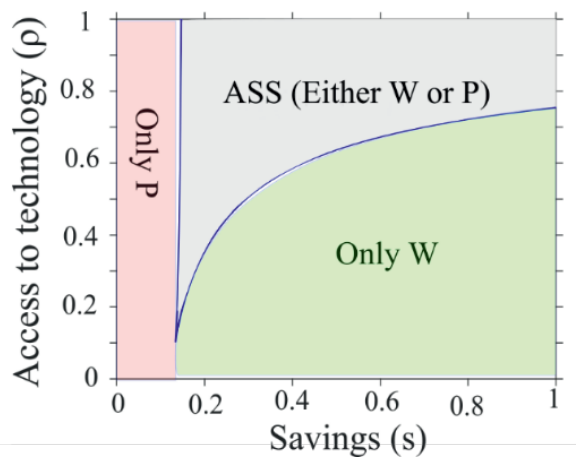

(b) Biotic resource

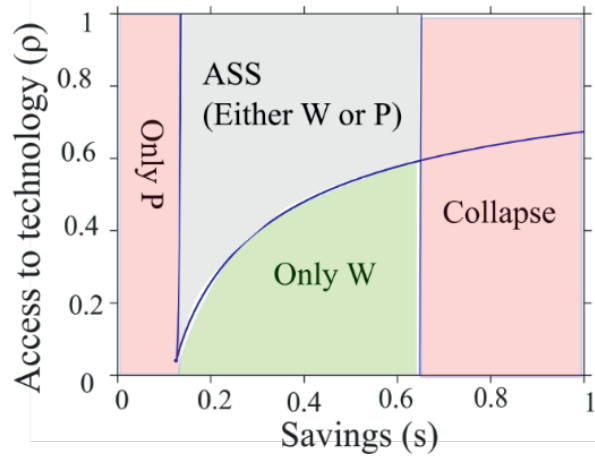

Figure 7: Two-parameter bifurcation analysis with respect to savings rate and access to technology for the abiotic and biotic resource case. ASS, W and P refers to alternative stable states, wealthy state and poor state respectively.

\section{Heterogeneous society case}

We now relax the homogeneity assumption by simulating a society with heterogeneous individuals in a differentiated technology setting i.e. individuals having access to both small and motorized boats with different savings rates and initial wealth endowments. We assume that each individual has an equal chance to receive some initial wealth in some set interval, giving rise to a uniform distribution. Thus, randomly distributed wealth levels drawn from a uniform $\mathrm{U}(\min =0, \max =100)$ distribution for $n=100$ individuals. For simplicity, savings are assumed to be normally distributed with mean 0.2 and standard deviation 0.01. Qualitatively, the model results do not depend on whether we use uniform or normal distributions. 
Simulating the system over time we see clusters emerge in the long run as individuals' wealth distributions transform from an initial uniform to a final bimodal distribution with high and low wealth levels [Fig 8(a)]. The rich and poor clusters go hand in hand with the evolution of local inequality in our model society. A positive upward trend is seen between inequality and growth in wealth [Fig. $8(b)$ ], approaching a moderately long-run value of around 0.5 Gini. This positive trend is independent of the type of underlying resource - abiotic or biotic, thus aligning well with our earlier discussion on observed rising inequalities in growing societies.

(a)

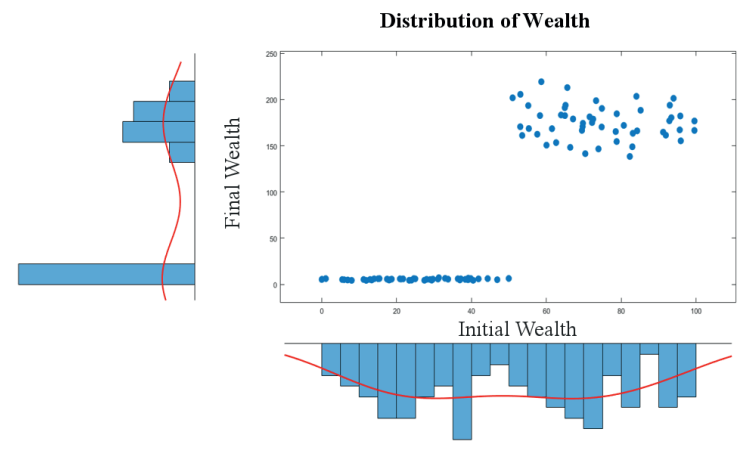

(b)

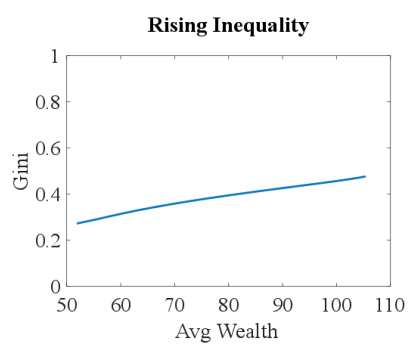

Figure 8: Individuals with fixed technology, and heterogeneous savings rates and initial wealth levels. (a) Distribution of final (bimodal) wealth by initial (uniform) wealth in society. (b) Rise in inequality with societal growth in average wealth.

Having modelled local inequality dynamics with a heterogeneous population we can now use the model to see how in a capitalistic society, rapid technological changes and emergence of highly productive sectors will affect the dynamics of inequality and poverty at the local societal level. By a capitalistic society, we mean enhanced overall productivity and technology due to capital growth. In our model, this is captured by the combination of access to advanced technology and overall productivity. To simulate variation in total productive capacity, we have modified the parameter $k$ in the technology function [Eq.(4)], which was so far assumed to be $k=1$ constant for all individuals. Contrasting with the homogeneous case $(k=$ 1), two more realistic but distinct scenarios are constructed where an individual's productivity $k$ is heterogeneous. First, we assume a society of relatively equal opportunities, where everyone has the same probability of benefiting from better technology and $k$ is following a uniform distribution with $U(\min =0, \max =2)$. Second, we look at the case where a few elite individuals benefit significantly more 
from the enhanced technology and productivity than the rest of society. Thus, $k$ follows a heavy tail gamma $G($ scale $=1$, shape $=1)$ distribution. Distribution parameters are chosen to keep average $k$ equal to 1 similar to the fixed $\mathrm{k}$ scenario, facilitating comparison.

The evolution of wealth distribution and total resource stock for all scenarios can be seen from the heat maps and resource dynamics plots respectively (Fig 9). For brevity, we only discuss the results for the abiotic resource case. Results for the biotic resource case are provided in the Appendix. In the uniform scenario, we see that local inequality grows in society and stabilises at a Gini value of around 0.60.7 [Fig 9(c)]. The relationship between inequality and average wealth is similar to that in the fixed $k$ scenario, though, in the scenario where $k$ is uniformly distributed, the average wealth is higher. Interestingly, this increase in wealth also leads to a higher final inequality level than what we saw in the homogeneous $k$ scenario (compare Fig. 8(b) with Fig 9(c)). So we can see that variation in technology may increase wealth in society on average, but this will benefit few individuals, giving rise to inequality. 
(a)

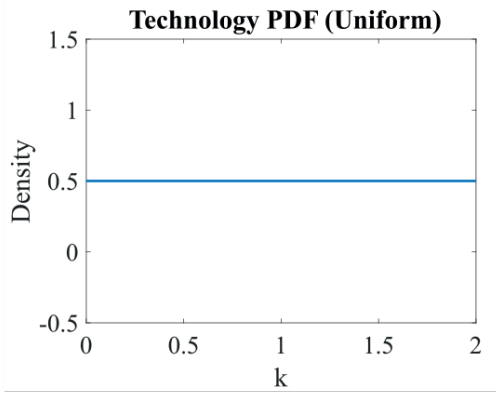

(b)

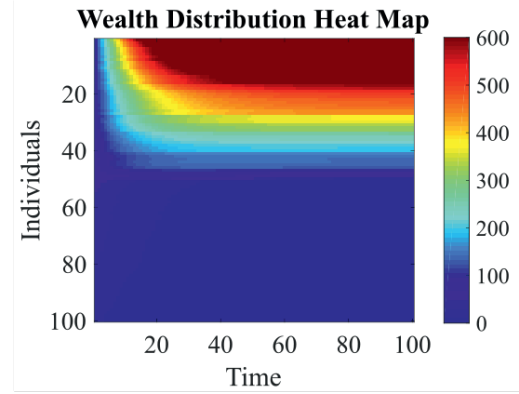

(c)

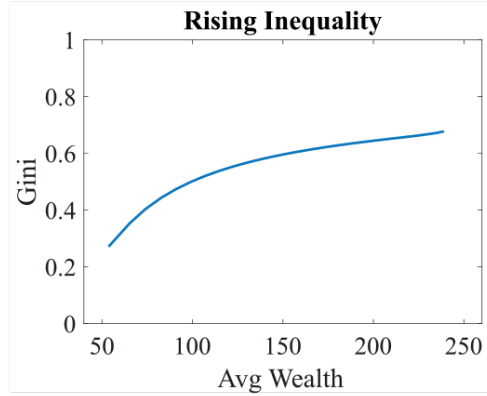

(d)

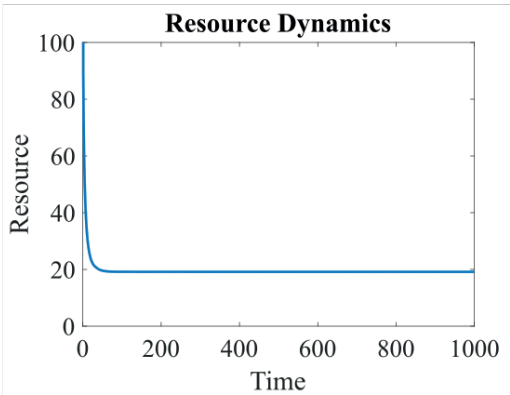

(e)

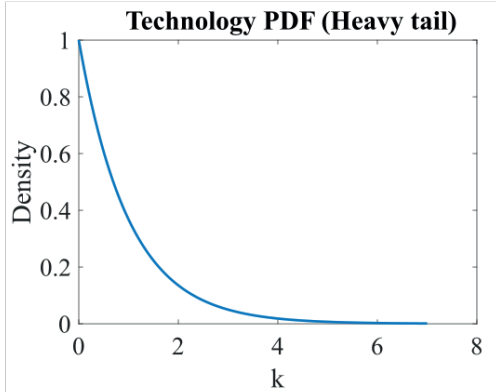

(f)

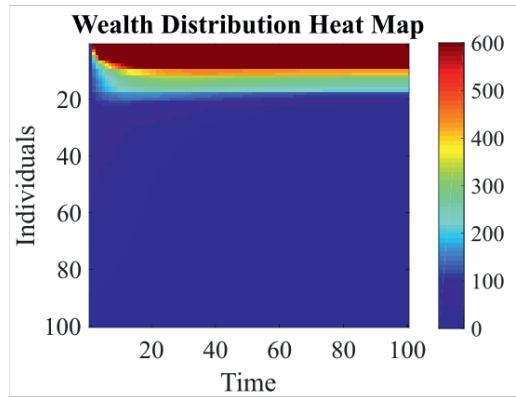

(g)

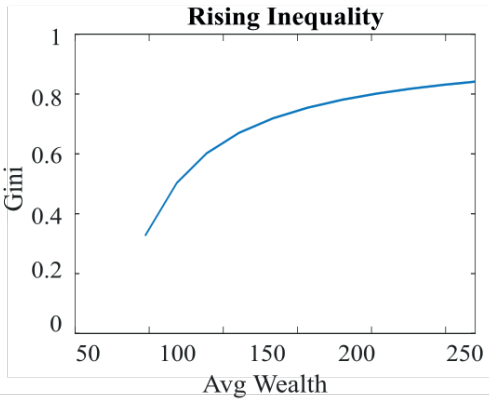

(h)

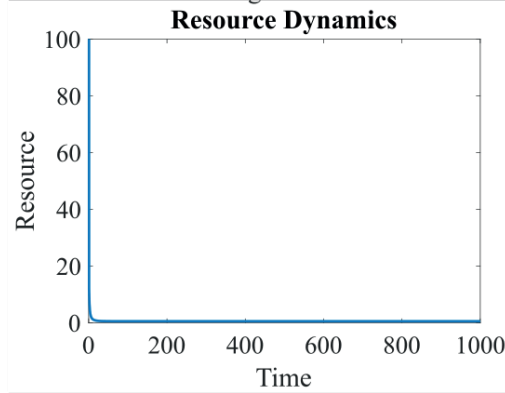

Figure 9: Effect of heterogeneous productivity via uniform $(\mathrm{a}-\mathrm{d})$ and heavy tail $(\mathrm{e}$ - h) distributions. For both cases, we see the effect on the evolution of wealth, inequality, and resource stock.

In a heavy tail scenario, we observe amplification of the rise of wealth for the elite few. The heavy tail causes local inequality to rise much faster than what we saw 
with a uniform distribution or homogeneous case, leading to a final long-term inequality value of around 0.8-0.9 Gini [Fig 9(g)]. Compared to the uniformly distributed technology case, three differences stand out. First, with fast-rising inequality, poverty increases are stronger, as indicated by the expanded blue section of the heat maps [Fig. 9(b \& f)]. Second, while average wealth is similar in both cases, we find that inequality is even higher in the case where technology is beneficial for very few individuals [Fig. 9(c \& g)]. Third, in both cases, we see resource depletion, though this effect is much stronger for the heavy-tail case. The poor are particularly disadvantaged by these adverse changes as both poverty increases and resource degrades in the society at the same time.

\section{Discussion}

Rising inequality, as seen in our model, is consistent with growth in wealth, in line with the positive relationship seen historically ${ }^{61}$. Overall rising average wealth levels do not lift people out of poverty as we see inequality persisting side by side with poverty. This steady persistence of inequality is seen as a standard feature of growing societies ${ }^{17,62}$, where the wealth-technology positive feedback skews growth gains towards the better-off, similar to a preferential attachment process. One example where these patterns can be observed comes from Sub-Saharan Africa where forest products constitute the main source of livelihood for rural households ${ }^{63,64}$. While forest income is essential for sustaining livelihoods of the poor, the wealthiest in society are the ones with the ability to harvest at a large scale and are consequently the heaviest users. The wealthy and powerful capture the resource at expense of the poor, due to their better skill set, technology and capital ${ }^{31}$. As a result, the poor are forced to alter their practices or shift to less productive areas with high failure and closure rates ${ }^{65,66}$.

Moreover, from the model results, we see that in the modern capitalized world, access to capital further accelerates these growth gains for a small elite, an observation consistent with literature ${ }^{67-69}$. Here inequality rise due to the emergence of new productive sectors and associated increasing returns, as people move from traditional ways of wealth accumulations to more productive capital assets. While, wealth and technology feed on each other, in a positive feedback, to push inequality up, such positive feedbacks may be reinforced by societies having access to highly productive capital intensive pathways to wealth generation, which may create poverty traps and result in rapidly rising inequality in society ${ }^{43,44}$. However, we show that capital growth may not, in all scenarios, result in a rapid rise in inequality and/or cause sudden changes in social-ecological dynamics. The 
growth of elites and final distribution in wealth depend largely on how productivity gains are distributed.

In a society with uniformly distributed capital productivity gains, local inequality rises slowly and innocuously while poverty remains at the same level. At the same time, pressure on the resource remains within the sustainable limits, irrespective of the resource type. However, if the same productivity improvement is achieved via a heavy-tailed distribution, the type of resource becomes important and inequality rises much faster. With few elites harbouring most of the productivity gains, the rapid rise in local inequality is seen to correlate with significant changes in wealth and resource dynamics. Wealth levels rise fast for the highly productive elites as they intensify extraction pressure due to their particularly high productivity. Pressure on the resource directly affects income for the poor who do not have the assets allowing for high productivity, while facing a depleted resource. Poverty levels and resource pressure both rise, where the impact is more severe for the biotic resource. This is due to the nature of biotic resources which are prone to collapse below a critical threshold abundance level. Nonetheless in both cases, the poor are pushed off the resource and into poverty. This is consistent with what is seen in intricately connected social-ecological systems, where catastrophic changes such as a rapid rise in persistent poverty and resource degradation can coincide dynamically in time, forming a tipping point ${ }^{70,71}$.

Current model simulations and results need to be interpreted with caution as this was conceived as a theoretical exercise. While our work is theoretical in nature, an obvious next step is to test the theoretical predictions with empirical cases and data. Furthermore, our model attempts to capture key mechanisms needed to analyse inequality dynamics within social-ecological interactions. In this ambition, we make a series of simplifying assumptions that make the model tractable and analysable while retaining key features. Below we discuss some of our key assumptions and give cautionary notes where necessary.

Wealth in the model is accumulated via income-generating activities, using a harvested resource as input. Since we have a single common pool resource, it is assumed that all parties whether rich or poor compete in generating income from the same source. We realize that in the real world multiple resources exist that may interact in ecologically and socially complex ways ${ }^{72}$. For instance, rich and poor people may not necessarily compete for the same resource, as evidenced in Lake Victoria, where poor people harvest a smaller species (dagaa) than big companies $(\text { Nile perch })^{29}$. A natural extension of our model would be to include $n$ resource types (where $n$ is small), thus investigating the effects of different ecological 
interactions between the resources and the effects of a secondary resource on society. Although the outcome of these complex interactions is hard to predict, we expect that it is still likely that the wealthy have an advantage in both the capacity to harvest and also access to a greater number of resources than available to the poor. It would be exciting to compare the relative importance of ecological interactions (e.g. predator-prey relationships) and economic interactions (e.g. wage or price effects) that could potentially magnify or reduce inequality.

In our social-ecological model, there is no response from policy or resource users as the resource is depleted based on the assumption of open access. A worthwhile extension to the model would be to analyse the policy response and effectiveness close to the tipping point, in an explicitly dynamic setting. An effective response would require decision-makers to anticipate a potential resource collapse, potentially in the form of early-warning signals and coordinate on an effective policy response. It remains doubtful whether both conditions will be met given that the time window to prevent a collapse is limited ${ }^{51,73}$.

Our paper paints a rather bleak picture of a developing society based on the assumptions that the system is capitalistic ${ }^{74}$ and there are no real effective redistribution mechanisms ${ }^{75}$. Without a government implementing tax mechanisms or social safety nets for the poor, we see the stabilization of poverty levels in the long run. One could hypothesize that with rising inequality societal mechanisms will unfold that will allow for further redistribution of income. In such cases, we would expect cyclic behaviour in poverty levels depending on the resource pressure and the effectiveness of government interventions. Such an analysis is no doubt a worthwhile exercise and a project in itself. We will leave this as a topic for future research. In a similar vein, countries that initially leave their resources to open access may start implementing private or common property right regimes upon technological improvements, potentially safeguarding the sustainability of such resources ${ }^{76}$. At the micro-level, users may start making cooperative agreements or craft rules to move towards a regime of sustainability ${ }^{77}$. It is an entirely open question whether evolving institutions would benefit the whole society or would be favouring the ruling elite.

\section{Conclusion}

Our results present key mechanisms which may explain the emergence of local inequality in a society. A positive feedback between wealth and technology will allow moderate levels of inequality to emerge in a growing society. Furthermore, if the initial distribution of technology and productivity are heterogeneous, as in a 
capitalistic society, this can potentially lead to a rapid rise in inequality. With a heavy-tailed distribution of improved technology in society, fast rise in inequality is observed where a small elite group achieves accelerated wealth accumulation due to the convolution of better technology, capital income and resource control. Left unabated, this fast rise in inequality will have catastrophic effects such as overharvesting of resources and throwing those dependent on the resource off the resource and into poverty.

Main results from the paper can be summarized as follows: First, in growing societies, inequality rises in our model society due to an inherent positive wealthtechnology feedback. Second, capitalistic development may result in a much faster rise in inequality and poverty depending on the distribution of productivity gains in society. Third, for uniformly distributed capital productivity gains, results show a slow innocuous rise in inequality. Pressure on resource use goes up but stays within sustainable levels. Fourth, for heavy-tailed distributed capital productivity gains, results show (i) rapid rise in inequality triggering a collapse in wealth and resource dynamics at the societal level, and (ii) sharp rise in poverty while resource stocks fall below sustainable levels. Finally, if the ecological system is prone to collapse, we see that the positive feedback between wealth accumulation and resource extraction results in social-ecological collapse with resource extinction.

From a policy perceptive, the key message here is that a growth-based agenda may not only fuel inequality, but also resource depletion. While it is a public policy choice, how to rank objectives in importance, our results are a cautionary note on an agenda that is purely driven by economic growth, i.e. wealth accumulation, without any consideration for equity. We show that ensuring equality in access to key resources is not only essential for social justice, but also for improving ecological resilience and reduction in poverty. We also show that there is not necessarily a trade-off between inequality and total welfare, as inequality may fuel overexploitation which erodes the foundation of society's wealth, making everyone worse off in case of a collapse. 


\section{Authors' contribution}

MUM, AR, EN, and MS designed the research. MUM developed the model and carried out the analysis. All authors contributed to writing the final manuscript.

\section{Code availability}

The model was implemented and simulated using modelling platform GRIND version 2.0 for MATLAB version R2016b (available online at http://www.sparcscenter.org/grind). Code to run simulations is available upon request from the corresponding author

\section{Data availability}

Raw data were generated using the dynamic model presented in the paper. Model parameters used in the study to generate this data are available in the online Appendix.

\section{Acknowledgement}

This project received funding from the European Union's Horizon 2020 research and innovation programme under the Marie Sklodowska-Curie grant agreement No 643073. 


\section{Appendix}

Model parameters description and further analysis:

\begin{tabular}{|c|c|c|c|}
\hline Parameters & Description & Value & Dimension \\
\hline$c$ & Resource inflow abiotic & 2000 & $\mathrm{M} \mathrm{t}^{-1}$ \\
\hline$X_{\max }$ & Maximum resource level & $\begin{array}{l}\text { Abiotic: } 1000 \\
\text { Biotic: } 100\end{array}$ & $\mathrm{M}$ \\
\hline$\epsilon$ & Resource growth rate & 10 & $\mathrm{t}^{-1}$ \\
\hline$X_{c}$ & Critical sustainable resource level & 30 & $\mathrm{M}$ \\
\hline$\alpha$ & Partial output elasticity of assets & 0.2 & DL \\
\hline$k_{i}$ & $\begin{array}{l}\text { Maximum productivity } \\
\text { (individual) }\end{array}$ & $\begin{array}{l}\text { Fixed: } 1 \\
\text { Random uniform: } \\
\mathrm{U}(0,2) \\
\text { Random Gamma: } \\
\mathrm{G}(1,1)\end{array}$ & DL \\
\hline$\rho$ & $\begin{array}{l}\text { State of society in a continuum } \\
\text { between uniform to differentiated } \\
\text { access to technology }\end{array}$ & $\begin{array}{l}\text { Equal access: }=0 \\
\text { Differentiated } \\
\text { access: }>0\end{array}$ & DL \\
\hline$\lambda$ & $\begin{array}{l}\text { Controls the enhanced wealth } \\
\text { generation capacity gained by } \\
\text { access to better technology }\end{array}$ & 20 & DL \\
\hline$\theta$ & $\begin{array}{l}\text { Asset level where increasing } \\
\text { returns starts to set in }\end{array}$ & 50 & $\$$ \\
\hline$\gamma$ & $\begin{array}{l}\text { cost-output elasticity of resource } \\
\text { abundance }\end{array}$ & 0.3 & DL \\
\hline$\tau$ & cost-output elasticity of assets & 0.2 & DL \\
\hline$\mu_{i}$ & Assets outflow or depreciation & 0.1 & $\mathrm{t}^{-1}$ \\
\hline$s_{i}$ & Savings rate & $\begin{array}{l}\text { Random Normal: } \\
\mathrm{N}(0.2,0.01)\end{array}$ & $\mathrm{t}^{-1}$ \\
\hline$a_{i}$ & Initial asset level of individuals & $\begin{array}{l}\text { Random uniform: } \\
\mathrm{U}(0,100)\end{array}$ & $\$$ \\
\hline$X$ & Initial resource level & 100 & $\mathrm{M}$ \\
\hline
\end{tabular}

$\mathrm{M}=$ Mass; $\mathrm{t}=$ time; $\$=$ Monitory value; $\mathrm{DL}=$ Dimensionless

Table A1: Parameter values and description

In the paper, particular values of the parameters were chosen to initialize the system in a bi-stable regime where individuals can either stay in poverty or get wealthy. Following Ayres, 1988; Juster, Lupton, Smith, \& Stafford, 2006 and 
Modigliani, 1986, we focus on technology and savings as key parameters in our model being the most important determinants of wealth creation. Thus $s_{i}, \rho$ and $k_{i}$ are analysed in the paper systematically to see how the model results change qualitatively.

It is beyond the scope of this paper to systematically test all other parameters in a sensitivity analysis. In part, such an exercise would also be redundant as some parameters do not affect the results substantively. For example, $\alpha, \tau$, and $\gamma$ are dimensionless elasticity exponents chosen as $\alpha+\tau+\gamma<1$ to ensure diminishing returns to scale; $\theta$ is chosen as $<100$ (maximum initial asset level) to indicate the asset level where locally increasing returns set in; $\mu_{i}$ is chosen as $<1$ to set a reasonable asset loss term; $c, X_{\max }, \epsilon$ and $X_{c}$ are resource inflow parameters and are chosen to allow each of the 100 individuals, at the start of the simulations, enough resource to harvest. However, it will aid understanding and interpreting model results to see how parameters controlling the flow of wealth or resource, $\mu, c$ and $\epsilon$, would affect the stability of our model's long-run dynamics (Fig A1). 
(a)

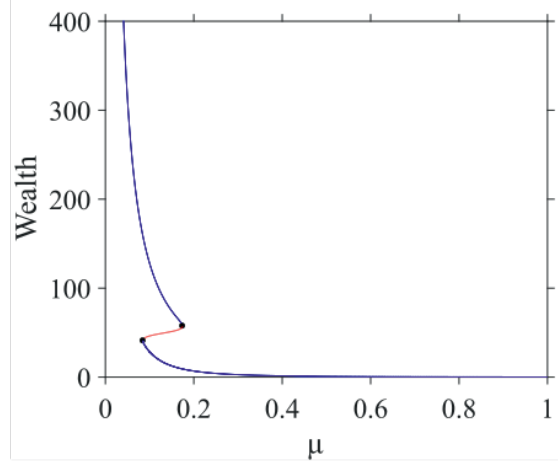

(c)

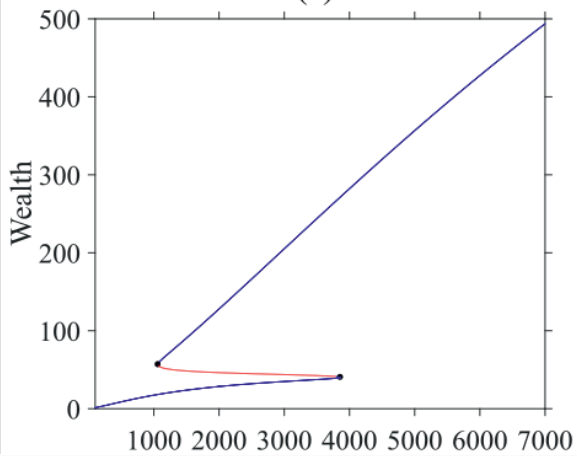

$\mathrm{c}$

(e)

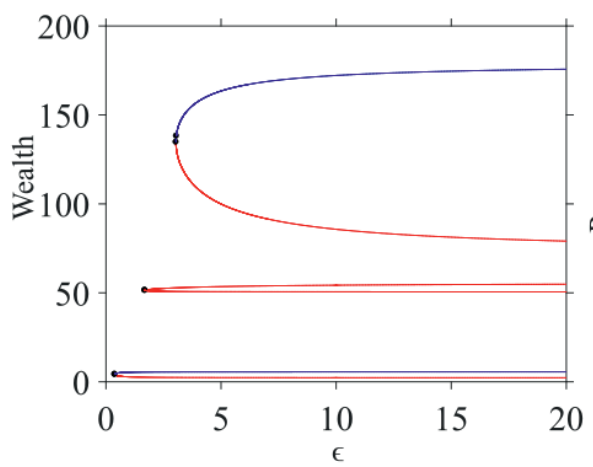

(b)

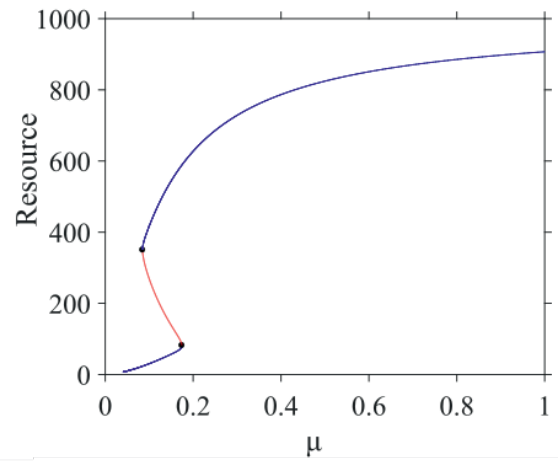

(d)

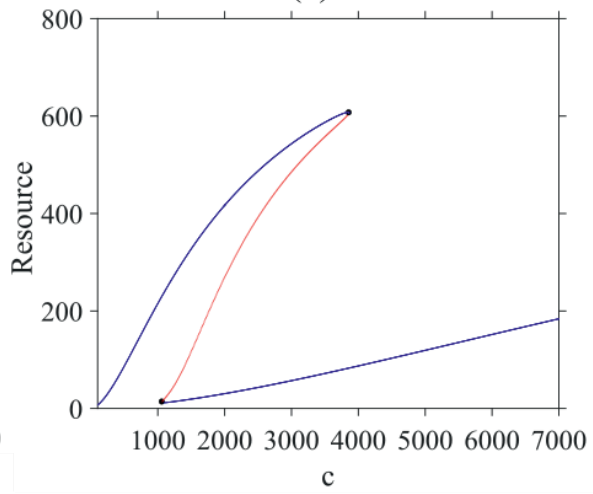

(f)

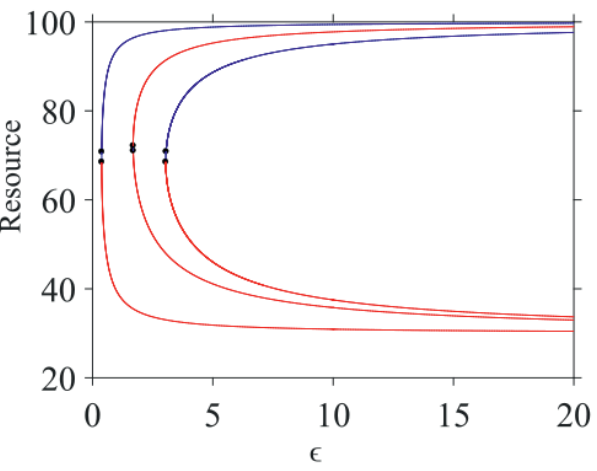

Figure A1: Bifurcation analysis for parameters $\mu, c$ and $\epsilon$. Blue and red lines show stable and unstable branched respectively

Since $\mu$ controls the depreciation of assets, a rise will lower equilibrium wealth levels, reduce extraction capacity and lead to higher resource levels [Fig A1(a)\&(b)]. Starting from a wealthy state, if the assets get obsolete quickly, less 
wealth will be accumulated. If the depreciation of assets becomes too high, the wealth stable (blue) branch becomes unstable (red) causing an individual to fall in a poverty trap. For $c$, controlling abiotic resource inflow, the situation is opposite. With high inflow, the resource grows faster, allowing for more resource extraction and wealth [Fig A1(c)\&(d)]. Starting from the poverty trap, at the critical point where the stable branch (blue) becomes unstable (red), wealth levels jump as more resource becomes available. Here, we see that higher resource availability facilitates the accumulated enough wealth to invest in the better technology thus accelerating to the wealthier state. For $\epsilon$, controlling biotic resource inflow, the situation is different since the biotic resource dynamics has an inherent nonlinearity due to the Allee effect. The upper blue line in Fig A1(e) and the inner blue line in Fig A1(f) are the wealthy stable branches, while the lower and outer blue lines in Fig A1(e) and (f) are the poor stable branches, respectively. Moving from right to left in $\mathrm{A} 1(\mathrm{e})$, as resource inflow decreases, the upper blue branch becomes unstable and the society drops to the poor equilibrium. Further decrease in resource inflow will cause the poor state to become unstable as well, thus causing the society to fall in the collapse state.

\section{Biotic resource case}

The evolution of wealth distribution in the society and total resource stock for uniform [Fig S2(a-d)] and heavy tail gamma [Fig A2(e-h)] scenarios can be seen from the heat maps and resource dynamics plots respectively. In the uniform scenario, we see local inequality grow in society but then stabilizing at a Gini value of around 0.7 in the long run [Fig A2(c)].

With the heavy tail scenario, local inequality rises much faster and hence the repercussions on poverty and the ecological system are disastrous. Here, both the social and ecological systems go through a simultaneous critical transition. Wealth levels drop, as indicated by the expanding blue region in Fig A2(f) and resource levels collapse as seen in Fig A2(h). The poor are at the receiving end of these abrupt changes as both poverty increases and resource collapses in the society at the same time. 
(a)

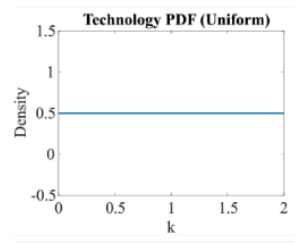

(e)

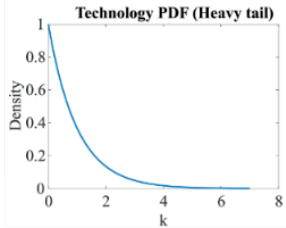

(b)

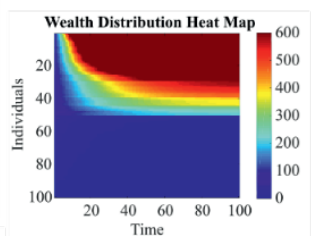

(f)

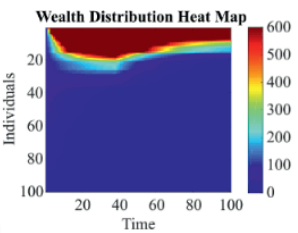

(c)

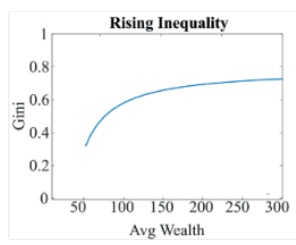

(g)

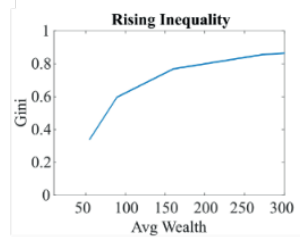

(d)

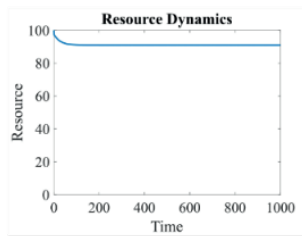

(h)

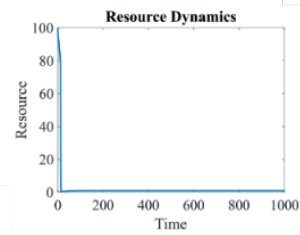

Figure A2: Effect of heterogeneous technology change via uniform $(a-d)$ and heavy tail $(\mathrm{e}-\mathrm{h})$ distributions. For both cases, we see the effect on the evolution of wealth, inequality, average wealth and resource stock. 


\section{References}

1. Carter, M. R. \& Barrett, C. B. The economics of poverty traps and persistent poverty: An asset-based approach. J. Dev. Stud. 42, 178-199 (2006).

2. Bowles, S. [Ed], Durlauf, S. N. [Ed] \& Hoff, K. [Ed]. Poverty traps. Poverty traps. (2006).

3. Naschold, F. Welfare Dynamics in Pakistan and Ethiopia - Does the Estimation Method Matter? J. Dev. Stud. 49, 936-954 (2013).

4. Barrett, C. B. et al. Welfare dynamics in rural Kenya and Madagascar. $J$. Dev. Stud. 42, 248-277 (2006).

5. Dutta, S. \& Kumar, L. Is Poverty Stochastic or Structural in Nature? Evidence from Rural India. Soc. Indic. Res. 128, 957-979 (2016).

6. Toth, R. Traps and thresholds in pastoralist mobility. Am. J. Agric. Econ. 97, 315-332 (2015).

7. Azariadis, C. \& Stachurski, J. Chapter 5 Poverty Traps. in Handbook of Economic Growth 1, 295-384 (2005).

8. Barrett, C. B. \& Carter, M. R. The Economics of Poverty Traps and Persistent Poverty: Empirical and Policy Implications. J. Dev. Stud. 49, 976-990 (2013).

9. Ghatak, M. Theories of poverty traps and anti-poverty policies. World Bank Econ. Rev. 29, S77-S105 (2015).

10. Zimmerman, F. J. \& Carter, M. R. Asset smoothing, consumption smoothing and the reproduction of inequality under risk and subsistence constraints. J. Dev. Econ. 71, 233-260 (2003).

11. Mookherjee, D. \& Ray, D. Persistent inequality. Rev. Econ. Stud. 70, 369393 (2003).

12. Mookherjee, D. \& Ray, D. Contractual structure and wealth accumulation. Am. Econ. Rev. 92, 818-849 (2002).

13. Barrett, C. B. et al. Well-Being Dynamics and Poverty Traps. Annu. Rev. Resour. Econ. 8, (2015).

14. Banerjee, A. V. \& Newman, A. Occupational choice and the process of development. The Journal of Political Economy 101, 274-298 (1993). 
15. Dillehay, D. L., Sander, M., Talkington, D. F., Thacker, W. L. \& Brown, D. R. Isolation of mycoplasmas from prairie voles (Microtus ochrogaster). Laboratory Animal Science 45, 631-634 (1995).

16. Vinet, L. \& Zhedanov, A. A 'missing' family of classical orthogonal polynomials. J. Phys. A Math. Theor. 44, 696 (2011).

17. de Miguel, J. M. Global Inequality: A New Approach for the Age of Globalization, de Branko Milanovic. Revista Española de Sociología 26, (Harvard University Press, 2017).

18. Hamann, M. et al. Inequality and the Biosphere. Annu. Rev. Environ. Resour. 43, 61-83 (2018).

19. Kohler, T. A. et al. Greater post-Neolithic wealth disparities in Eurasia than in North America and Mesoamerica. Nature 24646 (2017). doi:10.1038/nature24646

20. Mustafa, D., Akhter, M. \& Nasrallah, N. Understanding Pakistan's watersecurity nexus. (United States Institute of Peace, 2013).

21. Mustafa, D. Social Construction of Hydropolitics: the Geographical Scales of Water and Security in the Indus Basin*. Geogr. Rev. 97, 484-501 (2010).

22. Farooqi, H. \& Wegerich, K. Institutionalizing inequities in land ownership and water allocations during colonial times in Punjab, Pakistan. Water Hist. 7, 131-146 (2015).

23. Gilmartin, D. Scientific Empire and Imperial Science: Colonialism and Irrigation Technology in the Indus Basin. J. Asian Stud. 53, 1127 (1994).

24. Halsema, G. E. van \& Vincent, L. F. Of flumes, modules and barrels: the failure of irrigation institutions and technologies to achieve equitable water control in the Indus Basin. in A history of water. (eds. Tvedt, T., Jakobsson, E., Coopey, R. (Richard) \& Oestigaard, T.) 55-91 (I.B. Tauris, 2006).

25. Shah, T. Taming the Anarchy: Groundwater Governance in South Asia. Taming the Anarchy: Groundwater Governance in South Asia 1-310 (2008). doi:10.4324/9781936331598

26. Rahman, T. The Class Structure of Pakistan. (Oxford University Press, 2012).

27. Godoy, R. et al. The effect of wealth and real income on wildlife consumption among native Amazonians in Bolivia: estimates of annual trends with longitudinal household data (2002-2006). Anim. Conserv. 13, 265-274 (2010). 
28. Alam, S. Environmentally induced migration from Bangladesh to India. Strateg. Anal. 27, 422-438 (2003).

29. Downing, A. S. et al. Coupled human and natural system dynamics as key to the sustainability of Lake Victoria's Ecosystem services. Ecol. Soc. 19, (2014).

30. ISSC, IDS \& UNESCO. World social science report 2016: challenging inequalities: pathways to a just world (summary)*. International Social Science Journal 65, (UNESCO Publishing, 2014).

31. Arnold, M. \& Townson, I. Assessing the potential of forest product activities to contribute to rural incomes in Africa. Nat. Resour. Perspect. 37, (1998).

32. Lawton, J. H. Daily, G. C. (Ed.). 1997. Nature's services. Societal dependence on natural ecosystems. Island Press, Washington, DC. 392 pp. ISBN 1-55963-475-8 (hbk), 1559634766 (soft cover). Animal Conservation 01, 75-76 (1998).

33. Cavendish, W. Empirical regularities in the poverty-environment relationship of rural households: Evidence from Zimbabwe. World Dev. 28, 1979-2003 (2000).

34. Fisher, B. \& Christopher, T. Poverty and biodiversity: Measuring the overlap of human poverty and the biodiversity hotspots. Ecol. Econ. 62, 93101 (2007).

35. McNally, C. G., Uchida, E. \& Gold, A. J. The effect of a protected area on the tradeoffs between short-run and long-run benefits from mangrove ecosystems. Proc. Natl. Acad. Sci. U. S. A. 108, 13945-13950 (2011).

36. Coomes, O. T., Takasaki, Y. \& Rhemtulla, J. M. Land-use poverty traps identified in shifting cultivation systems shape long-term tropical forest cover. Proc. Natl. Acad. Sci. U. S. A. 108, 13925-13930 (2011).

37. Naughton-Trevesa, L., Alix-Garcia, J. \& Chapman, C. A. Lessons about parks and poverty from a decade of forest loss and economic growth around Kibale National Park, Uganda. Proc. Natl. Acad. Sci. U. S. A. 108, 1391913924 (2011).

38. Lybbert, T. J., Aboudrare, A., Chaloud, D., Magnan, N. \& Nash, M. Booming markets for Moroccan argan oil appear to benefit some rural households while threatening the endemic argan forest. Proc. Natl. Acad. Sci. U. S. A. 108, 13963-13968 (2011).

39. Farley, J. \& Voinov, A. Economics, socio-ecological resilience and 
ecosystem services. J. Environ. Manage. 183, 389-398 (2016).

40. Lawler, R. D. The Idea of Justice. New Scholasticism 44, (Belknap Press of Harvard University Press, 1970).

41. Mirza, M. U. \& Mustafa, D. Access, Equity and Hazards: Highlighting a Socially Just and Ecologically Resilient Perspective on Water Resources. in Sustainable Development and Disaster Risk Reduction: Methods, Approaches and Practices 143-159 (2016). doi:10.1007/978-4-431-5507859

42. Saez, E. \& Zucman, G. What comes to mind. Q. J. Econ. 131, 519-578 (2016).

43. Gabaix, X. et al. The Dynamics of Inequality. Econometrica 84, 2071-2111 (2016).

44. Rosen, S. The Economics of Superstars. Am. Econ. Rev. 71, 845-58 (1981).

45. Carpenter, S. R. \& Brock, W. A. Adaptive capacity and traps. Ecol. Soc. 13, (2008).

46. Scheffer, M. \& Westley, F. R. The evolutionary basis of rigidity: Locks in cells, minds, and society. Ecol. Soc. 12, (2007).

47. Scheffer, M., Carpenter, S., Foley, J. a, Folke, C. \& Walker, B. Catastrophic shifts in ecosystems. Nature 413, 591-6 (2001).

48. Lade, S. J., Tavoni, A., Levin, S. A. \& Schlüter, M. Regime shifts in a social-ecological system. Theor. Ecol. 6, 359-372 (2013).

49. Ibáñez, J., Martínez, S. \& Martínez, J. Competitive and optimal control strategies for groundwater pumping by agricultural production units. Water Resour. Res. 40, n/a-n/a (2004).

50. Tavoni, A., Schlüter, M. \& Levin, S. The survival of the conformist: Social pressure and renewable resource management. J. Theor. Biol. 299, 152-161 (2012).

51. Richter, A. \& Dakos, V. Profit fluctuations signal eroding resilience of natural resources. Ecol. Econ. 117, 12-21 (2015).

52. Kuparinen, A., Keith, D. M. \& Hutchings, J. A. Allee effect and the uncertainty of population recovery. Conserv. Biol. 28, 790-798 (2014).

53. Allee, W. C. Animal aggregations, a study in general sociology. / by W. C. Allee. Animal aggregations, a study in general sociology. / by W. C. Allee. 
(2011). doi:10.5962/bhl.title.7313

54. Dennis, B. Allee Effects: Population Growth, Critical Density, and the

Chance of Extinction. Nat. Resour. Model. 3, 481-538 (1989).

55. Kramer, A. M., Dennis, B., Liebhold, A. M. \& Drake, J. M. The evidence for Allee effects. Population Ecology 51, 341-354 (2009).

56. Berec, L., Angulo, E. \& Courchamp, F. Multiple Allee effects and population management. Trends Ecol. Evol. 22, 185-191 (2007).

57. Courchamp, F., Clutton-Brock, T. \& Grenfell, B. Inverse density dependence and the Allee effect. Trends in Ecology and Evolution 14, 405410 (1999).

58. Modigliani, F. Life cycle, individual thrift, and the wealth of nations. Science (80-. ). 234, 704-712 (1986).

59. Juster, F. T., Lupton, J. P., Smith, J. P. \& Stafford, F. The Decline in Household Saving and the Wealth Effect. Rev. Econ. Stat. 88, 20-27 (2006).

60. Ayres, R. U. Technology: The wealth of nations. Technol. Forecast. Soc. Change 33, 189-201 (1988).

61. Milanovic, B., Lindert, P. H. \& Williamson, J. G. Pre-Industrial Inequality. Econ. J. 121, 255-272 (2011).

62. Ravallion, M. Income inequality in the developing world. Science (80-. ). 344, 851-855 (2014).

63. Mead, D. C. The contribution of small enterprises to employment growth in southern and eastern Africa. World Dev. 22, 1881-1894 (1994).

64. Falconer, J. \& Koppell, C. R. S. The Major Significance of 'Minor' Forest Products: The local use and value of forests in the West African humid forest zone. Community Forestry Note 6, UN FAO, Rome (1990).

65. Mead, D. C. The contribution of small enterprises to employment growth in southern and eastern Africa. World Dev. 22, 1881-1894 (1994).

66. Townson, I. M. Incomes from non-timber forest products: patterns of enterprise activity in the forest zone of Southern Ghana. Draft Rep. to ODA For. Res. Program. (1995).

67. Atkinson, A. B., Piketty, T. \& Saez, E. Top incomes in the long run of history. J. Econ. Lit. 49, 3-71 (2011). 
68. Alvaredo, F., Atkinson, A. B., Piketty, T. \& Saez, E. The top 1 percent in international and historical perspective. J. Econ. Perspect. 27, 3-20 (2013).

69. Piketty, T. Piketty - 2015 - About Capital in the Twenty-First Century. Am. Econ. Rev. 105, 48-53 (2015).

70. Barrett, C. B., Travis, A. J. \& Dasgupta, P. On biodiversity conservation and poverty traps. Proc. Natl. Acad. Sci. U. S. A. 108, 13907-13912 (2011).

71. Scheidel, A. Flows, funds and the complexity of deprivation: Using concepts from ecological economics for the study of poverty. Ecol. Econ. 86, 28-36 (2013).

72. Barrett, C. B. Poverty Traps and Resource Dynamics in Smallholder Agrarian Systems. in Economics of poverty, environment and naturalresource use 31, 17-40 (Springer, 2008).

73. Biggs, R., Carpenter, S. R. \& Brock, W. A. Turning back from the brink: Detecting an impending regime shift in time to avert it. Proc. Natl. Acad. Sci. (2009). doi:10.1073/pnas.0811729106

74. Piketty, T. \& Zucman, G. Capital is back: Wealth-income ratios in rich countries 1700-2010. Q. J. Econ. 129, 1255-1310 (2014).

75. Besley, T. \& Persson, T. Why do developing countries tax so little? J. Econ. Perspect. 28, 99-120 (2014).

76. Copeland, B. R. \& Taylor, M. S. Trade, tragedy, and the commons. Am. Econ. Rev. 99, 725-749 (2009).

77. Richter, A., van Soest, D. \& Grasman, J. Contagious cooperation, temptation, and ecosystem collapse. J. Environ. Econ. Manage. 66, 141158 (2013). 


\title{
Chapter 3
}

\section{Institutions-inequality interplay shapes the impact of economic growth on biodiversity loss}

\author{
M Usman Mirza ${ }^{1,2}$, Andries Richter ${ }^{1}$, Egbert H. van Nes ${ }^{2}$, Marten Scheffer ${ }^{2}$ \\ ${ }^{I}$ Environmental Economics and Natural Resources Group, Wageningen University, \\ Netherlands ${ }^{2}$ Environmental Sciences, Wageningen University, Netherlands
}

\begin{abstract}
The latest global assessment of the Intergovernmental Science-Policy Platform on Biodiversity and Ecosystem Services (IPBES) warns that biodiversity loss can make ecosystems more vulnerable to the effects of climate change and other stressors. Economic growth has been identified as one of the key drivers of these losses, however, the impact pathway may depend on how society organizes economic activity and distributes its benefits. Here we use a global country-level dataset to show, how the strength of national institutions and economic inequality in society can mediate the loss of biodiversity worldwide. We find that the interplay of institutions and inequality fully mediates the impact of economic growth on plants biodiversity, but only partially mediates the impact on animals biodiversity. Furthermore, in sustaining biodiversity, the effectiveness of institutions depends on inequality in society, such that biodiversity loss is ameliorated when institutions are strong and inequality low, but in regions with high inequality, institutions tend to lose their efficacy. Our analysis also uncovers nonlinearities in inequality, institutions and biodiversity interactions, which are important to investigate further and consider for policy purposes.
\end{abstract}

Keywords: Inequality, Biodiversity, Nonlinearity, Economic growth 


\section{Introduction}

Anthropogenic drivers put unprecedented pressures on our planet, resulting in biodiversity loss and exploitation of renewable resources beyond sustainable limits $^{1,2}$. Biosphere impacts of societies are inherently socio-ecological in nature with complex interactions and feedbacks ${ }^{3,4}$. Earlier work has shown the detrimental effect of economic drivers, in particular economic growth, on the biosphere ${ }^{5-10}$. At the same time, economic growth creates wealth which may give societies the means to mitigate biosphere impacts ${ }^{11}$ and ultimately foster earth stewardship ${ }^{12}$.

The exact impacts of economic growth are therefore ambiguous, as the biosphere impacts are mediated through societal mechanisms, such as quality of institutions ${ }^{13,14}$ and incidence of economic inequality ${ }^{15,16}$. Especially less developed nations are often plagued with weak institutional structures and skewed economic returns to the wealthy, making collective action for biodiversity restoration difficult, and causing exploitative growth at the expense of the environment ${ }^{2}$.

It is widely known now that economic development does not translate into biosphere stewardship, without sound institutional mechanisms steering economic activity ${ }^{17}$. Indeed, economic growth does not ensure environmental quality ${ }^{18,19}$, as there are multiple mediating factors, such as the strength of institutions and how uniformly the benefits of growth are distributed, that determine how economic growth impacts the environment. Evidence suggests that these mediating factors influence each other, such that high inequality undermines institutional quality or conversely poor institutions allow inequality to flourish, potentially creating a positive feedback that multiplies detrimental effects on the biosphere ${ }^{20,21}$. Most of the existing work focus on direct single variable effects, with little or no insights on interactions and indirect paths ${ }^{22,23}$, while literature suggests that inequality and institutions move together in a bidirectional cause-effect relationship ${ }^{24-26}$, and there are pronounced nonlinearities between inequality and environmental linkages ${ }^{6,7}$.

In this paper, we use a global country level panel dataset to analyse the role of inequality and institutions, in explaining the biosphere impacts of economic growth. Considering its social and ecological significance ${ }^{27}$, we use biodiversity loss as the key biosphere impact variable for this study. Diversity of animals and plants in the biosphere are changing slowly, but have high impact on the 
functioning of our ecosystem and its ability to provide society means to prosperity $^{28}$. Drivers of biodiversity loss are multivariate and nonlinear, with both direct and indirect pathways from human economic activity and our social structures.

Our starting point is a conceptual model (Fig 1a), hypothesizing key relationships. Economic growth spurs output (GDP per capita), which can have both direct and indirect effects based on the impact pathway. While economic growth may affect biodiversity directly, there are also indirect affects mediated through pollution and resource use that can build strain on a much slower variable like biodiversity. In parallel, there can be more indirect routes via the evolution of societal variables like inequality and institutions, which affects pollution and resource use, in turn affecting biodiversity. We use a combination of generalized additive (GAM) and structural equations models (SEM) to investigate these and other impact pathways systematically. Within the SEM framework, additional covariates and generalized method of moments (GMM) ${ }^{29}$ estimators are used to control for confounding variables and reverse causation; see methods for details. 
(a)

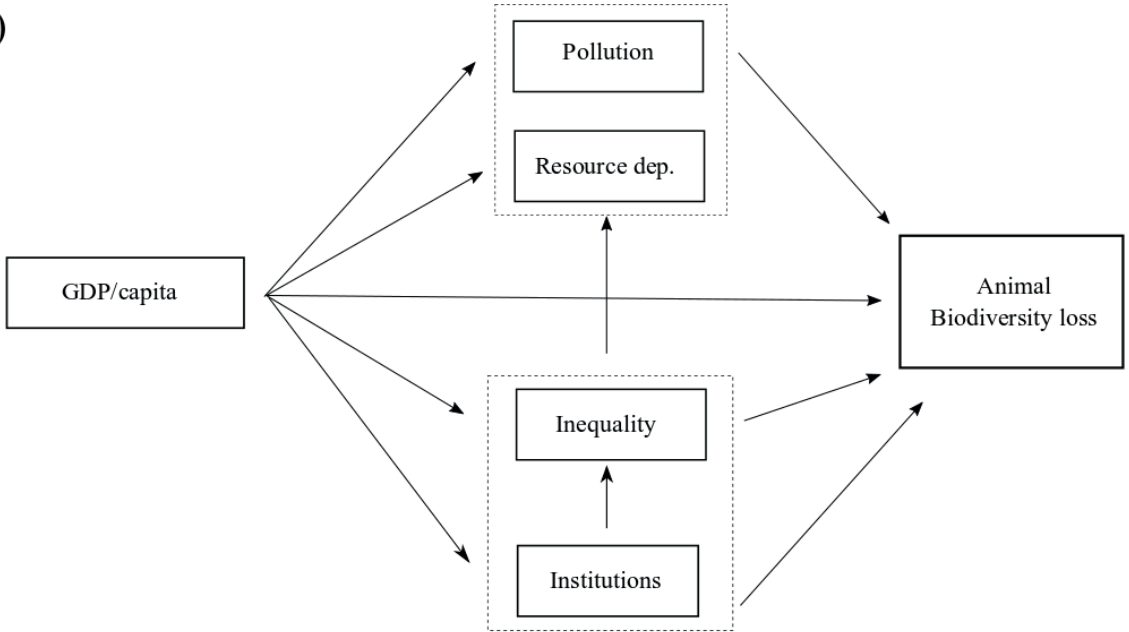

(b)

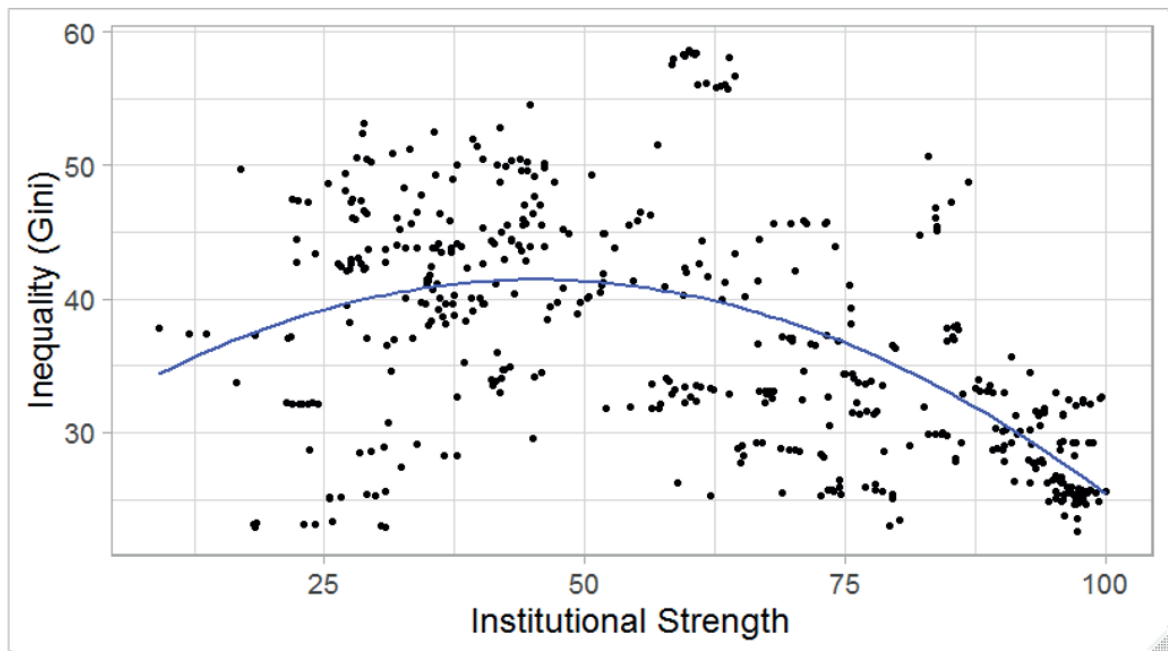

Figure 1: Direct and indirect effect pathways from economic growth to biodiversity loss (a) A conceptual model illustrating the structural relationship (b) The relationship between inequality-institutional interaction in the data across countries resembles an inverted $U$.

\section{Results}

A simple inspection of the data, pooled on the level of countries, reveal a nonlinear inverted-U shaped relationship between institutional strength and inequality (Fig 
1b). As we move from areas of low to high institutional strength, inequality first rises but then drops. The turning point where inequality is highest is seen for countries where institutions are at intermediate strength, while both low and high institutional strength areas have low inequality.

Exploring the nonlinearity further, we model inequality-institutions interactions against biodiversity loss, using generalized additive models, allowing us to investigate the underlying relationship. At the margins, we see an inverted-U shaped relationship for institutions and a positive relationship for inequality, with respect to animals biodiversity loss (Fig 2a). Biodiversity loss worsens as inequality rises, and this effect is strongest if institutions are in an intermediate development phase. When inequality is low, institutions are effective in improving biodiversity. Hence, biodiversity loss is lowest when institutions are strong and inequality is low.

A similar pattern emerges for plants biodiversity loss (Fig 2b). An inverted Ushaped relationship is apparent along the institutions axis, where low or high levels of institutional quality lead to less biodiversity loss. Higher inequality tends to be associated with greater biodiversity loss. A common feature in both plant and animal biodiversity figures is that we see a consistent pattern of institutional efficacy waning in the face of high inequality, while the combination of strong institutions and low inequality being the most effective way to curb biodiversity loss. Also, in general, biodiversity loss worsens, as inequality rises, irrespective of institutional strength. 
(a)
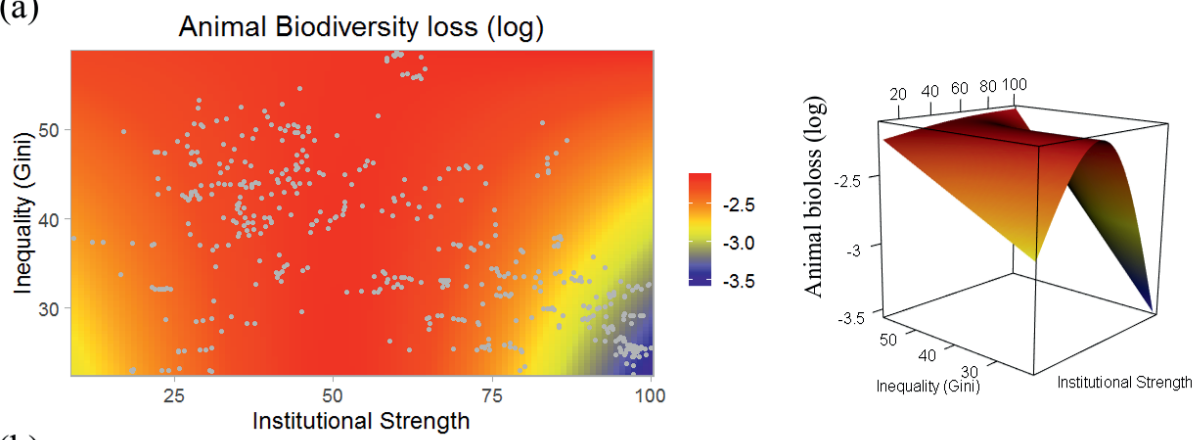

(b)

Plant Biodiversity loss (log)
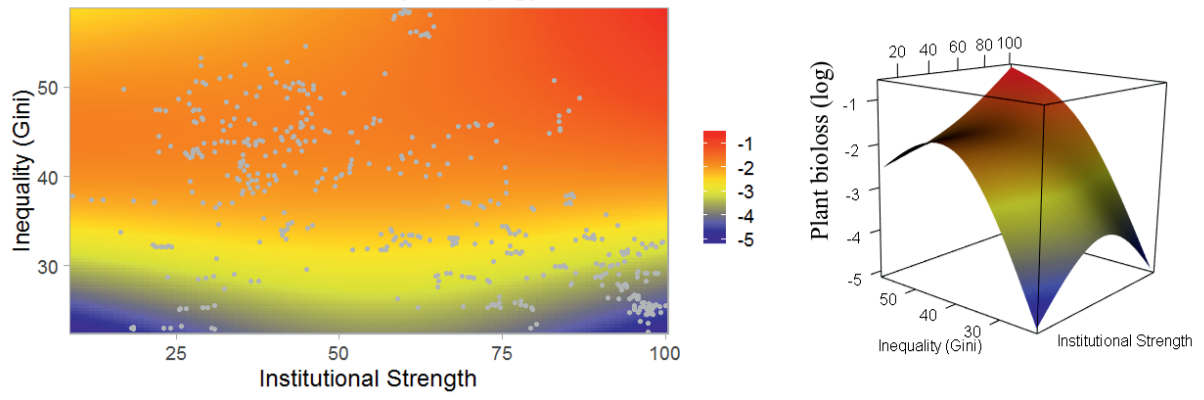

Figure 2: Trends in biodiversity loss due to inherent nonlinearities in inequalityinstitutions space. Red to blue region show high to low biodiversity loss respectively. Biodiversity loss values predicted using a generalized additive model (GAM) with inequality-institutions interactions.

Having analysed the general relationship of how institutions and inequality interact with biodiversity loss, we now explore specific impact pathways in the economic growth - biodiversity loss relationship, using the SEM meta model as introduced in Fig 1a. Direct and indirect effect pathways for animal and plant biodiversity loss are summarized graphically in Fig 3 and model estimates respectively in Table 1 and Table 2. By direct effect, we refers to a significant relationship in the model explaining animals and plants biodiversity loss (Model 1 in Table 1 and 2), after controlling for confounding factors. A direct effect is illustrated by an uninterrupted link between two variables (Fig 3). Indirect effects are significant relationships mediated by intermediate variables, such as those explained by models 2-5 in Table 1 and 2. An indirect effect is illustrated by a link through the respective mediated variable (Fig 3 ).

GDP per capita is significant across specified models that explain animals biodiversity loss and has a significant positive direct effect (Table 1). An increase 
in GDP per capita (economic growth) leads to increase in biodiversity loss. At the same time, for animals we find that indirect effects of GDP per capita are mediated through all intermediary variables. For plants, however we don't find any direct effects. Plants biodiversity loss is only affected indirectly by GDP per capita, and mediated through specified intermediary variables (Fig 3 and Table 2). Indirect effects of economic growth are via institutions, inequality, natural resource depletion and pollution for both animal and plant biodiversity loss. 
(a)

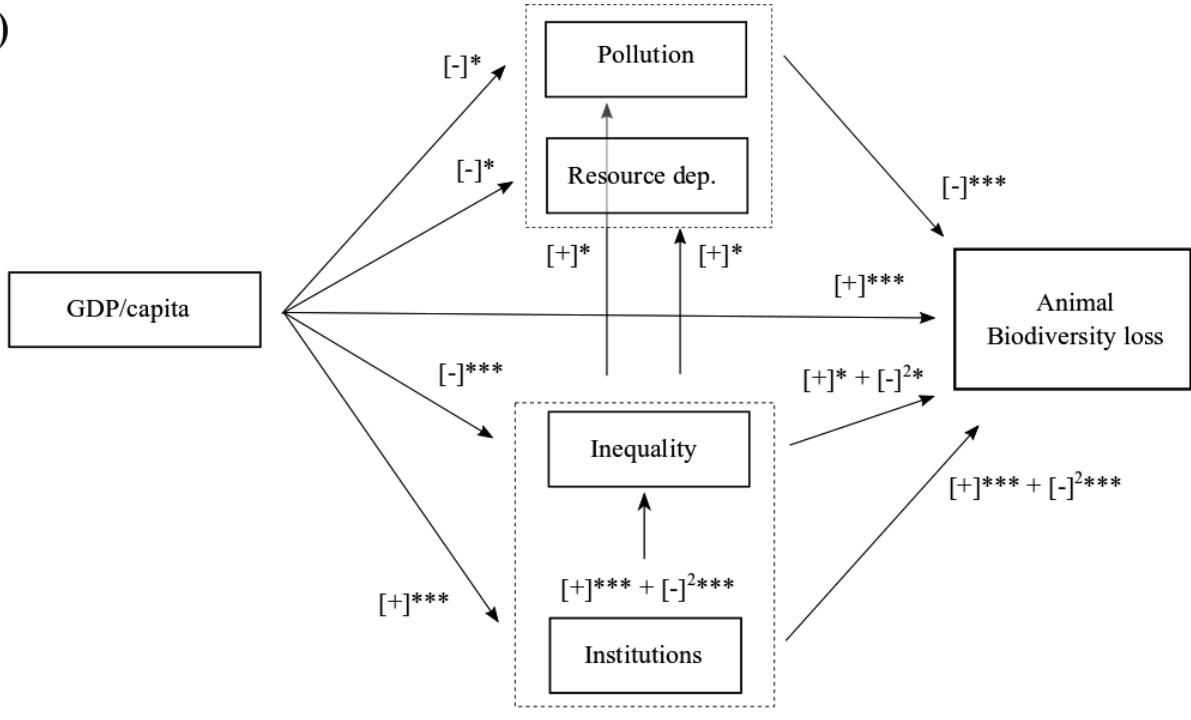

(b)

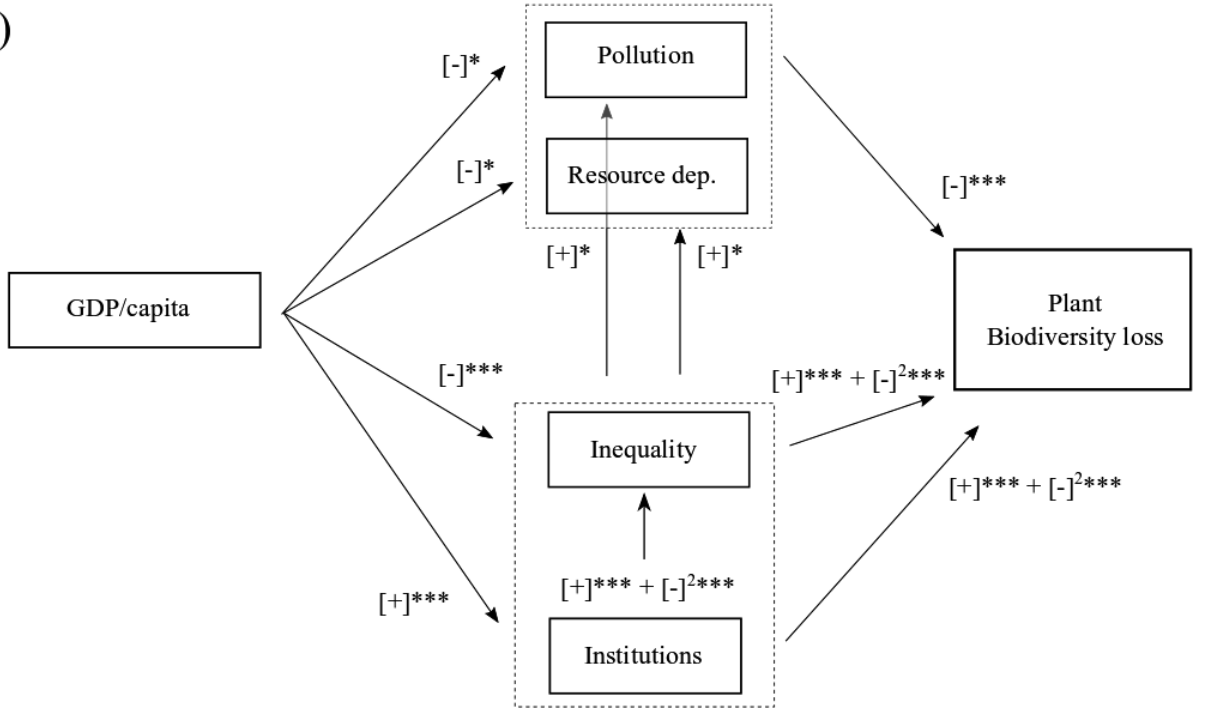

Figure 3: Effect pathway analysis revealing the nature of direct and indirect routes by which economic growth affects animal and plant biodiversity loss. Singe sign denotes a linear relation, while a combination of two signs represent nonlinear quadratic behaviour. See table 1 and 2 for coefficient values.

Next, we look closer into the role of intermediary variables. For institutions, the results confirm the inverted U-shaped relationship on biodiversity loss, evidenced by the highly significant negative quadratic coefficients. In addition, our results 
suggests that institutions have a further indirect effect, on biodiversity mediated through inequality. The relationship between institutions and inequality is an inverted $\mathrm{U}$, so that the net effect on biodiversity loss is ambiguous and depends on both the strength of institutions and level of inequality in society.

For inequality, the inverted U-shaped effect on biodiversity is also present, however the nonlinearity is more significant for plant than animal biodiversity loss. As we saw earlier from the GAM results, the nonlinear component in inequality is weaker, implying that biodiversity loss increases with inequality and the turning point is located only at very high inequality levels. In addition to the direct effect, inequality also affects biodiversity loss indirectly via pollution for animals and natural resource depletion for plants. Inequality aggravates both resource depletion and pollution, which in turn increases biodiversity loss. 


\begin{tabular}{|c|c|c|c|c|c|}
\hline & \multirow{2}{*}{$\begin{array}{c}\begin{array}{c}\text { Direct } \\
\text { effects }\end{array} \\
\text { Model 1 } \\
\text { Panel } \\
\text { (Within) } \\
\text { Ani. } \\
\text { biodiv. } \\
\text { loss (log) }\end{array}$} & \multicolumn{4}{|c|}{ Indirect effects } \\
\hline & & $\begin{array}{c}\text { Model 2 } \\
\text { Panel } \\
\text { (GMM) } \\
\text { Institutional } \\
\text { Strength }\end{array}$ & $\begin{array}{c}\text { Model 3 } \\
\text { Panel } \\
\text { (GMM) } \\
\text { Inequality }\end{array}$ & $\begin{array}{c}\text { Model } 4 \\
\text { Panel } \\
\text { (GMM) } \\
\text { Natural } \\
\text { Res. Dep. } \\
\text { (log) } \\
\end{array}$ & $\begin{array}{c}\text { Model 5 } \\
\text { Panel } \\
\text { (GMM) } \\
\text { Pollution } \\
\text { (log) }\end{array}$ \\
\hline Inequality & $\begin{array}{l}0.04^{*} \\
(0.02)\end{array}$ & & & $\begin{array}{c}0.09^{*} \\
(0.05)\end{array}$ & $\begin{array}{l}0.02^{*} \\
(0.01)\end{array}$ \\
\hline Inequality $^{2}$ & $\begin{array}{l}-0.0005^{*} \\
(0.0002)\end{array}$ & & & & \\
\hline $\begin{array}{l}\text { Institutional } \\
\text { Strength }\end{array}$ & $\begin{array}{l}0.03^{* * *} \\
(0.00)\end{array}$ & & $\begin{array}{l}0.67^{* * *} \\
(0.14)\end{array}$ & & \\
\hline $\begin{array}{l}\text { Institutional } \\
\text { Strength }^{2}\end{array}$ & $\begin{array}{l}-0.0003^{* * *} \\
(0.00003)\end{array}$ & & $\begin{array}{l}-0.00^{* * *} \\
(0.00)\end{array}$ & & \\
\hline $\begin{array}{l}\text { Surface area } \\
(\log )\end{array}$ & $\begin{array}{l}-0.06^{* * *} \\
(0.02)\end{array}$ & & & & \\
\hline Population (log) & $\begin{array}{l}0.16^{* * *} \\
(0.02)\end{array}$ & $\begin{array}{c}-3.52^{* * *} \\
(0.85)\end{array}$ & & & \\
\hline Pollution (log) & $\begin{array}{c}-0.21^{* * *} \\
(0.05)\end{array}$ & & & & \\
\hline $\begin{array}{l}\text { Natural Res. } \\
\text { Dep. (log) }\end{array}$ & $\begin{array}{l}-0.00 \\
(0.01)\end{array}$ & & & & \\
\hline GDP/capita (log) & $\begin{array}{l}0.09^{* * * *} \\
(0.03)\end{array}$ & $\begin{array}{c}17.70^{* * *} \\
(1.73)\end{array}$ & $\begin{array}{c}-5.87^{* * *} \\
(0.93)\end{array}$ & $\begin{array}{l}-0.77^{*} \\
(0.38)\end{array}$ & $\begin{array}{l}-0.18^{*} \\
(0.08)\end{array}$ \\
\hline Num. obs. & 472 & 472 & 472 & 472 & 472 \\
\hline $\begin{array}{l}\text { Sargan Test: } \\
\text { p-value }\end{array}$ & & 0.50 & 0.34 & 0.56 & 0.14 \\
\hline $\begin{array}{l}\text { Autocorrelation } \\
\text { test: } \\
\text { p-value }\end{array}$ & & 0.35 & 0.12 & 0.18 & 0.24 \\
\hline $\begin{array}{l}\text { Wald Test } \\
\text { Coefficients: } \\
\text { p-value }\end{array}$ & & 0.00 & 0.00 & 0.00 & 0.00 \\
\hline $\begin{array}{l}\text { Wald Test Time } \\
\text { Dummies: } \\
\text { p-value }\end{array}$ & & 0.00 & 0.00 & 0.00 & 0.00 \\
\hline
\end{tabular}

Table 1: Model results for Animal biodiversity loss (direct and indirect effects) 


\begin{tabular}{|c|c|c|c|c|c|}
\hline & Direct & & Indirect & fects & \\
\hline & $\begin{array}{c}\text { Model } 1 \\
\text { Panel } \\
\text { (Within) } \\
\text { Pla. } \\
\text { biodiv. } \\
\text { loss (log) } \\
\end{array}$ & $\begin{array}{c}\text { Model 2 } \\
\text { Panel } \\
\text { (GMM) } \\
\text { Institutional } \\
\text { Strength }\end{array}$ & $\begin{array}{c}\text { Model 3 } \\
\text { Panel } \\
\text { (GMM) } \\
\text { Inequality }\end{array}$ & $\begin{array}{c}\text { Model } 4 \\
\text { Panel } \\
\text { (GMM) } \\
\text { Natural } \\
\text { Res. Dep. } \\
\text { (log) } \\
\end{array}$ & $\begin{array}{c}\text { Model 5 } \\
\text { Panel } \\
\text { (GMM) } \\
\text { Pollution } \\
\text { (log) }\end{array}$ \\
\hline Inequality & $\begin{array}{c}0.44^{* * *} \\
(0.04)\end{array}$ & & & $\begin{array}{c}0.09^{*} \\
(0.04)\end{array}$ & $\begin{array}{l}0.01^{*} \\
(0.01)\end{array}$ \\
\hline Inequality $^{2}$ & $\begin{array}{c}-0.004^{* * *} \\
(0.00)\end{array}$ & & & & \\
\hline $\begin{array}{l}\text { Institutional } \\
\text { Strength }\end{array}$ & $\begin{array}{l}0.04^{* * *} \\
(0.01)\end{array}$ & & $\begin{array}{l}0.62^{* *} \\
(0.22)\end{array}$ & & \\
\hline $\begin{array}{l}\text { Institutional } \\
\text { Strength }^{2}\end{array}$ & $\begin{array}{c}-0.0004^{* * *} \\
(0.00)\end{array}$ & & $\begin{array}{l}-0.004^{*} \\
(0.00)\end{array}$ & & \\
\hline $\begin{array}{l}\text { Surface area } \\
(\log )\end{array}$ & $\begin{array}{c}-0.15^{* * *} \\
(0.05)\end{array}$ & & & & \\
\hline Population (log) & $\begin{array}{l}0.29^{* * * *} \\
(0.05)\end{array}$ & $\begin{array}{l}-2.60^{*} \\
(1.09)\end{array}$ & & & \\
\hline Pollution (log) & $\begin{array}{c}-0.71^{* * *} \\
(0.12)\end{array}$ & & & & \\
\hline $\begin{array}{l}\text { Natural Res. } \\
\text { Dep. (log) }\end{array}$ & $\begin{array}{l}0.06^{*} \\
(0.02)\end{array}$ & & $\begin{array}{l}1.25^{* * *} \\
(0.34)\end{array}$ & & \\
\hline GDP/capita (log) & & $\begin{array}{c}18.94^{* * *} \\
(1.61)\end{array}$ & $\begin{array}{l}-4.64^{* *} \\
(1.54)\end{array}$ & $\begin{array}{l}-0.75^{*} \\
(0.33)\end{array}$ & $\begin{array}{l}-0.19^{*} \\
(0.07)\end{array}$ \\
\hline Num. obs. & 464 & 464 & 464 & 464 & 464 \\
\hline $\begin{array}{l}\text { Sargan Test: } \\
\text { p-value }\end{array}$ & & 0.33 & 0.21 & 0.59 & 0.18 \\
\hline $\begin{array}{l}\text { Autocorrelation } \\
\text { test: } \\
\text { p-value }\end{array}$ & & 0.31 & 0.16 & 0.10 & 0.26 \\
\hline $\begin{array}{l}\text { Wald Test } \\
\text { Coefficients: p- } \\
\text { value }\end{array}$ & & 0.00 & 0.00 & 0.00 & 0.00 \\
\hline $\begin{array}{l}\text { Wald Test Time } \\
\text { Dummies: } \\
\text { p-value }\end{array}$ & & 0.00 & 0.00 & 0.00 & 0.00 \\
\hline
\end{tabular}

Table 2: Model results for Plant biodiversity loss (direct and indirect effects) 


\section{Discussion}

The effects of economic inequality on institutional strength and vice versa, are well studied ${ }^{24,30,31}$. Income concentrated in the hands of the few grants access to power and political influence that can inhibit institutional evolution ${ }^{32}$, while a transparent society with effective institutions, promotes equality and justice in the distribution of economic gains ${ }^{33}$. Our work probes the mutually counteracting relationship ${ }^{24}$ between inequality and institutions further, asking how this interaction might play a role in the explaining the effects of economic growth on the biodiversity loss.

We find an inverted U-shaped relationship between institutional strength and inequality, a result consistent with the literature ${ }^{34}$. One interpretation of the causality behind this relationship is that institutional changes may initially favour the rich, due to the persistence of their power, but that subsequent improvements would lead to a level playing field for all ${ }^{35}$. Our results suggest that this core mechanisms drive further nonlinearities with respect to biosphere impact variables. With stronger institutions, biodiversity loss in both animal and plants seems to worsen first, before improving, depending on both the quality of institutions and level of inequality.

Additionally, in regions of high inequality, the potency of institutions withers away to protect biodiversity loss. This idea is supported by assertions in literature pointing out that, while governance is important, it can be overshadowed by economic variables ${ }^{7}$, and institutions may be less likely to regulate biosphere indicators, like biodiversity loss, in poor countries which are often unequal as well ${ }^{36}$.

Nonlinear relationships involving inequality are now commonly reported in the literature. The root of much of this work is in the ideas put forward by Kuznets $(1955)^{37}$. Boyce $(1994)^{16}$ was the first to hypothesize environmental degradation as a function of inequality, but later work showed that the effect of inequality and economic development can be highly complex and nonlinear ${ }^{38,39}$. Our results suggest that, both animal and plants biodiversity loss variables, first deteriorate but then improve, in the institutions-inequality domain. The improvements correlate with better institutions, this does not necessarily imply a causal relationship. Societal choices to mitigate biosphere impacts differ across regions and income levels ${ }^{38}$, so a comparison between countries may not necessarily reflect 
developments within countries over time. We mitigate this concern to use countryfixed effects in the GMM and time-invariant covariates, such as land surface area in all other specifications. Even with strong institutions, highly unequal societies with concentrated power may be more likely to preclude an effective and enforceable consensus on environmental quality and conservation, thus reinforcing the status-quo of elites ${ }^{40}$.

Our results suggest that inequality and institutions play a central role in mediating the effects from economic growth on biodiversity loss. After taking into account the effects of inequality and institutions, we don't see a significant direct effect of economic growth on plant biodiversity loss and a dual direct and indirect effect on animal biodiversity loss. Furthermore, strong institutions can be fruitless in the face of rising inequality, where a highly unequal society can circumvent the system and choose to benefit at the expense of biodiversity.

Discussion of structural relationships, explored in this paper, merits a note about causality, which is also very central in the literature on the Environmental Kuznets Curve $^{41}$. Defining causal interpretation when variables can be independently varied is easy, however in the real world, where causes are often interrelated and confounding unobserved variables are omnipresent, recovering causal effects by mere statistics is impractical. Statistical techniques like SEMs, 'assume' causal relations between the variables of interest ${ }^{42}$, which does not in any way mean SEM establishes causal relations from associations alone ${ }^{43}$. Here, our aim is to use the SEM framework to marshal support for our assumed structural relationships, not proving it. Significance of effects presented, does not prove causality, however using a dynamic instrument variables approach with country fixed effects like GMM and controlling for observed covariates within the SEM framework, does make it more plausible. Further research, with recourse to natural experiments with randomized controls are needed to establish causal link based on the effects identified in this paper.

Our results highlights the complex and nonlinear nature of inequality-institutions interaction that can mediate impacts on the biosphere. Focusing on institutions and inequality, as two key handles for policy, is of paramount importance, without which following a biosphere protection agenda can be wasteful and counterproductive. 


\section{Methods}

Analysis presented in the paper, is based on a longitudinal panel dataset, compiled from various sources including IUCN's Red List of Threatened Species, World Bank's Development Indicators, The Standardized World Income Inequality Database, World Bank's Governance Indicators and UEA CRU. See supplementary material for a detailed description of all variables with units.

Biodiversity loss is calculated as the ratio of threatened species (as defined by IUCN) to total number of species identified, thus taking country specific species richness into account. Biodiversity loss variables are log transformed to standardize and aid comparison.

Income inequality is quantified by the widely used standardized index of Gini coefficients $^{44}$. No similar widely accepted estimate exists for institutional strength. To construct a standardized indicator we use principal component analysis (PCA) on set of six national level World Bank's governance indicators, reflecting institutional effectiveness. While highly correlated these indicators all measure different dimensions such as Voice and Accountability, Political Stability and Absence of Violence, Government Effectiveness, Regulatory Quality, Rule of Law and Control of Corruption. For our purposes, we standardized these six dimensions into a single measure of institutional quality by using principal component analysis (PCA). PCA parses data into orthogonal components thus capturing most of the variation in one component. The resulting estimate, which we term as institutional strength, captures $84.7 \%$ of the variance over country's regulatory quality, control of corruption, governance effectiveness and rule of law (see supplementary material).

In addition to the effects via inequality and institutions, more direct impacts of economic growth included in the model are measured by air pollution and natural resource depletion. A number of covariates are also used to control for other observable factors affecting biodiversity loss. These include temperature, precipitation, country surface area and country population and income.

With the data set up, we first explore nonlinearities in the institutions-inequality space using a generalized additive model (GAM). Separate models were fitted for 
biodiversity loss (plants), and biodiversity loss (animals) as response variables. The general GAM structure used is as follows:

$$
\begin{gathered}
B_{i j}=\beta_{0}+f_{1}\left(Q_{i j}, S_{i j}\right) * Y+f_{n}(X)+\varepsilon_{i j}-(1) \\
f_{n}(X)=f_{2}\left(I_{i j}\right)+f_{4}\left(O_{i j}\right)+f_{5}\left(U_{i j}\right)+f_{7}\left(T_{i j}\right)+f_{8}\left(P_{i j}\right)+f_{9}\left(D_{i j}\right)+f_{10}\left(A_{i}\right)+Y \\
\varepsilon_{i j} \sim N\left(0, \sigma^{2}\right)
\end{gathered}
$$

Subscript $i j$ refers to observations of country $i$ in year $j$. Here $B$ is the chosen log biodiversity loss (animals or plants) response variable and $Q$ and $S$ are key explanatory variables of interest denoting inequality and institutional quality respectively. $I$ is $\log$ income, $O$ is $\log$ population, $U$ is $\log$ pollution, $T$ is temperature, $P$ is $\log$ precipitation, $D$ is $\log$ natural resource depletion, $A$ is $\log$ country surface area and $Y$ is years. $f(Q, S)$ is a smoothing function using tensor product smooths. Tensor product smooths are used for smooth interaction of two or more variables especially when they are measured in different units. The basic idea is to start with 'smooths' in one variable with any basis functions and then construct products by varying in the other dimension to get ${ }^{45}$ :

$$
f_{1}(Q, S)=\sum_{l=1}^{L} \sum_{m=1}^{M} \alpha_{l m} b_{l}(Q) c_{m}(S)
$$

$L$ and $M$ are the dimensions or degrees of freedom of $b_{j}$ and $c_{i}$, the smoothing basis functions. $\alpha_{i j}$ is the vector of unknown regression coefficients. For the rest we have the following standard smoothing structure:

$$
f_{n}(X)=\sum_{k=1}^{K} \beta_{k n} d_{k n}(X)
$$

Basis dimensions $(L, M, K)$ are restricted to 3 to limit over-smoothing.

Moving on from studying the general structure, we now statistically test specific interactions in the conceptual model using a structural equation model (SEM) framework. SEM are, simply put, multiple simultaneously estimated regression models in which the response variable in one regression equation can appear as an explanatory variable in another equation ${ }^{46}$. Global or simultaneous estimation of 
SEMs assumes a number of restriction on the underlying data structure such as linearity, normality and one-way effects. A more powerful and flexible approach is piecewise estimate ${ }^{47}$, where each model is fitted separately, such that the complexity of each relation can be addressed individually.

Utilizing the piecewise SEM framework, we use a combination of panel regressions and GMM (generalized method of moments) estimators, to control for unobserved heterogeneity across countries, and suspected endogeneity within some of our modelled relations. Our estimated equations, for direct and indirect effects, are as follows:

For animal biodiversity loss:

Direct effects

$$
\begin{aligned}
B_{i j}=\beta_{0}+\beta_{1} Q_{i j} & +\beta_{2} Q_{i j}^{2}+\beta_{3} S_{i j}+\beta_{4} S_{i j}^{2}+\beta_{5} I_{i j}+\beta_{6} O_{i j}+\beta_{7} U_{i j}+\beta_{8} A_{i}+\beta_{9} D_{i}+\mu_{j} \\
& +\varepsilon_{i j}-(2 a)
\end{aligned}
$$

Indirect effects

$$
\begin{gathered}
S_{i j}=\beta_{0}+\beta_{1} I_{i j}+\beta_{2} O_{i j}+v_{i}+\mu_{j}+\varepsilon_{i j}-(2 b) \\
Q_{i j}=\beta_{0}+\beta_{1} I_{i j}+\beta_{2} S_{i j}+\beta_{3} O_{i j}+\beta_{4} U_{i j}+\beta_{5} D_{i j}+v_{i}+\mu_{j}+\varepsilon_{i j}-(2 c) \\
D_{i j}=\beta_{0}+\beta_{1} I_{i j}+\beta_{2} Q_{i j}+v_{i}+\mu_{j}+\varepsilon_{i j}-(2 d) \\
U_{i j}=\beta_{0}+\beta_{1} I_{i j}+\beta_{2} Q_{i j}+v_{i}+\mu_{j}+\varepsilon_{i j}-(2 e)
\end{gathered}
$$

For plant biodiversity loss

Direct effects

$$
\begin{gathered}
B_{i j}=\beta_{0}+\beta_{1} Q_{i j}+\beta_{2} Q_{i j}^{2}+\beta_{3} S_{i j}+\beta_{4} S_{i j}^{2}+\beta_{5} I_{i j}+\beta_{6} O_{i j}+\beta_{7} P_{i j}+\beta_{8} A_{i}+\beta_{9} D_{i} \\
+\mu_{j}+\varepsilon_{i j}-(3 a)
\end{gathered}
$$

Indirect effects

$$
S_{i j}=\beta_{0}+\beta_{1} I_{i j}+\beta_{2} O_{i j}+v_{i}+\mu_{j}+\varepsilon_{i j}-(3 b)
$$




$$
\begin{gathered}
Q_{i j}=\beta_{0}+\beta_{1} I_{i j}+\beta_{2} S_{i j}+\beta_{3} O_{i j}+\beta_{4} U_{i j}+\beta_{5} D_{i j}+v_{i}+\mu_{j}+\varepsilon_{i j}-(3 c) \\
D_{i j}=\beta_{0}+\beta_{1} I_{i j}+\beta_{2} Q_{i j}+v_{i}+\mu_{j}+\varepsilon_{i j}-(3 d) \\
U_{i j}=\beta_{0}+\beta_{1} I_{i j}+\beta_{2} Q_{i j}+v_{i}+\mu_{j}+\varepsilon_{i j}-(3 e)
\end{gathered}
$$

As before, subscript $i j$ refers to the individual (country) and time (years) dimensions respectively. Since biodiversity loss is a slow variable, we estimated eq. 2(a) and 3(a) using time fixed effects panel estimates, to control for any unobserved heterogeneity across time. Time invariant covariate such as country surface area was included to absorb individual country level heterogeneity.

Equations $2(b-e) \& 3(b-e)$, contain variables potentially posing an endogeneity problem due to simultaneity bias, such as between inequality and institutions in Eq. $2-3(b)$ and $2-3(c)$, between inequality and natural resource depletion in Eq. $2-3(d)$ and between inequality and pollution in Eq. $2-3(e)$. To deal with endogeneity, we use lagged transformations of the endogenous variables as instruments in a two-step Blundell and Bond ${ }^{29}$ type system GMM estimator with robust standard errors ${ }^{48}$. Within the GMM estimator, a two-way individual and time fixed effects model was applied, taking into account both heterogeneity across countries and time in our analysis. Fixed as opposed to a random model specification was chosen based on the Hausman test which rejected the null hypothesis of random effects with a $p$-value $<0.001$. 


\section{Data, software and code}

Data and code used for the analysis and generating figures, are available and can be requested from the corresponding author. The analysis was carried out in $\mathrm{R}$ (https://www.r-project.org) using the packages plm, PiecewiseSEM and mgcv.

\section{Acknowledgements}

This project received funding from the European Union's Horizon 2020 research and innovation programme under the Marie Sklodowska-Curie grant agreement No 643073. CX acknowledges supports from the National Natural Science Foundation of China (No. 31770512) and the CTF foundation.

\section{Authors' contribution}

MUM initiated the research and conceived the idea. MUM with AR, EN, and MS developed the idea and design. MUM carried out the analysis and took the lead in writing the manuscript. All authors contributed to the final version of the manuscript. 


\section{Supplementary information for \\ 'Institutions-inequality interplay shapes the impact of economic growth on biodiversity loss'}

\section{Data}

Dataset used in the analysis is built based on multiple sources including IUCN's Red List of Threatened Species, World Bank's Development Indicators, The Standardized World Income Inequality Database, World Bank’s Governance Indicators and UEA CRU. Detailed description of individual variables are given in Table S1.

\begin{tabular}{|c|c|c|c|}
\hline Variables & Units & Description & Source \\
\hline Inequality & Unit-less & Gini coefficient & $\begin{array}{l}\text { Standardized } \\
\text { World } \\
\text { Income } \\
\text { Inequality } \\
\text { Database }\end{array}$ \\
\hline Institutions & Unit-less & World governance indicators & $\begin{array}{l}\text { World } \\
\text { Bank's } \\
\text { Governance } \\
\text { Indicators }\end{array}$ \\
\hline $\begin{array}{l}\text { Economic } \\
\text { growth }\end{array}$ & Rate & GDP per capita growth (annual \%) & $\begin{array}{l}\text { World } \\
\text { Bank's } \\
\text { Development } \\
\text { Indicators }\end{array}$ \\
\hline $\begin{array}{l}\text { Animal } \\
\text { biodiversity } \\
\text { loss }\end{array}$ & Ratio & $\begin{array}{l}\text { Ratio of threatened species to total } \\
\text { number of species identified }\end{array}$ & $\begin{array}{l}\text { IUCN's Red } \\
\text { List }\end{array}$ \\
\hline $\begin{array}{l}\text { Plant } \\
\text { biodiversity } \\
\text { loss }\end{array}$ & Ratio & $\begin{array}{l}\text { Ratio of threatened species to total } \\
\text { number of species identified }\end{array}$ & $\begin{array}{l}\text { IUCN's Red } \\
\text { List }\end{array}$ \\
\hline Temperature & Celsius & Mean temperature for the country & $\begin{array}{l}\text { Climatic } \\
\text { Research } \\
\text { Unit, UEA }\end{array}$ \\
\hline Precipitation & $\begin{array}{c}\text { Volume } \\
\text { (Millimetre) }\end{array}$ & Total precipitation for the country & $\begin{array}{l}\text { Climatic } \\
\text { Research } \\
\text { Unit, UEA }\end{array}$ \\
\hline Surface area & $\begin{array}{c}\text { Area } \\
\left.\text { (kilometre }^{2}\right)\end{array}$ & $\begin{array}{l}\text { Surface area is a country's total } \\
\text { area, including areas under inland }\end{array}$ & $\begin{array}{l}\text { World } \\
\text { Bank's }\end{array}$ \\
\hline
\end{tabular}




\begin{tabular}{|l|c|l|l|}
\hline & & $\begin{array}{l}\text { bodies of water and some coastal } \\
\text { waterways. }\end{array}$ & $\begin{array}{l}\text { Development } \\
\text { Indicators }\end{array}$ \\
\hline Population & Count (sum) & $\begin{array}{l}\text { Total population counting all } \\
\text { residents regardless of legal status } \\
\text { or citizenship }\end{array}$ & $\begin{array}{l}\text { World } \\
\text { Bank's } \\
\text { Development } \\
\text { Indicators }\end{array}$ \\
\hline Pollution & $\begin{array}{c}\text { PM2.5 air } \\
\text { pollution, } \\
\text { mean annual } \\
\text { exposure } \\
\text { (micrograms } \\
\text { per cubic } \\
\text { meter) }\end{array}$ & $\begin{array}{l}\text { Population-weighted exposure to } \\
\text { ambient PM2.5 pollution is } \\
\text { defined as the average level of } \\
\text { exposure of a nation's population } \\
\text { to concentrations of suspended } \\
\text { particles measuring less than 2.5 } \\
\text { microns in aerodynamic diameter. }\end{array}$ & $\begin{array}{l}\text { World } \\
\text { Bank's } \\
\text { Development } \\
\text { Indicators }\end{array}$ \\
\hline $\begin{array}{c}\text { Resource } \\
\text { depletion }\end{array}$ & $\begin{array}{c}\text { natural } \\
\text { resources } \\
\text { depletion }\end{array}$ & $\begin{array}{l}\text { Natural resource depletion is the } \\
\text { sum of net forest depletion, } \\
\text { energy depletion, and mineral } \\
\text { depletion. }\end{array}$ & $\begin{array}{l}\text { World } \\
\text { Bank's } \\
\text { Development } \\
\text { Indicators }\end{array}$ \\
\hline
\end{tabular}

Table S1: Data set description of variables

\section{Principal component analysis}

Principal component analysis (PCA) is used to analyse variation across a set of correlated variables to get a corresponding uncorrelated but reduced set. The six indicators of governance, collected by the World Bank, reflecting institutional effectiveness, are highly correlated and we need a combined measure to reflect most of the variation. A matrix showing the correlations and results of the PCA is shown in figure $\mathrm{S} 1$. 
(a)

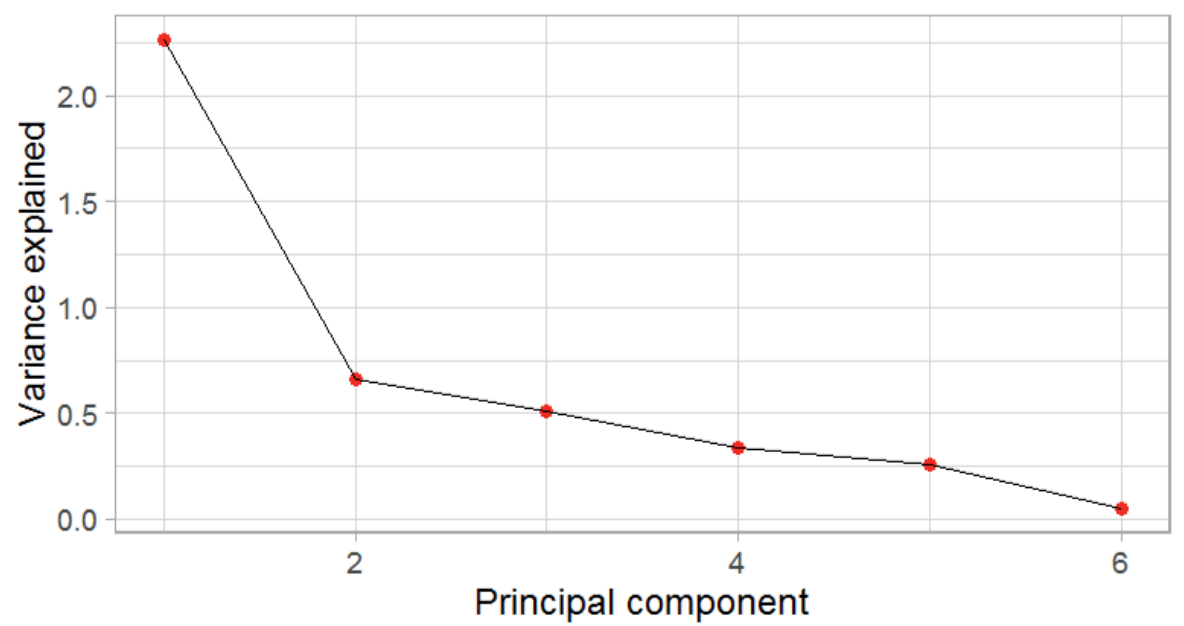

(b)

\section{Correlation plot}

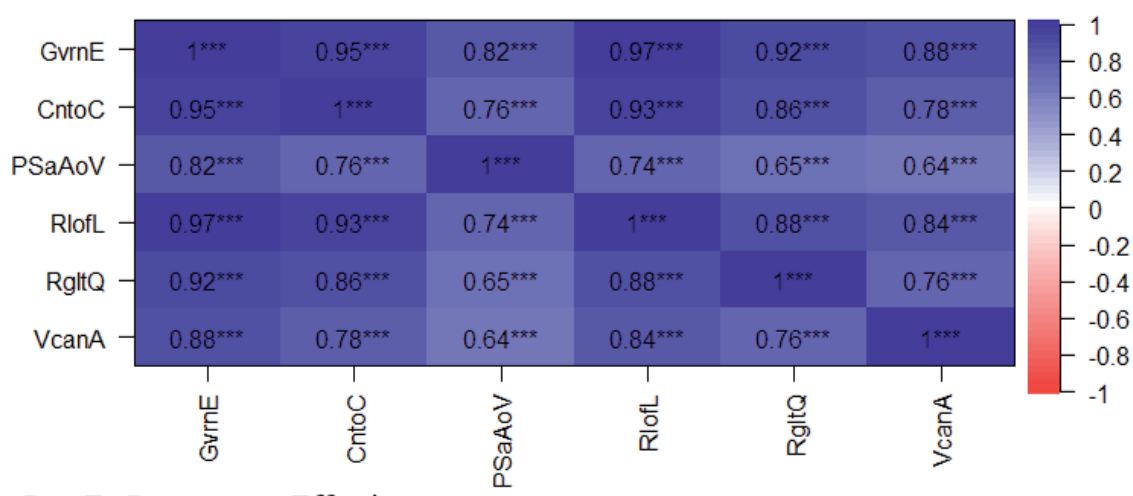

GvrnE: Government Effectiveness

CntoC: Control of Corruption

PSaAoV: Political Stability and Absence of Violence

RlofL: Rule of Law

RgltQ: Regulatory Quality

VcanA: Voice and Accountability

Figure S1: Principal component analysis (a) and correlation plot (b) for institutional quality variables. 


\section{Reference}

1. Rockström, J. et al. A safe operating space for humanity. The Future of Nature: Documents of Global Change 491-501 (2013). doi:10.1038/461472a

2. Bongaarts, J. IPBES, 2019. Summary for policymakers of the global assessment report on biodiversity and ecosystem services of the Intergovernmental Science-Policy Platform on Biodiversity and Ecosystem Services. Population and Development Review 45, (2019).

3. Steffen, W. et al. Trajectories of the Earth System in the Anthropocene. Proc. Natl. Acad. Sci. U. S. A. 115, 8252-8259 (2018).

4. Ostrom, E. A general framework for analyzing sustainability of socialecological systems. Science 325, 419-422 (2009).

5. Asafu-Adjaye, J. Biodiversity loss and economic growth: A cross-country analysis. Contemp. Econ. Policy 21, 173-185 (2003).

6. Mikkelson, G. M., Gonzalez, A. \& Peterson, G. D. Economic inequality predicts biodiversity loss. PLoS One (2007).

doi:10.1371/journal.pone.0000444

7. Holland, T. G., Peterson, G. D. \& Gonzalez, A. A cross-national analysis of how economic inequality predicts biodiversity loss. Conserv. Biol. 23, 1304-1313 (2009).

8. Naidoo, R. \& Adamowicz, W. L. Effects of economic prosperity on numbers of threatened species. Conserv. Biol. 15, 1021-1029 (2001).

9. Dietz, S. \& Adger, W. N. Economic growth, biodiversity loss and conservation effort. J. Environ. Manage. 68, 23-35 (2003).

10. Mills, J. H. \& Waite, T. A. Economic prosperity, biodiversity conservation, and the environmental Kuznets curve. Ecol. Econ. 68, 2087-2095 (2009).

11. Mirza, M. U., Richter, A., van Nes, E. H. \& Scheffer, M. Technology driven inequality leads to poverty and resource depletion. Ecol. Econ. 160, 215-226 (2019).

12. Folke, C. et al. Reconnecting to the biosphere. in Ambio 40, 719-738 (2011).

13. Klooster, D. Institutional choice, community, and struggle: A case study of forest co-management in Mexico. World Dev. (2000). doi:10.1016/S0305750X(99)00108-4 
14. Leach, M., Mearns, R. \& Scoones, I. Environmental entitlements: Dynamics and institutions in community-based natural resource management. World Dev. 27, 225-247 (1999).

15. Heerink, N., Mulatu, A. \& Bulte, E. Income inequality and the environment: Aggregation bias in environmental Kuznets curves. Ecol. Econ. (2001). doi:10.1016/S0921-8009(01)00171-9

16. Boyce, J. K. Inequality as a cause of environmental degradation. Ecological Economics 11, 169-178 (1994).

17. Arrow, K. et al. Economic growth, carrying capacity, and the environment. Environ. Dev. Econ. 1, 104-110 (1996).

18. Grossman, G. M. \& Krueger, A. B. Economic Growth and the Environment. Q. J. Econ. 110, 353-377 (1995).

19. Shafik, N. Economic development and environmental quality: An econometric analysis. Oxf. Econ. Pap. 46, 757-773 (1994).

20. Easterly, W., Ritzen, J. \& Woolcock, M. Social cohesion, institutions, and growth. Economics and Politics 18, 103-120 (2006).

21. Mehlum, H., Moene, K. \& Torvik, R. Cursed by resources or institutions? World Econ. 29, 1117-1131 (2006).

22. Mazor, T. et al. Global mismatch of policy and research on drivers of biodiversity loss. Nat. Ecol. Evol. 2, 1071-1074 (2018).

23. Carpenter, S. R. et al. Science for managing ecosystem services: Beyond the Millennium Ecosystem Assessment. Proc. Natl. Acad. Sci. (2009). doi:10.1073/pnas.0808772106

24. Chong, A. \& Gradstein, M. Inequality and institutions. Review of Economics and Statistics (2007). doi:10.1162/rest.89.3.454

25. Rogowski, R. \& MacRae, D. C. Inequality and institutions: What theory, history, and (some) data tell us. in Democracy, Inequality, and Representation : A Comparative Perspective 354-386 (2008).

26. Chong, A. \& Calderón, C. Institutional quality and income distribution. Econ. Dev. Cult. Change 48, 761-786 (2000).

27. Hooper, D. U. et al. A global synthesis reveals biodiversity loss as a major driver of ecosystem change. Nature 486, 105-108 (2012).

28. Cardinale, B. J. et al. Biodiversity loss and its impact on humanity. Nature 
(2012). doi:10.1038/nature11148

29. Blundell, R. \& Bond, S. Initial conditions and moment restrictions in dynamic panel data models. J. Econom. (1998). doi:10.1016/S03044076(98)00009-8

30. Easterly, W. The middle class consensus and economic development. $J$. Econ. Growth 6, 317-335 (2001).

31. Keefer, P. \& Knack, S. Polarization, politics and property rights: Links between inequality and growth. Public Choice 111, 127-154 (2002).

32. Glaeser, E., Scheinkman, J. \& Shleifer, A. The injustice of inequality. Journal of Monetary Economics (2003). doi:10.1016/S03043932(02)00204-0

33. Gradstein, M. Inequality, democracy and the protection of property rights. Econ. J. 117, 252-269 (2007).

34. Chong, A. \& Calderón, C. Institutional Quality and Income Distribution. Econ. Dev. Cult. Change (2005). doi:10.1086/452476

35. Acemoglu, D. \& Robinson, J. A. Persistence of power, elites, and institutions. Am. Econ. Rev. 98, 267-293 (2008).

36. Ostrom, E. Reformulating the commons. Swiss Polit. Sci. Rev. 6, 29-52 (2000).

37. Dillehay, D. L., Sander, M., Talkington, D. F., Thacker, W. L. \& Brown, D. R. Isolation of mycoplasmas from prairie voles (Microtus ochrogaster). Laboratory Animal Science 45, 631-634 (1995).

38. Scruggs, L. A. Political and economic inequality and the environment. Ecol. Econ. (1998). doi:10.1016/S0921-8009(97)00118-3

39. Torras, M. \& Boyce, J. K. Income, inequality, and pollution: A reassessment of the environmental Kuznets curve. Ecol. Econ. (1998). doi:10.1016/S0921-8009(97)00177-8

40. Kashwan, P. Inequality, democracy, and the environment: A cross-national analysis. Ecol. Econ. 131, 139-151 (2017).

41. Brock, W. A. \& Taylor, M. S. Chapter 28 Economic Growth and the Environment: A Review of Theory and Empirics. in Handbook of Economic Growth 1, 1749-1821 (2005).

42. Pearl, J. Graphs, causality, and structural equation models. Sociol. Methods 
Res. 27, 226-284 (1998).

43. Bollen, K. A. \& Pearl, J. Eight Myths About Causality and Structural Equation Models. in Handbook of causal analysis for social research 301328 (Springer, 2013). doi:10.1007/978-94-007-6094-3_15

44. Gini, C. Variabilità e mutabilità. Memorie di metodologica statistica (1912).

45. Wood, S. N. Low-rank scale-invariant tensor product smooths for generalized additive mixed models. Biometrics 62, (2006).

46. Grace, J. B. Structural equation modeling and natural systems. Structural Equation Modeling and Natural Systems (2006). doi:10.1017/CBO9780511617799

47. Lefcheck, J. S. piecewiseSEM: Piecewise structural equation modelling in $\mathrm{r}$ for ecology, evolution, and systematics. Methods Ecol. Evol. 7, 573-579 (2016).

48. Windmeijer, F. A finite sample correction for the variance of linear efficient two-step GMM estimators. J. Econom. 126, 25-51 (2005). 


\title{
Chapter 4
}

\section{Income growth and the structure of inequality}

\author{
M Usman Mirzal and Florian Wagener ${ }^{2}$ \\ ${ }^{1}$ Environmental Economics and Natural Resources, Wageningen University, \\ Netherlands \\ ${ }^{2}$ Economics and Business, University of Amsterdam, Netherlands
}

\begin{abstract}
Income inequality has risen globally after 1980. Documenting this rise, improved data coverage show that income growth rates differ considerably between income groups. While most of the income growth is attributed to the top or high incomes, the dependence between high and low incomes is much less explored. We first explain the structure of inequality through incorporating the dependence of low and high-income group growths to the size of the low-income group. Second, using income data, we predict the long-run income inequality levels for the US, France, China and India in the time periods, 1960-1989 and 1990-2015.
\end{abstract}

Keywords: Long-run inequality, Income groups, Income growth, US, France, China, India 


\section{Introduction}

Explaining the nature of income inequality and its variation across countries remains a central question in economics. Inequality evolves slowly over time, while it varies widely over countries ${ }^{1}$. For instance incomes in the Scandinavian region are relatively equal and have stayed that way for a long time, while regions such as Latin America and Asia, incomes have remained highly unequal. During the 1980s income inequality rose sharply in particular regions of the developed world, especially English speaking countries, which had seen falling inequality over most of the $20^{\text {th }}$ century ${ }^{2}$. The US, UK and Canada, all experienced rising inequality in the latter part of the twentieth century, fuelled by top income growth (Piketty and Saez (2003); Atkinson (2005); Atkinson, Piketty, and Saez (2011)). A trend reversal like this motivates us to study the structure of inequality in details, with respect to income growth rates and the size of income groups.

Evolution of inequality depends on income growth rates that differ by income groups, as illustrated by the empirical elephant curve of inequality and income growth ${ }^{6}$. These differentiated growth rates, within groups in the income distribution, can be explained at the micro-level by differentiated access to opportunities, technology and capital, which can lead to heterogeneous income growth rates over the population income groups ${ }^{7}$. We will not delve into the micro-foundations here (see Piketty; (2014); Guvenen (2007); and Mirza et al. (2019)) but will take the heterogeneity of growth rates as given. Country-level US data show us that this heterogeneity in income growth rates can be split into two broad groups, low and high incomes (see the section on Data below).

Income groups do not evolve independently, but their growth depends on structural relations within a society. For example, high incomes can dominate growth, while restricting gains for the bottom low incomes ${ }^{11,12}$. Moreover, income growth can be socially determined by interactions with high-income individuals and one's aspirations to match them ${ }^{13}$.

The central theme of this paper is to study how heterogeneous income growth rates and the dependence structure of income growth rates on the size of income groups drive long term inequality. The main contributions of this paper are twofold. First, we analyse income data from the period 1960-2015 to estimate the long term stable distribution of income for the US, France, China and India. Our results suggest that inequality is expected to stay around the same level in the US, to decline in China and India, and to increase in France, as they converge to their respective estimated 
long-run value. Recent trends in inequality data are in line with our results, though the convergence in France and China is slow.

Second, we examine the sensitivity of our long-run income inequality predictions with respect to variations in the rate of high-income growth and the sensitivity of high-income growth to the size of low incomes, for the US, France, China and India. In the US and France, reducing long-term inequality would require positive sensitivity of high-income growth to the size of low incomes, implying that as more people get out of low incomes, high incomes growth should decline. In China and India, the effect is reversed, indicating that reducing inequality would require a negative sensitivity of high-income growth to the size of low incomes. Here inequality reduction is most likely in the scenario when high incomes growth rises together with people getting out of low incomes.

\section{Data: Income groups and growth rates}

Since the $21^{\text {st }}$ century, a significant effort has gone into systematically compiling data on income distribution, grouped by income percentiles, by the World Inequality Database ${ }^{14}$. A key insight from the data is that "income inequality has increased in nearly all world regions in recent decades but at different speeds" ${ }^{1}$. From a policy perspective, this variation in speed suggests that country-specific structural factors such as institutions, demographics, and technology matter. It is however in no way obvious on which aspects policy should focus. Atkinson, Piketty, and Saez (2011) highlight the importance of top incomes as a key driver of inequality. Data suggests that the growth of top incomes is considerably different from the rest, making them, using Rosen (1981)'s term, economic superstars, dominating any activity they engage in.

Documenting the evolution of income inequality, the World Inequality Database records country-wise time series of individual's average income for each income percentile of the distribution. Using average incomes, we compute income growth rates for each income percentile in our dataset, for the US, France, China and India. Income growth rates change gradually over time. To incorporate this change, we calculate income growth rates per decade for the time period between 1960 and 2015. Decadal income growth rates are then de-trended using the average longterm (1960-2015) income growth to get the stationary income growth rates per decade. This panel of country-level decadal income growth per income percentiles is then used to estimate the thresholds defining high and low-income groups. Piecewise linear regression with ordinary least squares (OLS) fit is iteratively fitted 
over the data to get the best fit value of the threshold using Akaike information criterion (AIC).

Best fit threshold values for the US highlight a clear split in the structure of income growth rates (Fig 1a). Note that except for the period 1960-69, where low incomes experienced higher growth rates, all succeeding decades showed higher growth rates for the high incomes. It fact, the $60 \mathrm{~s}$ saw significant poverty reduction in the US ${ }^{16}$. Post-1960, the estimated income threshold ( $T$ ) for US incomes, separating low and high incomes, first decreases and then increases in a U-shaped pattern over time (Fig 1b). From 1960-1980, the threshold decreased, denoting reduction in low incomes. However the turning point was 1980s, when the population size of low incomes started to expand while high incomes began to grow faster, thus fuelling both poverty and inequality. This observation is in line with the what Piketty and Saez (2014) found for US inequality in the long run. 
(a)
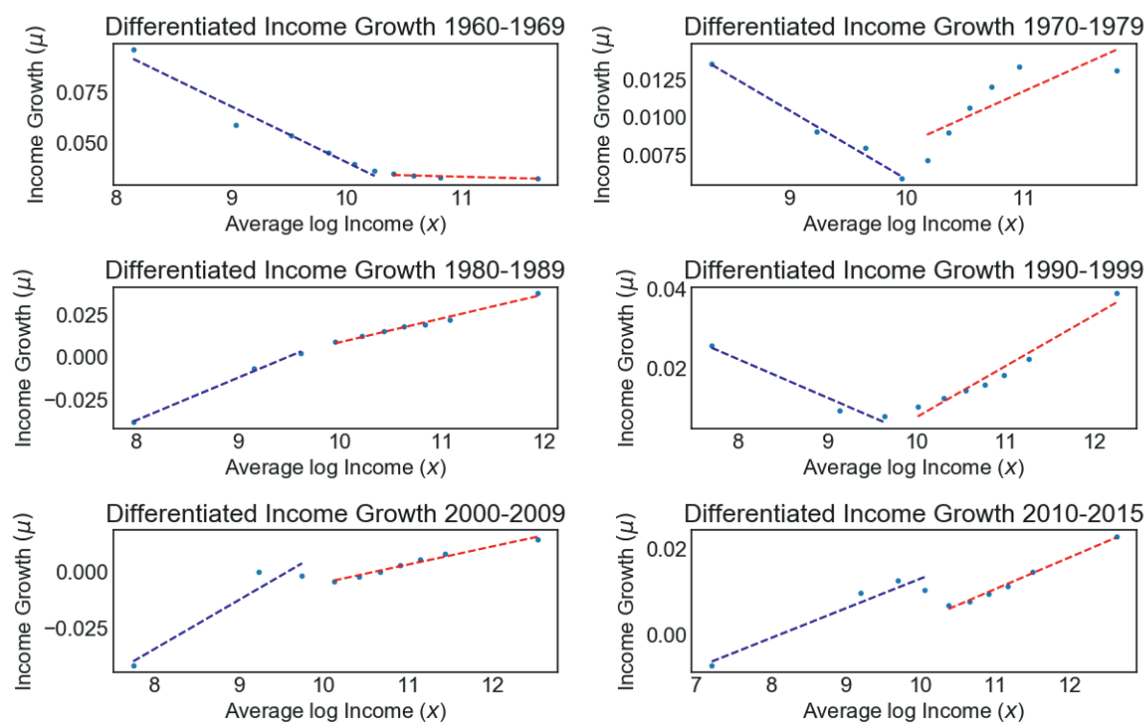

(b)

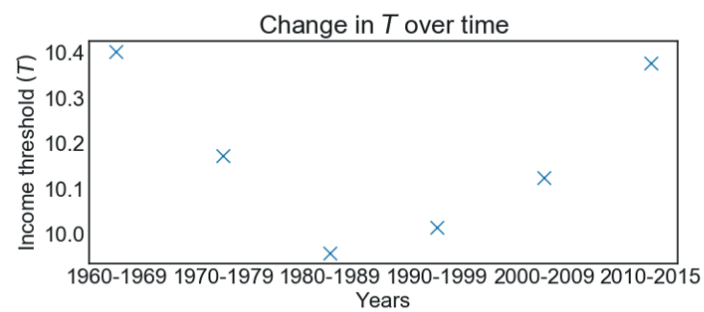

Figure 1: (a) Decade-wise income growth data, for the US from 1960 to 2015, differentiated by low and high-income groups. (b) Evolution of the split threshold (T) between low and high-income groups for the US in the long-run 1960-2015.

The change in inequality dynamics in the 1980s is a global phenomenon.

Globalization of the world economy and technological changes in the late 1970s not only caused wage differentials for highly skilled workers to shift upwards ${ }^{18}$ but also caused capital income shares to push top incomes even higher ${ }^{19}$. To capture this change in top income dynamics we consider two different data periods for modelling inequality and subsequent analysis. The first period covers 1960 to 1989, while the second spans the period 1990 to 2015.

\section{Model of structural long-run inequality}


Our starting point is an inequality dynamic model introduced by Gabaix et al. (2016), in continuous time (Eq. 1).

$$
d x_{i t}=\mu(x) d t+\sigma_{i t} d W_{i t}
$$

Here $x$ is $\log$ of income, $\mu$ is income growth, $W$ is standard white noise process and $\sigma$ is its standard deviation. The dynamics are indexed by time $(t)$ and individuals $(i)$. The evolution of the income distribution $(P)$ generated by Eq. 1 is given by the associated Fokker-Planck equation:

$$
P_{t}=-\mu(x) P_{x}+\frac{\sigma^{2}}{2} P_{x x}
$$

We modify the model by introducing forces that would stabilize the distribution in the long run ${ }^{20}$. First, workers leave the workforce at a rate $\gamma$ and are subsequently replaced by new workers with income drawn from a random distribution with density $\beta(x)$. For simplicity and the ease of later interpreting proportions of $P$ as ratios we assume $\int_{0}^{\infty} \beta(x)=1$. Second, we impose a lower bound on income in the form of a reflecting boundary. As with the original model, the lower bound is specified as $x=0$. This gives us the modified Fokker-Planck equation.

$$
P_{t}=-\mu(x) P_{x}+\frac{\sigma^{2}}{2} P_{x x}-\gamma P+\gamma \beta(x)
$$

Note that Eq. 3 describes the evolution of the income distribution in the population, that Gabaix et al. (2016) shows has a stationary distribution with a Pareto tail. With $\int_{0}^{\infty} \beta(x)=1$, we can normalize the steady state distribution $\int_{0}^{\infty} P d x=1$, so that the proportions of low and high incomes add up to 1 .

With the basic setup defined, we now model the dependence of income growth rates on the income levels and the size of income groups. The structural difference between how low and high-income growth rates depending on income levels is specified using a simple stepwise linear relationship:

$$
\mu(x)= \begin{cases}\mu_{0}^{-}+\mu_{1}^{-} x, & x<T \\ \mu_{0}^{+}+\mu_{1}^{+} x, & x>T\end{cases}
$$

Where $T$ is the income threshold separating the two income groups, while $\mu_{0}$ and $\mu_{1}$ are respectively the base growth rate and sensitivity of the growth rate on income. The superscripts (-) and (+) are respectively denoting low and highincome groups. 
Next, to incorporate the dependence of income growth rates on the size of low incomes, we proceed in two steps. First, we introduce a helper constant $\bar{\theta}$ defined within $P(x, \bar{\theta})$, such that:

$$
f(\bar{\theta})=\int_{0}^{T} P(x, \bar{\theta}) d x
$$

With $\bar{\theta}$ we still have a closed-form stationary solution for Eq. (3). However, if $\theta$ is defined as the fraction of low-income group in the population, then $\theta$ also depends on $P$ and we have an integro-differential equation with no closed-form solution. To solve, in the second step, we use the definition of $\theta$ to construct a fixed point equation:

$$
\theta=f(\theta)=\int_{0}^{T} P(x, \theta) d x
$$

Since the integral is a function of $\theta$ itself, we have a map to work with to derive the fixed value of $\theta$. With this setup, the stationary solutions of Eq. (3) are defined where the map in Eq. (6) have a fixed point(s), which is also the asymptotic value of the size of the low income group.

Additionally, we have the following boundary conditions on Eq. (3):

$$
\begin{array}{lll}
\text { Reflection } & 0=-\mu^{-} P+\frac{\sigma^{2}}{2} P_{x} & \text { at } x=0 \\
\text { Continuity } & P_{-}=P_{+} & \text {at } x=T \\
\text { Natural } & \lim _{x \rightarrow \infty} P=0 &
\end{array}
$$

With $\theta$ defined, we extend Eq. (4), to include the dependence of income growth rates on the size of low incomes, such that if $\frac{\partial \mu^{-}(x, \theta)}{\partial \theta}<0$, for all $x$, then the larger the proportion of low incomes, the lower their growth prospects. The full dependence is specified as follows:

$$
\begin{aligned}
& \mu^{-}(x, \theta)=\mu_{00}^{-}+\mu_{01}^{-} \theta+\left(\mu_{10}^{-}+\mu_{11}^{-} \theta\right) x \\
& \mu^{+}(x, \theta)=\mu_{00}^{+}+\mu_{01}^{+} \theta+\left(\mu_{10}^{+}+\mu_{11}^{+} \theta\right) x
\end{aligned}
$$

Here, $\mu_{00}$ is the base growth rate, $\mu_{01}$ is the base rate sensitivity on the size of low incomes, $\mu_{10}$ is the base rate sensitivity on income and $\mu_{11}$ is the cross-sensitivity (sensitivity of income sensitivity). $\mu(x, \theta)$ evolves slowly over time, as it models 
the structural relations within a society. We, therefore, model $\mu(x, \theta)$ for two time period - first 1960-1989 and second 1990-2015.

\section{Results}

\section{Estimating the sensitivity of income growth rates}

A piecewise linear OLS fitted on the country income growth data gives us the threshold splitting low and high incomes, and models how income growth rates relate to the average income for each of the ten percentiles (Fig 1). We obtain estimates for $\mu_{0}^{-}, \mu_{1}^{-}, \mu_{0}^{+}$, and $\mu_{1}^{+}$per decade that parameterize our growth rate dependence on income, as specified in Eq. 4. Using the variation in decades, we project these estimated parameters along with income population percentiles, for our two model time periods - 1960-1989 and 1990-2015 (Fig 2). A linear fit gives us estimates for the relationship of income growth rates to the size of the lowincome population $(\theta)$, as specified in Eq. 6 and 7.

(a)

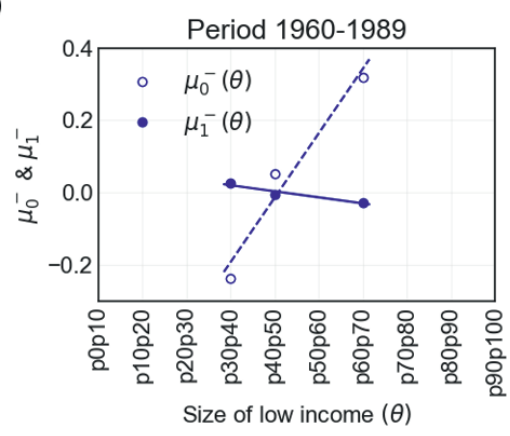

(b)

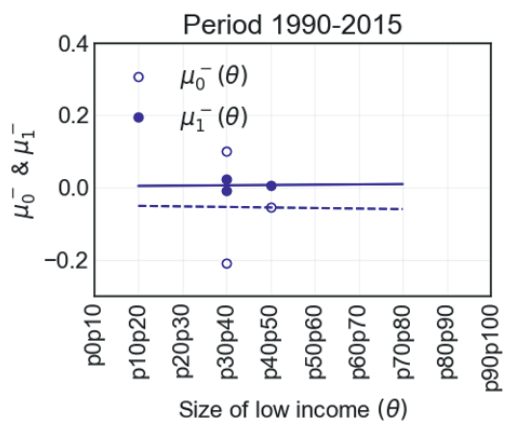

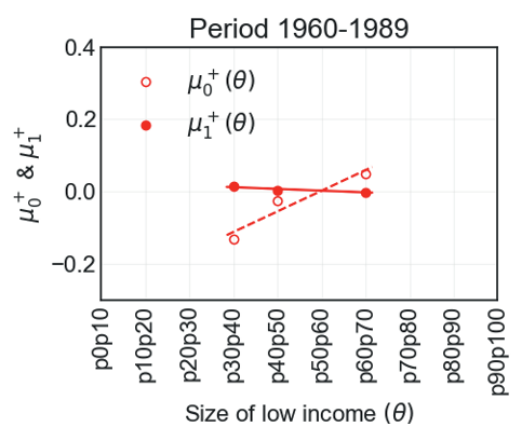

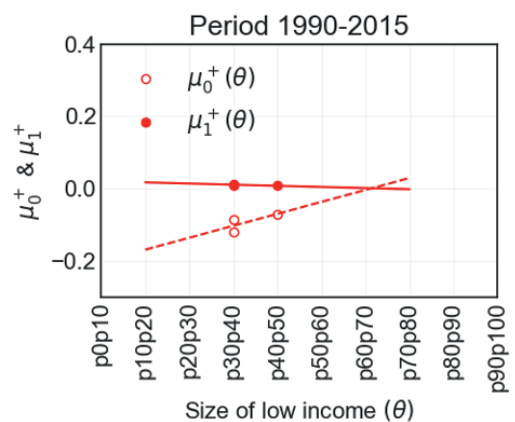

Figure 2: Sensitivity of low and high-income growths to the size of low incomes in the US for (a) 1960-1989 and (b) 1990-2015 
For the US, the base growth rate of high incomes $\left(\mu_{0}^{+}\right)$increases as the proportion of low incomes increases for both periods 1960-1989 and 1990-2015 (Fig 2). The story, however, is different for low incomes. The base growth rate low incomes $\left(\mu_{0}^{-}\right)$is positively related to the proportion of low incomes in 1960-1989 but the relationship weakens in 1990-2015. The sensitivity of incomes growth rates is largely independent of the size of low incomes. There is a slight negative trend between the sensitivity of high $\left(\mu_{1}^{+}\right)$and low $\left(\mu_{1}^{-}\right)$income growth rates and the size of low incomes $(\theta)$ in 1960-1989, but otherwise no significant relationship can be seen for 1990-2015. This lack of variation in $\mu_{1}^{+}$and $\mu_{1}^{-}$means that the crosssensitivity terms $\mu_{11}^{-}$and $\mu_{11}^{+}$in Eq. $6 \& 7$ are negligible, and thus any further higher-order terms are not needed to model this relationship.

The effect on the inequality of the relationship between low and high-income growths can be seen by comparing Fig 2 with empirical inequality data for the US (Fig 3a). Depending on the gap between the low and high-income growth rates, inequality can respectively rise or fall, as more individuals slide into low incomes. For example, in 1960-1989 (Fig 2a), low-income growth rates were greater than high incomes, thus resulting in low inequality in the US. But when high incomes started to grow faster than low incomes, as in 1990-2015 (Fig 2b), inequality starts to rise in the US (Fig 3a).

\section{Predicting long-run income distribution}

With information on low and high-income growth relationships, we can now predict the long-run income distribution using the model and estimated parameters from the data on the US, France, China and India (Fig 3 and Table 1). Accounting for the changes in inequality pre and post 1990 , we model long-run inequality for two time periods - 1960-1989 and 1990-2015. 
(a)

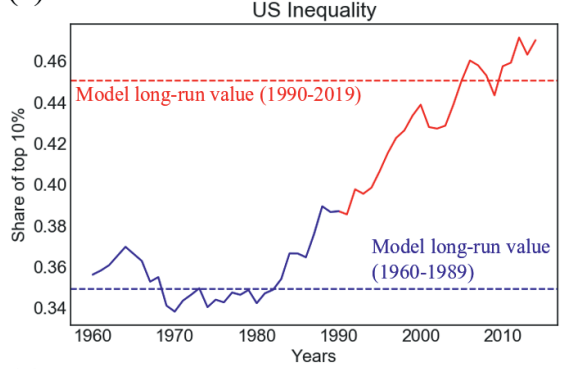

(c)

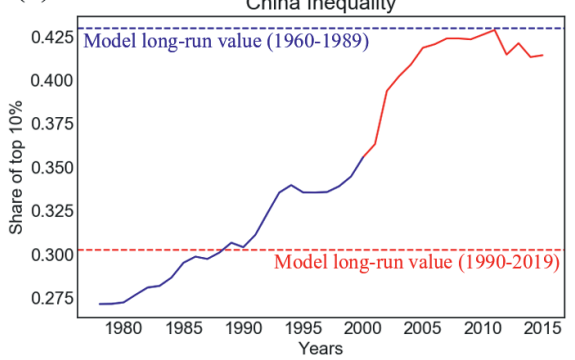

(b)

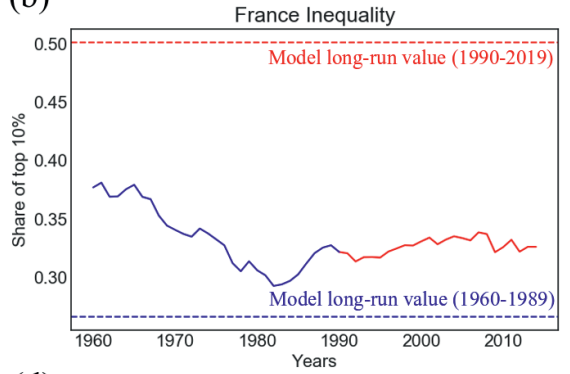

(d)

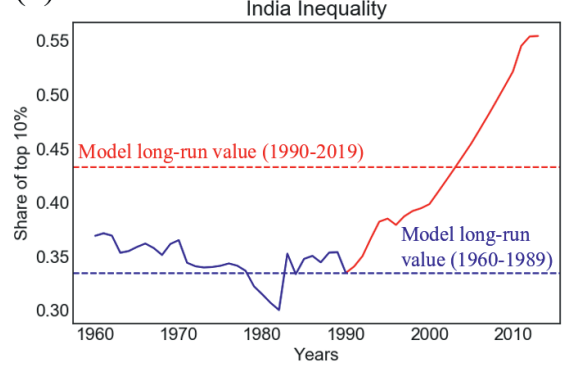

Figure 3: US, France, China and India inequality data (share of top 10\%) for 19602015 and model long-run values for 1960-1989 and 1990-2015.

Our best fits are obtained for the US, which can be due to the quality of available US data. From 1960 to 1989, our model captures accurately the empirical inequality level for the US (Fig 3a). For 1990-2015 our predicted inequality level is higher than that in 1960-1989. Here again, empirical US inequality values converge fast to our predicted 1990-2015 level, giving us a correct prediction. Based on the recent work ${ }^{7,21}$ on the rapid inequality dynamics in the US, this fast convergence is expected. For the future, our model predicts inequality in the US to slow down and stay close to the current level.

For France, the model correctly forecasts the trajectory of inequality decline between 1960-1989 towards the predicted level (Fig 3b). This decline reverses in the 1980s, after which inequality rises, but gradually. Post-1990, our model rightly predicts a higher inequality level in France, but the convergence is slower, as compared to the US. For the future, inequality in France is expected to rise further towards the long-run predicted value.

For China, the model's inequality prediction levels are reversed. The 1960-1989 level is higher than in 1990-2015. In 1960-1989, inequality in China is rising fast, which our model captures correctly with a higher level, consistent with inequality's upward trajectory. For 1990-2015, the model predicts a lower long-run inequality value, which empirical values seem to corroborate, considering the downturn in 
inequality after 2000 . For the future, the model predicts inequality in China to decline.

For India, the model predicts accurately the 1960-1989 level of inequality. Post1990 inequality rises dramatically in India. Though our model predicts a higher inequality level based on 1990-2015 data, the empirical values approach but then overshoot our predictions. This can be a transitionary phase before inequality settles to the expected long-run value, as inequality shows signs of slowing down post-2010 for India. For the future, the model predicts inequality in India to decline.

Summarizing, based on model long-run values, we expect inequality to stay stable in the US, to go down in China and India, but to rise in France. The expected change in inequality is lowest for the US, as the difference between its current empirical value and long-run modelled state is the smallest among all, while China and India both expect major improvements, as inequality heads downwards for China and seems to level-off for India as well. France presents the contrasting case, where modelled long-run inequality is higher than the current empirical level. 


\begin{tabular}{|c|c|c|c|c|}
\hline Parameters & $\begin{array}{l}\text { United } \\
\text { States }\end{array}$ & France & China & India \\
\hline \multicolumn{5}{|c|}{ Period 1960-1989 } \\
\hline$\mu_{00}^{+}$ & -0.28 & -0.25 & -0.0004 & -0.31 \\
\hline$\mu_{01}^{+}$ & 0.06 & 0.09 & -0.003 & 0.06 \\
\hline$\mu_{10}^{+}$ & 0.03 & 0.02 & 0.0002 & 0.03 \\
\hline$\mu_{11}^{+}$ & -0.005 & -0.006 & 0.001 & -0.005 \\
\hline$\mu_{00}^{-}$ & -0.73 & 0.24 & -0.001 & 0.14 \\
\hline$\mu_{01}^{-}$ & 0.18 & -0.02 & -0.008 & -0.02 \\
\hline$\mu_{10}^{-}$ & 0.07 & -0.03 & 0.0002 & -0.01 \\
\hline$\mu_{11}^{-}$ & -0.02 & 0.005 & 0.002 & 0.002 \\
\hline $\begin{array}{c}\text { Long-run } \\
\text { Share of Top } \\
10 \% \text { incomes }\end{array}$ & 35.10 & 26.66 & 43.5 & 33.36 \\
\hline \multicolumn{5}{|c|}{ Period 1990-2015 } \\
\hline$\mu_{00}^{+}$ & -0.20 & 0.002 & 0.002 & -0.006 \\
\hline$\mu_{01}^{+}$ & 0.03 & 0.006 & 0.007 & -0.04 \\
\hline$\mu_{10}^{+}$ & 0.02 & -0.0001 & 0.0006 & 0.0005 \\
\hline$\mu_{11}^{+}$ & -0.003 & -0.0004 & 0.002 & 0.004 \\
\hline$\mu_{00}^{-}$ & -0.05 & -0.02 & 0.01 & 0.0006 \\
\hline$\mu_{01}^{-}$ & -0.001 & -0.05 & 0.03 & 0.004 \\
\hline$\mu_{10}^{-}$ & 0.003 & 0.002 & -0.0002 & 0.00002 \\
\hline$\mu_{11}^{-}$ & 0.001 & 0.006 & -0.0007 & -0.0002 \\
\hline $\begin{array}{c}\text { Long-run } \\
\text { Share of Top } \\
10 \% \text { incomes }\end{array}$ & 45.10 & 50.11 & 30.10 & 43.54 \\
\hline
\end{tabular}

Table 1: Model parameter values for the US, France, China and India.

\section{Robustness analysis: Understanding the structure of inequality}

To understand the structure of long-run modelled inequality, we explore the parameter space around the predicted inequality values. Since most of the variation in growth rates were seen in the high incomes base rate $\left(\mu_{00}^{+}\right)$and the high incomes base rate sensitivity to the size of low incomes $\left(\mu_{01}^{+}\right)$, we focus on them to explore the parameter space around long-run modelled inequality levels for the US (Fig 4). 
Model long-run inequality values, as earlier, are calculated based on two time periods - 1960-1989 and 1990-2015.

\section{United States}

(a)

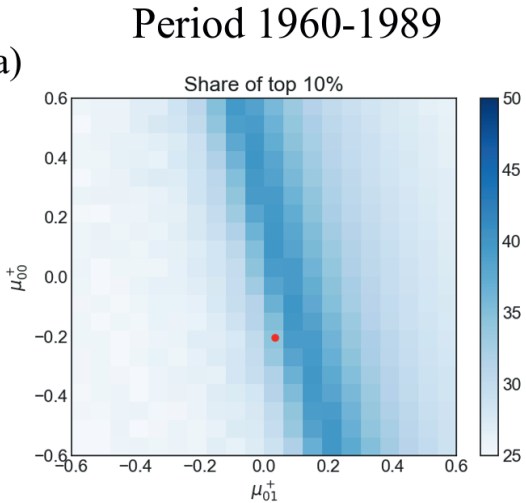

(b)

Period 1990-2015

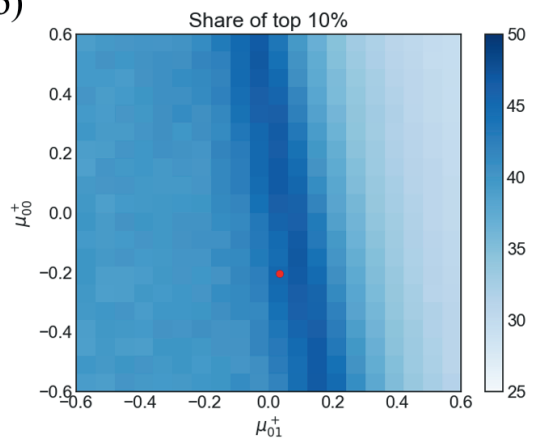

Figure 4: Variation in long-run inequality for the US, with respect to changes in base rate high-income growth $\left(\mu_{00+}\right)$ and its sensitivity to the size of low incomes $\left(\mu_{01+}\right)$. Red dots denote empirical estimates based on the specified period.

For the US, long-run inequality responds in a nonlinear fashion to $\mu_{00}^{+}$and $\mu_{01}^{+}$, in both 1960-1989 and 1990-2015 (Fig 4). Inequality is low in both far-right and farleft of Fig 4a, which means that in the period 1960-1989, inequality decreased only when high incomes were highly sensitive to the size of low incomes, either positive or negative. When $\mu_{01}^{+}$was close to zero, inequality increased. This is understandable, because if high-income growth is independent to the size of low incomes then there won't be any 'trickle-down' effect. Economic growth would benefit only high incomes, with no effect on low incomes, thus fuelling inequality.

On the other hand, in period 1990-2015, inequality is low only in the right half of Fig $4 \mathrm{~b}$, where high-income growth is positively sensitive to the size of low incomes. Going from right to left (Fig 4b), as $\mu_{01}^{+}$moves from high positive to low values, high-income growth becomes less sensitive to $\theta$ and, as before inequality rises. A further decrease in $\mu_{01}^{+}$, into the negative region (Fig 4b), will again lead to a reduction in inequality, albeit not to the 1960-1989 level. As high-income growth now becomes negatively sensitive to the size of low incomes, increase in low incomes will now decrease high-income growth rate, thus pulling everyone down. This wavelike response to $\mu_{01}^{+}$suggests that long-run inequality depends greatly on the sensitivity of high-income growth to the size of low incomes. 
Empirical estimates (Fig 4) for the US are close to the region where inequality is high. From a policy perspective, our results suggest that inequality in the US would decline if high-income growth is positively sensitive to the size of low incomes. A positive sensitivity here means that any redistribution policy by the government, while decreasing poverty should also decrease the growth of high incomes, to have an inequality reducing effect.

Comparing countries in the recent time period (1990-2015), France, China and India exhibit a similar nonlinear relationship between growth rates and long-run inequality, like the US, but the scales are different (Fig 5). France is closest to the US in scale, although with a slightly higher inequality spread. For France, the low inequality region is located where both the base rate of high-income growth $\left(\mu_{00}^{+}\right)$ and sensitivity of high-income growth to the size of low incomes $\left(\mu_{01}^{+}\right)$are high and positive. Empirical estimates (1990-2015 period) for France lie in the high inequality region but note that while $\mu_{01}^{+}$is similar to that of the US, the base of high incomes growth $\left(\mu_{00}^{+}\right)$is markedly higher. This means that not only is longrun inequality high for France, but it is also the only country of the four where the model predicts an increase in inequality from the current level. 


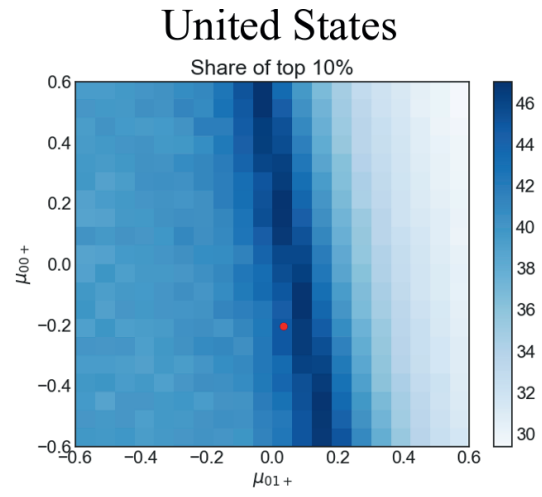

China

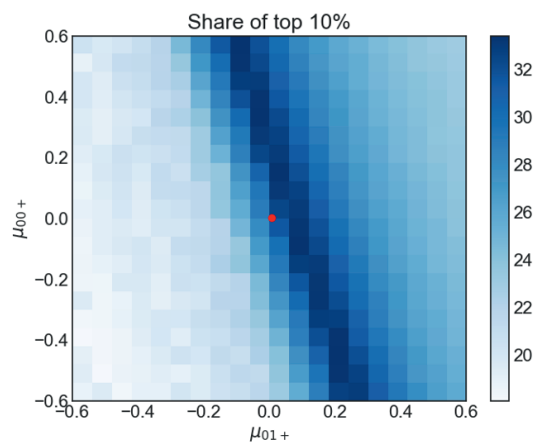

France

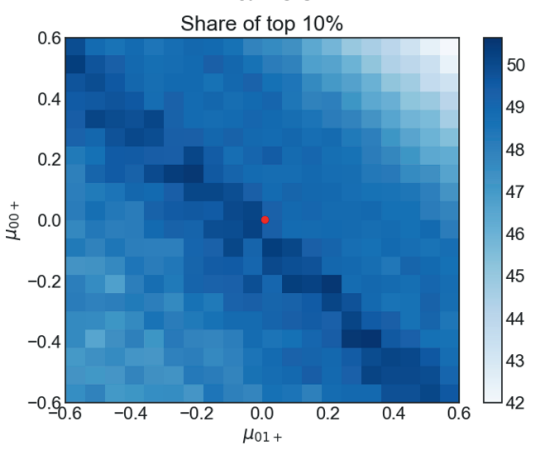

India

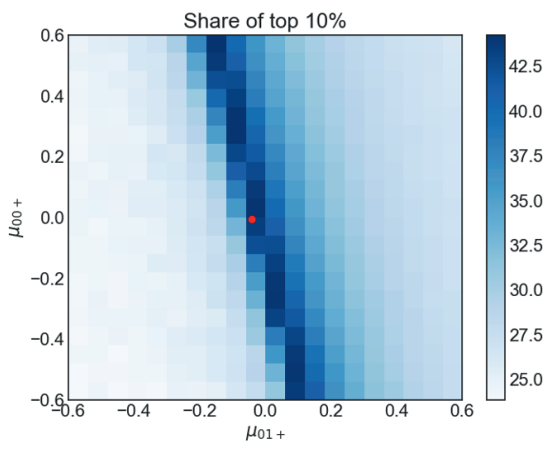

Figure 5: Comparison of variations in long-run inequality between the US, France, China and India, for the recent time period 1990-2015.

For China, the scale of long-run inequality is closer to India, than to either the US or France. Contrary to the US and France, the low inequality region for China is where high incomes are negatively sensitive to the size of low incomes $\left(\mu_{01}^{+}\right)$. This can be a feature of growing economies, where low inequality can most likely be achieved when high incomes grow with lessening the size of low incomes. Empirical estimates (1990-2015 period) for China lie close to the high inequality region. India closely follows China in long-run inequality variation. The low inequality region for India is also where high incomes are negatively sensitive to the size of low incomes $\left(\mu_{01}^{+}\right)$, corroborating this as a feature of growing economies. The key difference from China is that for India the empirical income growth estimates (1990-2015 period) lie squarely in the high inequality region. This translates into a much higher long-run inequality level than China.

\section{Discussion}


An extensive existing literature has informed our understanding of the various drivers of income inequality. These not only include exogenous factors such as high wages, bonuses and rents available for high-end professionals (e.g. finance executives, start athletes and CEOs) ${ }^{22-24}$, but also endogenous income growth mechanisms, for instance, human capital, innovations and firm technology adoption ${ }^{25,26}$. While acknowledging and appreciating the multiple drivers of inequality, we took a different approach to explain income inequality, by focusing on the observed dependence structure between income growth rates and income group sizes. Through not limiting ourselves to one or a particular set of drivers, we present a general framework to model long-run inequality and its robustness to changes in income growth sensitivities.

Among the countries we have studied, France presents a curious case, as the modelled long-run inequality level is substantially above empirical values. Though current inequality is rising slowly, Garbinti, Goupille-Lebret, and Piketty (2018) find that not only high incomes are growing much faster in the period 1983-2015, but also that the low incomes are slowing down compared with either 1900-1950 or 1950-1983. Thus recent trends in income growth support that inequality will accelerate in France. In contrast, rising inequality in the US is expected to slow down, though the growth in high incomes is similar to France. No doubt, the recent fast rise of inequality in the US has been spectacular with a large number of papers exploring underlying causes, such as rent-seeking ${ }^{28}$, labour incomes ${ }^{29}$ and globalization ${ }^{30}$. Much less attention is given to forces that counteract high growth individuals, thus leading to a stabilization or decline in inequality. Recently, Jones and Kim (2018) use a simple inequality model and micro-data to describe forces such as creative destruction and competition that can potentially slow down the rise of inequality in the US.

The rising inequality trend in China is in part attributed to the "opening-up" in the late 1970s, which started a gradual transition from communism to capitalism. Propagation of private property rights and rapid capital accumulation triggered inequality in China from as low as $27 \%$ income share of the top $10 \%$ incomes to close to US levels by $2010^{31}$. Despite the dramatic rise, inequality in China declined post-2000, which is in line with our long-run inequality result. This decline can be attributed to higher savings in China which, unlike a similarly transitioning from communism to capitalism Russia, are used to finance domestic investments and capital investments, thus ensuring broad-based growth ${ }^{32}$. India is comparable to China, in showing signs of slowing down in inequality after a steep increase between 1990-2010. This is striking, provided high incomes growth in 
India outpaces China and the difference between high and low-income growth is the highest among all the US, France and China (Chancel \& Piketty (2017)). While inequality rose with opening up of the Indian economy, Datt, Ravallion, and Murgai (2016) find that concurrent growth and urbanization, especially post 2000 had a poverty reduction effect. With such signs of broad-based growth, expecting an inequality downturn in the future is not unusual for India.

\section{Conclusion}

Using a parsimonious model, we attempt to understand if differentiated income growths and their sensitivity to the size of low incomes can explain the long-run level of inequality. Our approach is more in line with Gabaix et al. (2016) and more recently Jones and Kim (2018), in focusing explicitly on heterogeneous income to understand recent patterns in inequality data. Our results, in estimating long-run inequality level and explaining the structural relation of inequality with differentiated income growths, have considerable policy implications with respect to identifying income groups to focus on to spur or contain growth and manage the long-run level of inequality. We hope future work can build on our contribution by incorporating trade and/or financial links between countries that can have significant but different impacts on high and low income growths, depending on base inequality levels and degree of openness. 


\section{Author's contribution}

MUM initiated the research and conceived the idea. Both MUM and FW developed the idea and model. MUM carried out the analysis and took the lead in writing the manuscript. Both MUM and FW contributed to the final version of the manuscript.

\section{Code availability}

The code used for the analysis and generating figures, are available and can be requested from the corresponding author. The analysis was carried out in Python (https://www.python.org/) using numpy, matplotlib, scipy and statsmodels.

\section{Acknowledgements}

This project received funding from the European Union's Horizon 2020 research and innovation programme under the Marie Sklodowska-Curie grant agreement No 643073. CX acknowledges supports from the National Natural Science Foundation of China (No. 31770512) and the CTF foundation. 


\section{References}

1. Alvaredo, F., Chancel, L., Piketty, T., Saez, E. \& Zucman, G. World Inequality Report 2018. Tijdschr. Geneeskd. (2017). doi:10.2143/TVG.70.09.2001601

2. Alvaredo, F., Atkinson, A. B., Piketty, T. \& Saez, E. The Top 1 Percent in International and Historical Perspective. J. Econ. Perspect. (2013). doi:10.1257/jep.27.3.3

3. Piketty, T. \& Saez, E. Income inequality in the United States, 1913-1998. Quarterly Journal of Economics (2003). doi:10.1162/00335530360535135

4. Atkinson, A. B. Top incomes in the UK over the 20th century. J. R. Stat. Soc. Ser. A Stat. Soc. (2005). doi:10.1111/j.1467-985X.2005.00351.x

5. Atkinson, A. B., Piketty, T. \& Saez, E. Top Incomes in the Long Run of History. J. Econ. Lit. (2011). doi:10.1257/jel.49.1.3

6. Alvaredo, F., Chancel, L., Piketty, T., Saez, E. \& Zucman, G. The Elephant Curve of Global Inequality and Growth. AEA Pap. Proc. 108, 103-08 (2018).

7. Gabaix, X., Lasry, J.-M., Lions, P.-L. \& Moll, B. The Dynamics of Inequality. Econometrica 84, 2071-2111 (2016).

8. Piketty; Capital in the 21st Century. Cambridge Harvard Uni 696 (2014). doi:9780674430006

9. Guvenen, F. Learning your earning: Are labor income shocks really very persistent? Am. Econ. Rev. (2007). doi:10.1257/aer.97.3.687

10. Mirza, M. U., Richter, A., van Nes, E. H. \& Scheffer, M. Technology driven inequality leads to poverty and resource depletion. Ecol. Econ. (2019). doi:10.1016/j.ecolecon.2019.02.015

11. van der Weide, R. \& Milanovic, B. Inequality is bad for growth of the poor (but not for that of the rich). World Bank Econ. Rev. (2018). doi:10.1093/wber/lhy023

12. Ravallion, M. Income inequality in the developing world. Science (80-. ). 344, 851-855 (2014).

13. Genicot, G. \& Ray, D. Aspirations and Inequality. Econometrica (2017). doi:10.3982/ecta13865

14. Alvaredo, F., Chancel, L., Piketty, T., Saez, E. \& Zucman, G. World 
inequality database. URL https//wid.world (2018).

15. Rosen, S. The Economics of Superstars. Am. Econ. Rev. 71, 845-858 (1981).

16. Mogull, R. G. American Poverty in the 1960's. Phylon (1960-) 33, 161-168 (1972).

17. Piketty, T. \& Saez, E. Inequality in the long run. Science 344, 838-43 (2014).

18. Johnson, G. E. Changes in Earnings Inequality: The Role of Demand Shifts. J. Econ. Perspect. (1997). doi:10.1257/jep.11.2.41

19. Bengtsson, E. \& Waldenström, D. Capital Shares and Income Inequality: Evidence from the Long Run. J. Econ. Hist. (2018). doi:10.1017/S0022050718000347

20. Gabaix, X. Power Laws in Economics and Finance. Annu. Rev. Econom. 1, 255-294 (2009).

21. Jones, C. I. \& Kim, J. A schumpeterian model of top income inequality. $J$. Polit. Econ. (2018). doi:10.1086/699190

22. Piketty, T., Saez, E. \& Stantcheva, S. Optimal taxation of top labor incomes: A tale of three elasticities. Am. Econ. J. Econ. Policy (2014). doi:10.1257/pol.6.1.230

23. Bell, B. \& Van Reenen, J. Bankers and their bonuses. Econ. J. (2014). doi:10.1111/ecoj.12101

24. Bénabou, R. \& Tirole, J. Bonus culture: Competitive pay, screening, and multitasking. J. Polit. Econ. (2016). doi:10.1086/684853

25. Lucas, R. E. \& Moll, B. Knowledge growth and the allocation of time. $J$. Polit. Econ. (2014). doi:10.1086/674363

26. Perla, J. \& Tonetti, C. Equilibrium imitation and growth. J. Polit. Econ. (2014). doi:10.1086/674362

27. Garbinti, B., Goupille-Lebret, J. \& Piketty, T. Income inequality in France, 1900-2014: Evidence from Distributional National Accounts (DINA). $J$. Public Econ. 162, 63-77 (2018).

28. Rothschild, C. \& Scheuer, F. Optimal taxation with rent-seeking. Rev. Econ. Stud. (2016). doi:10.1093/restud/rdw017 
29. Kaplan, S. N. \& Rauh, J. Wall street and main street: What contributes to the rise in the highest incomes. Rev. Financ. Stud. (2010). doi:10.1093/rfs/hhp006

30. Haskel, J., Lawrence, R. Z., Leamer, E. E. \& Slaughter, M. J. Globalization and U.S. wages: Modifying classic theory to explain recent facts. in Journal of Economic Perspectives (2012). doi:10.1257/jep.26.2.119

31. Piketty, T., Yang, L. \& Zucman, G. Capital accumulation, private property, and rising inequality in China, 1978-2015. American Economic Review (2019). doi:10.1257/aer.20170973

32. Novokmet, F., Piketty, T., Yang, L. \& Zucman, G. From Communism to Capitalism: Private versus Public Property and Inequality in China and Russia. AEA Pap. Proc. (2018). doi:10.1257/pandp.20181074

33. Piketty, T. \& Chancel, L. Indian income inequality, 1922-2015 : From British Raj to Billionaire Raj ? Lucas Chancel. World Inequality Database (2017).

34. Datt, G., Ravallion, M. \& Murgai, R. Growth, Urbanization and Poverty Reduction in India. NBER Work. Pap. Ser. (2016). 


\title{
Chapter 5
}

\section{Global inequality, remotely sensed}

\author{
M Usman Mirza ${ }^{1,2}$, Chi Xü ${ }^{3}$, Bas van Bavel ${ }^{4}$,Egbert H van Nes ${ }^{2}$, Marten Scheffer ${ }^{2}$ \\ ${ }^{1}$ Environmental Economics and Natural Resources, Wageningen University, \\ Netherlands \\ ${ }^{2}$ Environmental Sciences, Wageningen University, Netherlands \\ ${ }^{3}$ Life Sciences, Nanjing University, China \\ ${ }^{4}$ Economic and Social History, Utrecht University, Netherlands
}

\begin{abstract}
Inequality is increasingly being recognized as a key characteristic of societies. Yet, reliable data on income distributions are mostly limited to Northern America and Europe. Here we show that this gap may be filled using a remotely sensed proxy for income inequality based on night-time light data. Using the tendency of residential households to spatially segregate, we analyse the spatial distribution of light per person as a proxy for variance in economic prosperity. The resulting lightbased Gini coefficients relate well to existing estimates of net income inequality at the scale of countries globally but also for states within the USA. Building on this association, we present the first high-resolution global maps of light-based inequality and its change from 1990 to 2010 . Our estimates suggest that in this period inequality increased markedly in China and Brazil, but also in the western US, parts of Africa, Pakistan, Myanmar and the Philippines. In Europe, inequality increased in the UK, Portugal and Greece. The new light-based inequality patterns can be used to investigate interactions with key spatial variables, including political change, trade, biodiversity loss, resource use and resilience to natural disasters.

Keywords: Inequality, Night-time lights, remote sensing, Spatial segregation
\end{abstract}




\section{Introduction}

Over the past decades, there has been a slow transition from theoretical to datadriven inequality research ${ }^{1}$. However, progress is limited by a lack of data on economic prosperity at the household level ${ }^{2}$ as well as the absence of consensus on ways of measuring economic inequality ${ }^{3,4}$. Practical constraints include limited coverage, incomparability at population subscales, dependence on misreported income surveys and low-quality data collection in developing economies ${ }^{5-7}$. Furthermore, since traditional inequality measures are not georeferenced at different geographic scales, they cannot be used in sub-regional studies. Thus, despite broad interest in inequality, empirical approaches remain contentious ${ }^{8}$.

Since the late $20^{\text {th }}$-century promising initiatives like the World Income Inequality Database, Luxembourg Income Study Database and World Wealth and Income Database have partly filled this lacuna. However, these datasets still suffer from large regional variations in coverage, data quality and lack of compatibility with respect to collection methodologies ${ }^{9,10}$. As a result, inequality research is dominated by data limited to Northern America and Western Europe which account for over $80 \%$ of all publications ${ }^{11}$. Indeed, while inequality in the developed world is relatively well documented ${ }^{12-14}$, our knowledge about inequality in the developing world is limited by paucity, poor quality, uncertainty and incomparability of data ${ }^{15,16}$. Thus, we know the least about areas where inequality presents the most serious developmental policy challenge.

Here we propose the use of remotely sensed night-time light (NTL) to fill this gap. Remotely sensed data source like NTL is independent of locally collected information such as tax records or surveys, where variation in measurement methodology and reporting accuracy inevitably leads to inconsistencies across regions. Essentially, NTL is a globally uniform metric reflecting the nocturnal anthropogenic use of lights ${ }^{17,18}$. Almost all economic activities occurring in post daylight hours, be it consumption or production, require the use of artificial lights, an assertion corroborated by studies showing NTL to be highly related with indicators of economic activity ${ }^{19-21}$.

\section{Approach}

In general, as income rises, the per person light detected grows due to increased consumption leading to conspicuously visible outcomes such as bigger brighter-lit houses and well-illuminated neighbourhoods in richer areas ${ }^{22}$. While the link between NTL and economic thriving is well established, the idea to use NTL for 
detecting economic inequality is new. Our reasoning is that assuming households with different incomes live more-or-less segregated across landscapes ${ }^{23}$, spatial variation in per capita NTL should to a certain extent reflect variance in per capita income.

The approach is straightforward. We calculate average light intensity per person (i.e. LPP) for each grid cell, dividing available NTL data by population density estimates (see methods). We then infer economic inequality from the distribution of LPP across sets of grid cells by computing Gini coefficients. This way we compute Gini coefficients for nations as well for a finer sub-national level. As we focus on consumption activities we exclude areas that have no residential population (such as industries, highways) or no detectable night lights (deserts, forests).

Our approach is fundamentally different from the traditional way of characterizing economic inequality, as we estimate inequality between spatial units rather than between households. Since remote sensing is to course to detect individual households our approach can only work if households of different wealth are not homogeneously distributed across neighbourhoods and regions. While indeed there is a well-established tendency for spatial segregation in residential housing ${ }^{24}$, it raises the a-priory question of when spatial variation in lights may reasonably be expected to reflect household variation in economic prosperity. To explore how segregation and sampling resolution should theoretically be expected to affect our remotely sensed indicators, we used an adapted version of the well-studied Schelling segregation model ${ }^{25}$ to generate different levels of spatial segregation in income and subsequently sampled at different resolutions to mimic remote sensing (See supplementary material). The results illustrate how depending on the scale of remote sensing, the Gini coefficient across spatial units converges to the Gini coefficients on household basis (Supplementary Fig 1). Although the level of residential segregation varies across the globe, it tends to co-vary with economic inequality ${ }^{26-28}$. Thus, it seems reasonable a priori to expect a relationship between spatial variance of LPP and economic inequality. Although georeferenced income census data is not available globally to test the fine-grained relationship to NTL, some existing empirical work using data at the household level does supports detection of income by night lights at the finer scale ${ }^{29}$.

\section{Validation of light-based inequality estimates}

To see if we remotely sensed light-based Gini relate in a meaningful way to income Gini, we examined patterns at global as well as more detailed scales. It turns out 
that our light-based proxy is closely related to available estimates of national net income inequalities across the globe (Fig 1c), with the linear model explaining $74 \%$ of the variation. Variation in population denseness and production activities that might influence country-level brightness are controlled for by using covariates - population count and gross output (GDP). The average global light-based Gini of 58.3 is higher than the average net income-based Gini of 38.1, however, trends in both estimates are comparable. For instance, comparing light and income-based estimates, broadly speaking, high inequality hotspots like Russia, China, Southeast Asia and most of Africa and South America come out as prominent by both light and income Gini estimates, while Western Europe and Canada feature consistently as regions of lower inequality (Fig 1a, b).

Global Inequality: Light Gini estimate by country 2010

(a)

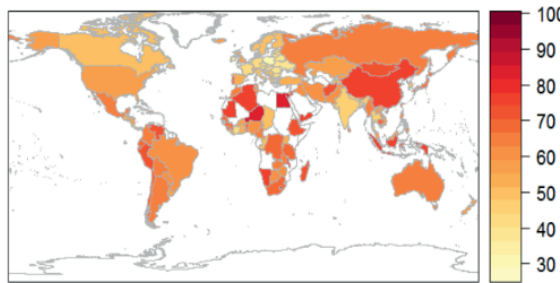

Global Inequality: Income Gini estimate by country 2010

(b)

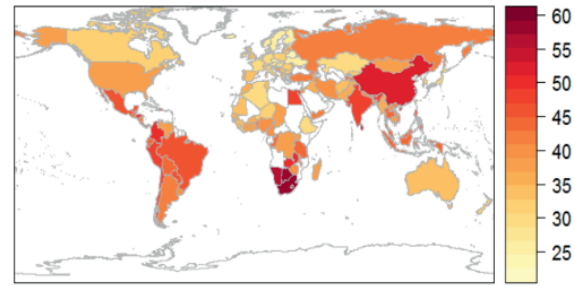

(c)

Relationship by country: Light and income based inequality 2010

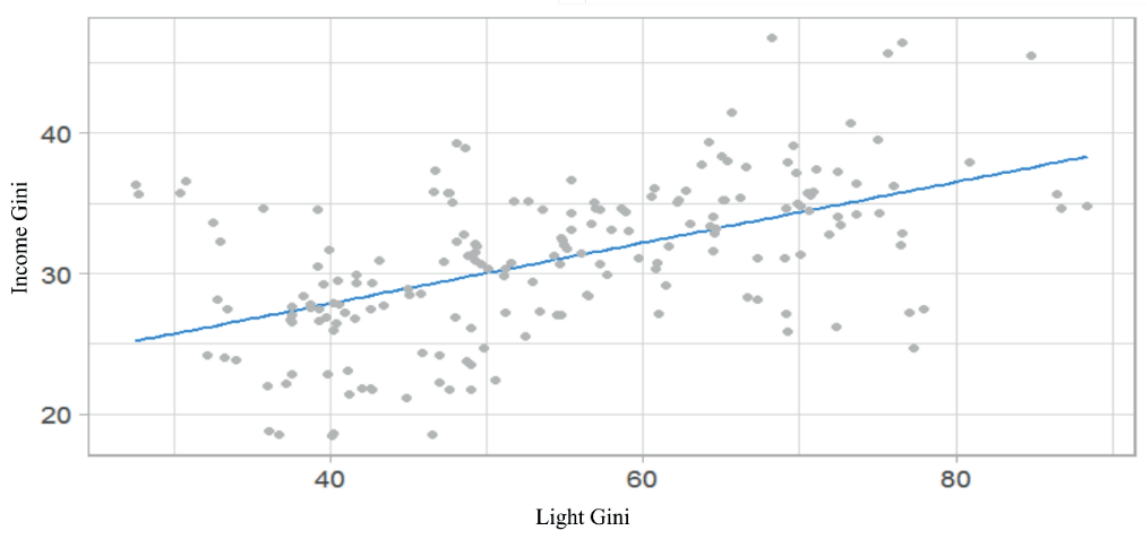

Figure 1: Comparison and model fit of global national estimates of light and income-based inequality. Light-based Gini can explain a large proportion of $74 \%$ (indicated by the $R^{2}$ of the ordinary least square model, $P<0.01$ ) variance in income Gini. 
In addition to being globally comparable and consistent, another useful feature of using a remotely sensed measure of economic inequality is that it can easily be computed at much finer scales. This is unlike existing economic inequality data which is available mostly at courser scales (national, state) and that too with varying accuracy. This also implies that we cannot systematically validate our light-based measure at finer scales globally. However, within the US we could zoom in to finer scales using state-level income Gini data from the American Community Survey (ACS) (https://www.census.gov/programs-surveys/acs/) ${ }^{30}$. Here we find a significant correlation $(0.50, \mathrm{p}$-value $<0.01)$ between income and light Gini (Fig 2b). Both indicators corroborate among other things, that the western and southern areas of the US are more unequal than northern and central states (Fig 2 a, c, d). One would expect that the accuracy here is limited, because nationwide factors such as spatial segregation patterns, housing policies, light usage practices etc., would make sub-national regions, such as US states, too similar. Nonetheless, in view of the robust associations found at the national and state levels, it seems reasonable to expect a meaningful signal of economic inequality in our light-based proxy at higher resolutions as well.
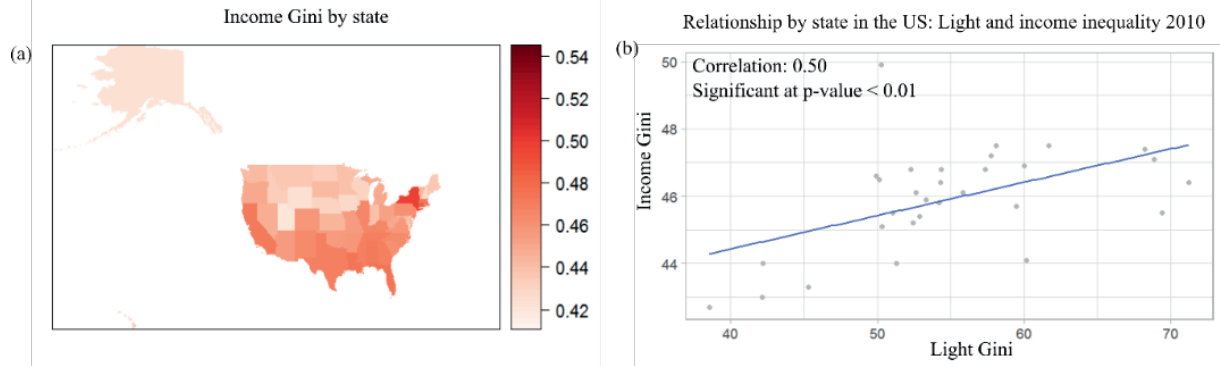

Light Gini by state
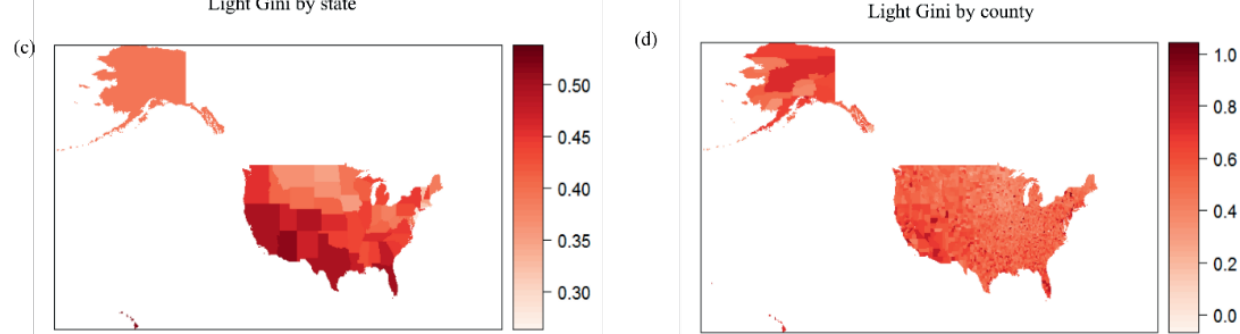

Figure 2: Sub-national state-level comparison for the US between light and income-based estimates of inequality. Light-based Gini can explain a large proportion of $50 \%$ (indicated by the $R^{2}$ of the ordinary least square model, $P<0.01$ ) variance in income Gini. 


\section{A global map of light-based inequality}

To explore global patterns at the sub-national level, we calculated high-resolution maps of global light-based inequality (Fig 3). These indicate the potential of our approach to making progress over existing datasets and inequality studies. The global light-based inequality map suggests hot-spots of inequality in areas within Eastern China, Southern Africa, Central Brazil, Northwest Egypt, Portugal and close to coastal areas of the United States (Fig 3a, b). An interesting pattern appears when we calculate the change from 1990 to 2010 (Fig 3 c, d). Most of the world shows little or no change in light-based inequality at the fine-scale. However, light-based inequality increased in areas within the US, Brazil and Uruguay in the Americas; Tanzania, Kenya, Namibia and Ethiopia in Africa; UK, Portugal and Greece in Europe; China, Pakistan, Myanmar and Philippines in Asia and some parts of Australia. Light-based inequality went down only in areas within a few countries including Canada, the Scandinavian countries, Japan and Indonesia. 
(a)

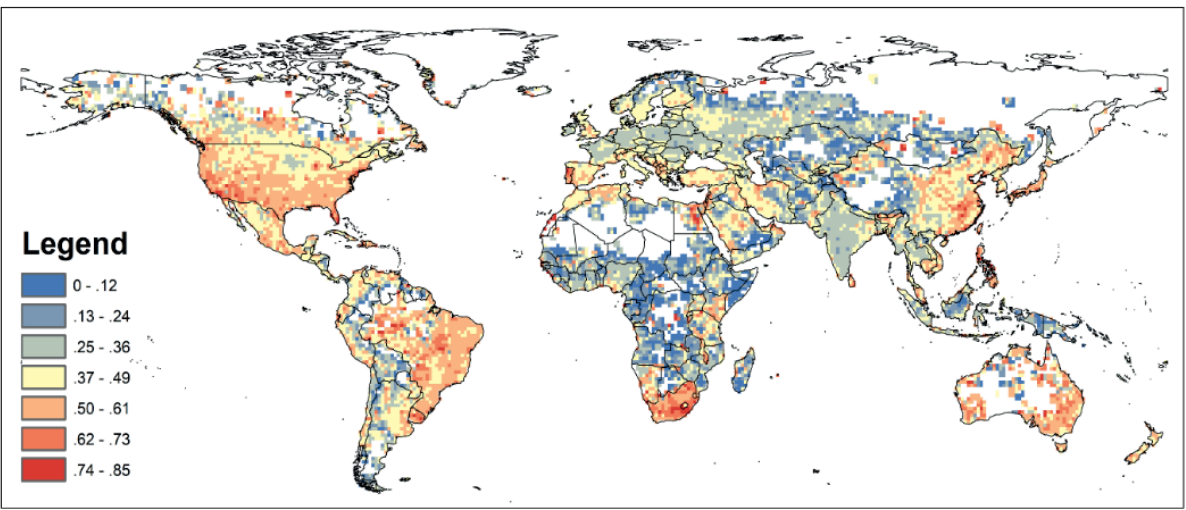

(c)

Global Inequality: High resolution change map 1990 - 2010
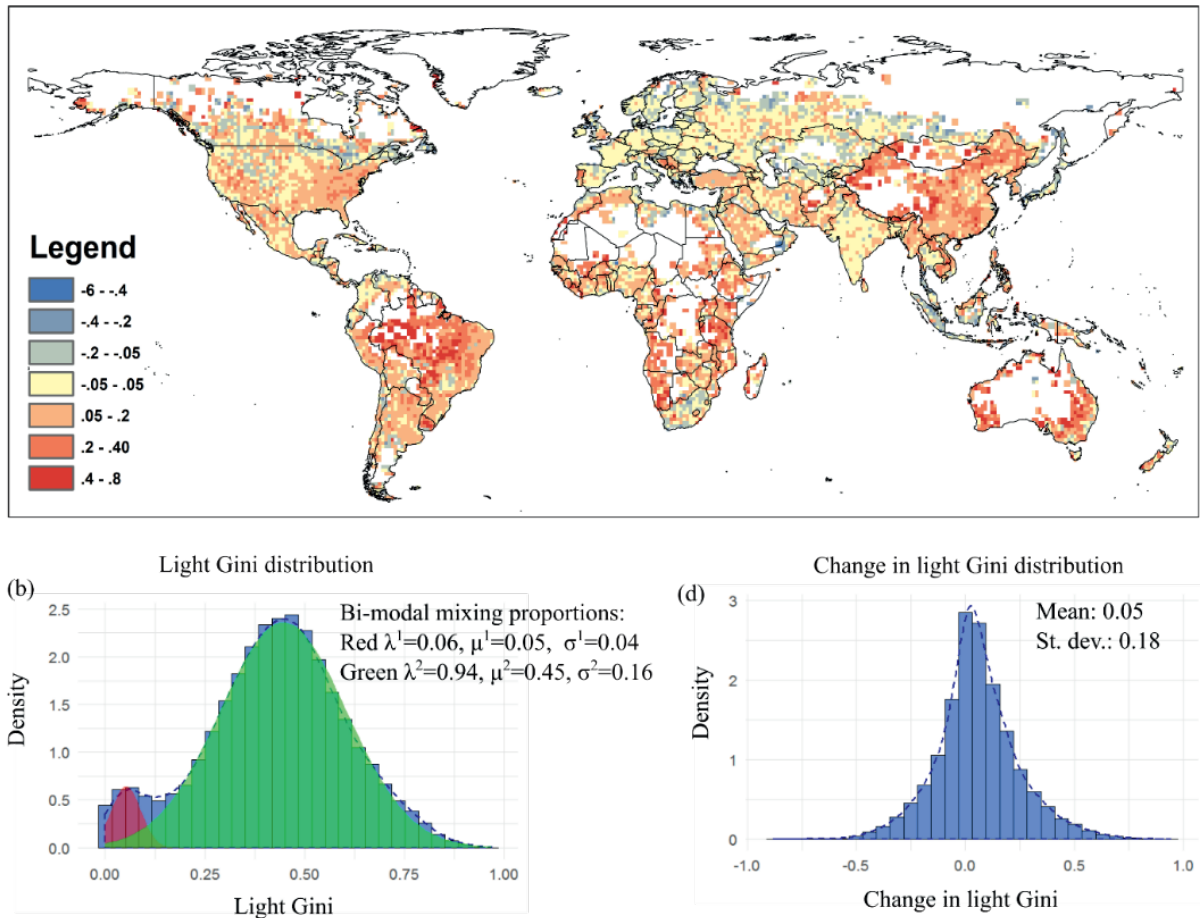

Figure 3: Global high-resolution map for 2010 and change map for 1990-2010 of light-based estimates of inequality

Grouping income and light-based inequality and seeing them by income groups (using World Bank classification of the world's economies) and regions (continents) globally confirm the image that the light-based inequality estimators 
relate in meaningful ways to patterns of income inequality. Light-based Gini is significantly lesser ( $p$-value $<0.01$, Welch Two Sample t-test) for high-income countries than for both lower and middle-income countries (Fig 4a), consistent with the pattern for income Gini (Fig 4b). Looking at regions, the light-based Gini of Europe is the lowest ( $\mathrm{p}$-value $<0.01$, Welch Two Sample t-test) among all continents followed by Asia, the Americas, Oceania and Africa (Fig 4c). This is in line with the pattern for income Gini, although here the Americas emerged as the most unequal continent (Fig 4d).

Inequality by income group 2010

(a)
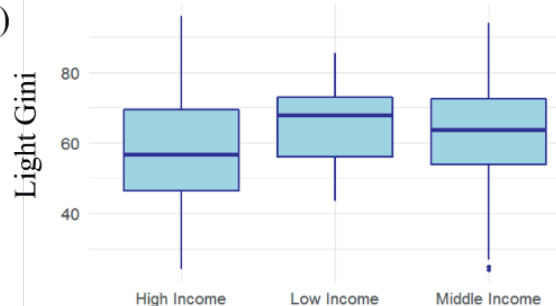

Inequality by continent 2010

(c)

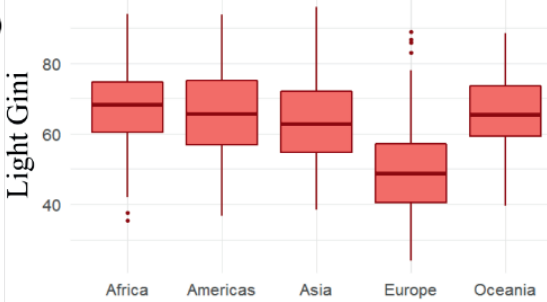

(b)

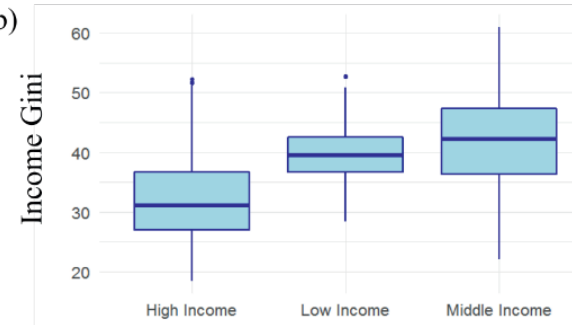

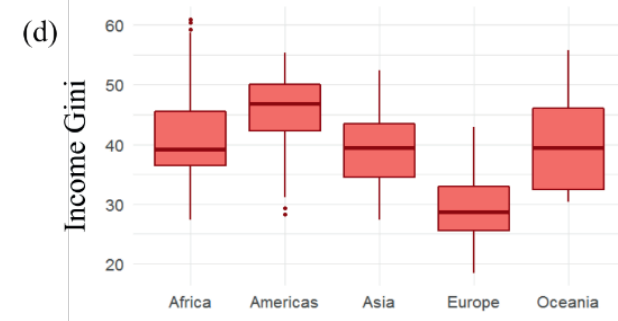

Figure 4: Comparing light and income-based estimates of inequality by region and income groups

\section{Discussion}

In view of the methodological differences, the strong association between our lightbased proxy and available data on income Gini is remarkable. Clearly, there is no gold-standard, as uncertainty in estimates of income inequality is notoriously large. Therefore it is not possible to infer how well our light-based proxy might indicate 'true' income inequality. The good association with existing income inequality estimates we find is encouraging. However, our exploratory exercise is only a starting point and more empirical work is needed to further the preliminary results 
presented here. Nonetheless, it is worthwhile reflecting on some of the patterns we find.

First, we find that our light-based proxy is not associated with gross income-based Gini estimates, evident by a low correlation $(0.094$, $p$-value $=0.01)$. This suggests that the night time lights reflect consumption but not production.

Second, our light-based inequality proxy critically depends on spatial segregation. The fact that we do find strong relationships to income inequality estimates, is in line with the observation that spatial residential segregation is a near omnipresent phenomenon ${ }^{23,24}$, and also with findings that spatial residential segregation increases with income inequality ${ }^{27,28,31}$. Nonetheless, it is likely that higher spatial correlation within a country, due to nationwide patterns in spatial segregation or some other factor like culture or demographic, can make sub-national regions too alike, thus possibly confounding our remotely sensed light-based inequality proxy, especially at sub-national levels. A recent alternate method ${ }^{32}$, independent of spatial segregation requirement, first predicts income by night-lights at the subnational regional level and then uses predicted income to calculate an estimate of income Gini. Though not affected by segregation, their method is heavily influenced by sub-regional heterogeneity, such as geographic, political or climatic differences. Be it sub-regional heterogeneity (for them) or national patterns in spatial segregation (in our case), unravelling such issues will require more detailed follow-up studies in regions where geo-coded income data at different spatial scales or other estimators allow deeper analyses of localized patterns.

Third, our light-based Gini estimate is, on average, higher than the income-based Gini, whereas our theoretical segregation model illustrates that one should expect an underestimation if LPP would be a faithful estimate of income. Theoretically, the model does not allow for segregation being sharper than income disparities would suggest. Thus our model approaches the true value of income Gini from below, as segregation better matches the true distribution of income. However, empirically one possible explanation for this discrepancy is observed evidence that rich people are less likely to report all of their income, thus making top incomes elusive in survey-based estimates like income Gini ${ }^{5,33}$. Underreporting top incomes will make income Gini of inequality underestimate and hence lower than comparative survey independent measures like light Gini. Furthermore, very poor areas which do not have enough light emission, and very rich areas which are 'topcoded' in the NTL data, are both undetected in our analysis, due to their undistinguishable nature. Hence, we expect some nonlinearity in the true light- 
income relationship. Exploring the effects of such nonlinearities is beyond the scope of this paper, but would be an interesting avenue for further research.

In spite of the obvious limitations, it is promising that our results suggest that remotely sensed night-time light may be used, not only to estimate economic prosperity ${ }^{19-21}$ but also to reveal patterns of economic inequality. Although it is widely acknowledged that inequality has profound effects on the functioning of societies, data remain frustratingly scarce. The prospect of monitoring economic inequality using remotely sensed data opens exciting perspectives for exploring its drivers and consequences at finer and also across spatial scales. Furthermore, being a geo-coded estimate, the global light-based inequality map can also be used to investigate interactions with spatially-explicit social and ecological variables, such as social mobility ${ }^{34}$, trade ${ }^{35}$, bio-diversity ${ }^{36}$, resilience to natural disasters ${ }^{37}$ and resource use ${ }^{38}$, which are hypothesized to be closely associated with economic inequality. Such studies would have significant potential to guide development policy.

\section{Materials and Methods}

We estimate a proxy for economic inequality using a combination of night-time lights and population data. For light, we use annual average visible, stable lights, and cloud-free coverages of NTS composites data from DMSP-OLS version 4 at a spatial resolution of 0.01 decimal degree $(\sim 1 \mathrm{~km})$. Data is publicly available at https://ngdc.noaa.gov/eog ${ }^{39}$. For the population, we use the UN-Adjusted Population Count GPWv4 and GPWv3 datasets by SEDAC at 0.01 decimal degree, publicly available at http://sedac.ciesin.columbia.edu/ ${ }^{40}$. Combining NTL and population datasets from 1990-2010, we analysed five-yearly time points from 1990 to 2010 globally. For country-level net income Gini estimates, we use The Standardized World Income Inequality Database (SWIID) version $6.1^{41}$ available at http://fsolt.org/swiid/.

The close relationship between NTL and a range of economic indicators, as alluded to in the main text, makes light intensity a suitable measure to assign economic prosperity or income spatially. However, areas like cities are brighter not only because they are more economically active but also because they are more densely populated. To take spatial population into account we calculated average light intensity per person (i.e. LPP) globally at five-yearly time points between 19902010. At these five-year time points, we resampled both light and population raster data to a resolution of 0.01 decimal degree and then derived LPP by dividing NTL by the population count. For calculating LPP we only included those grid cells 
which had an NTL value greater than 0 and a population count of greater than 1 . In this way, places with too few houses and/or places without detectable anthropogenic lights were discarded (e.g. industries, highways, deserts, water bodies, forests and the like). Assuming NTL captures the economic prosperity spatially ${ }^{20,22}$, inequality is then inferred from the distribution of LPP, over a specified spatial scale. Since inequality is an aggregate quantity, calculations for Gini coefficients based on LPP were done mainly at two levels - first a coarser national level and second a finer sub-national 1-degree grid level.

National and state-level light-based inequality maps were generated to validate light derived Gini coefficients with corresponding available estimates of incomebased Gini estimates for the globe and US, respectively using a mixed model approach. To achieve this, light-based Gini coefficients were calculated using LPP values within the administrative boundary of each country and each state of the US, respectively. For most developing countries, income inequality estimates are prone to data comparability and quality issues, as already explained in the main text, and hence we set a cut-off of $<=1$ as per Solt's ${ }^{41}$ SWIID standard errors to exclude estimates with large confidence intervals. For US states although the data is of good quality, our light-based estimate is prone to insufficient sensitivity of the satellite sensor for detecting very low or very high light intensities (the saturation problem) in some areas ${ }^{42}$. Thus 30 US states with sufficient lights, as measured by summed annual average visible stable light values $>1.1 \times 10^{6}$ were included in the correlation analysis (fig $4 b$ ).

Grouping observations by available years for the same set of countries, we use a mixed model approach to study the relationship between light and income Gini, taking into account the randomness of available years. Available years would have been different if e.g. the satellite was launched at a different time or kept for a longer duration. In the mixed model, years and light Gini are included as random effects intercept and slope respectively. Furthermore, a parsimonious set of covariates are included to control for country-specific features such as economic output and population.

$$
\begin{gathered}
I G_{i j}=\beta_{0}+\beta_{1} L G_{i j}+\beta_{2} \ln (G D P)_{i j}+\beta_{3} \ln (P O P)_{i j}+b_{0 j}+b_{1 j} L G_{i j}+\varepsilon_{i j} \\
\varepsilon_{i j} \sim N\left(0, \sigma^{2}\right), \quad \boldsymbol{b}_{\boldsymbol{j}} \sim N(0, B)
\end{gathered}
$$

Subscript $i j$ refers to the respective estimate of country $i$ in year $j$. Here $I G_{i j}$ refers to income Gini, $L G_{i j}$ is light Gini, $G D P_{i j}$ is the country's GDP (constant 2010 US\$), $P O P_{i j}$ is country's population count, $b_{0 j}$ is year random intercept, $b_{1 j} L G_{i j}$ is 
the year random slope, $\varepsilon_{i j}$ are the error terms, $\sigma^{2}$ is the variance of the error terms and $B$ is the variance-covariance matrix of the random effects. Here the fixed part captures the overall relationship between light and income Gini while the random part informs how that relationship varies across years. Table 1 reports model comparison and results. The reported generalized linear mixed model version of the $\mathrm{R}^{2}$ is interpreted as the variance explained by the entire model, including both fixed and random effects and is calculated using Nakagawa et al. (2014) method ${ }^{43}$. AIC, $\mathrm{AICc}$ and BIC model comparison criterion is used to select model 3. Here, AICc is approximately equivalent to carrying out a leave-one-out cross-validation (see Fang, 2011) ${ }^{44}$.

For fine-grain quantification of light-based inequality globally we calculated Gini coefficients of LPP within 1-degree grid cells. To use all data points, a moving window approach was used to calculate focal values of light Gini for every 0.01 decimal degree grid centred within a 1-degree moving window. The resulting global maps for years 1990, 1995, 2000, 2005, 2010 and change maps for 1990-95, $1995-00,2000-05,2005-10$ were used to analyse trends in light-based inequality over time and space. We fitted a mixture normal distribution using the expectationmaximization (EM) algorithm to characterize the global distribution of light Gini. The mixing proportions are $\lambda_{1}=0.06$ for the red and $\lambda_{2}=0.94$ for the green normal mode. Mean and standard deviations are $\mu_{1}=0.05, \sigma_{1}=0.04$ and $\mu_{2}=$ $0.45, \sigma_{2}=0.16$ respectively for the red and green mode. For the change map, the distribution is unimodal and close to normal with mean 0.06 and standard deviation 0.2 . 


\begin{tabular}{|l|c|c|c|c|}
\hline \multicolumn{1}{|c|}{$\begin{array}{c}\text { Independent } \\
\text { variables }\end{array}$} & \multicolumn{4}{c|}{ Dependent variable: Income Gini } \\
\hline \multicolumn{1}{|c|}{ Fixed effects } & $(1)$ & $(2)$ & $(3)$ & $(4)$ \\
& \multicolumn{5}{c|}{$\begin{array}{c}\text { Estimate } \\
\text { (standard error) }\end{array}$} \\
\hline Light Gini & $0.35^{* *}$ & $0.31^{* *}$ & $0.22^{* * *}$ & $0.17^{* * *}$ \\
& $(0.073)$ & $(0.064)$ & $(0.03)$ & $(0.028)$ \\
\hline Log(POP) & & $1.49^{* * *}$ & $6.66^{* * *}$ & $6.89^{* * *}$ \\
& & $(0.36)$ & $(0.39)$ & $(0.42)$ \\
\hline Log(GDP) & & & $-5.68^{* * *}$ & $-5.90^{* * *}$ \\
& & & $(0.35)$ & $(0.38)$ \\
\hline Intercept & $14.98^{* *}$ & -7.55 & $61.46^{* * *}$ & $66.12^{* * *}$ \\
& $(3.11545)$ & $(6.01)$ & $(5.76)$ & $(6.14)$ \\
\hline \multicolumn{1}{|c|}{ random effects } & & Standard deviation & \\
\hline year (intercept) & 4.49 & 3.16 & 0.85 & - \\
\hline year:light gini (slope) & 0.13 & 0.11 & 0.03 & - \\
\hline Observations & 188 & 188 & 188 & 188 \\
\hline Countries & 57 & 57 & 57 & 57 \\
\hline Years & 5 & 5 & 5 & 5 \\
\hline$R^{2}$ & 0.37 & 0.41 & 0.74 & 0.69 \\
\hline AIC & 1323.216 & 1318.690 & 1149.070 & 1156.53 \\
\hline AICC & 1323.681 & 1319.313 & 1149.874 & 1156.86 \\
\hline
\end{tabular}

Significance codes: $\mathrm{p}$-value $<$ '***’ 0.001 '**’ $0.01^{\text {'*’ }} 0.05$.

Table 1: Columns (1), (2) and (3) show results for mixed models fitted using REML (restricted maximum likelihood estimation), while column (4) is only fitted with fixed effects. Best fit model is column (3) based on $\mathrm{R}^{2}$, AIC and AICc. 


\section{Data, software and code}

Data on light-based estimates of light-based inequality are available at the pubic server Zenodo (http://...TBD) and can be downloaded with open access. The code used for the analysis and generating figures, are available and can be requested from the corresponding author. The analysis was carried out in R (https://www.rproject.org) using the packages raster, rasterVis, sp, rgdal, ggplot2 and mixtools and Python (https://www.python.org/) using numpy, matplotlib, scipy and statsmodels.

\section{Acknowledgements}

This project received funding from the European Union's Horizon 2020 research and innovation programme under the Marie Sklodowska-Curie grant agreement No 643073. CX acknowledges supports from the National Natural Science Foundation of China (No. 31770512) and the CTF foundation.

\section{Authors' contribution}

MUM and MS designed the research. MUM and CX carried out the analysis.

MUM took the lead in writing the manuscript. All authors contributed to the final version of the manuscript. 


\title{
Supplementary information to
}

\section{Global inequality, remotely sensed}

\author{
M Usman Mirza*l,2, Chi Xü ${ }^{3}$, Bas van Bavel ${ }^{4}$, Egbert H van Nes ${ }^{2}$, Marten \\ Scheffer ${ }^{* 2}$ \\ ${ }^{1}$ Environmental Economics and Natural Resources, Wageningen University, \\ Netherlands \\ ${ }^{2}$ Environmental Sciences, Wageningen University, Netherlands \\ ${ }^{3}$ Life Sciences, Nanjing University, China \\ ${ }^{4}$ Economic and Social History, Utrecht University, Netherlands
}

\section{Linking spatial information to household inequality, a theoretical analysis}

To explore how segregation and sampling resolution may affect our remotely sensed indicators, we use an adapted version of the well-studied Schelling segregation model ${ }^{25}$. We generate different levels of spatial segregation in income and subsequently sample at different resolutions to mimic remote sensing.

To begin, $n$ individuals $i \in\{1 \ldots n\}$, where $n=1000$ were randomly placed uniformly to reside on a unit square. Each individual has a certain income $y_{i}$ drawn from a heavy tail Gamma distribution with parameters $G($ shape $=2$, scale $=$ 100), thus initializing a random set of individuals with a Gini coefficient of 0.38 . Gamma is one of the most used distributions to model income ${ }^{45,46}$. In each simulation cycle, local individual dynamics are governed by the following set of simple rules.

1. An individual compares own income $y_{i}$ with the average of $m$ immediate neighbours $j \in\{1 \ldots m\}$, where $m=10$.

2. If the individual's own income $y_{i}$ is beyond an income interval defined by one standard deviation $\left(\sigma_{y_{j}}\right)$ above or below the average $\left(\mu_{y_{j}}\right)$ income of immediate neighbours, the individual feels misplaced and will decide to move to a new random location, else the individual will not move:

$$
\begin{gathered}
\text { if } y_{i}>\mu_{y_{j}}+\sigma_{y_{j}} \rightarrow \text { move new location } \\
\text { if } y_{i}<\mu_{y_{j}}-\sigma_{y_{j}} \rightarrow \text { move new location } \\
\text { else } \rightarrow \text { settle down }
\end{gathered}
$$

This simple rule determining local interactions results in segregation based on income at the aggregate spatial level (Fig 1b). 
Subsequently, we mimic remote sensing of income inequality by superimposing a regular square grid over the square and averaging the income of all individuals within each cell (Fig 1c). The accuracy of remotely sensed light-based inequality to capture actual income inequality is simulated by varying both the levels of spatial segregation and grid resolution at which lights are sensed.

Level of segregation increases by each simulation cycle, starting from a randomly well mixed spatial distribution to a clustered one, based on model rules. This gives us different degrees of segregation to analyse. All those sets are analysed at different grid resolutions mimic how remote sensing might pick up inequality from spatially aggregated data at different scales.

For spatial segregation, starting from a random distribution, we see that the accuracy of light Gini to capture income Gini is poor when individuals reside unsegregated spatially. As spatial segregation increases, light Gini converges to actual income Gini (Fig 1d). The convergence indicates that in areas where residential patterns are spatially segregated based on income, we would expect a better inequality estimate via the distribution of lights.

Not surprisingly, the spatial resolution of the remote sensing is key. Starting from a coarser grid, as the resolution gets finer, our ability to capture the underlying income distribution increases. As grid resolution increases, we see convergence of light Gini towards actual Gini (Fig 1e). This analysis illustrates that both sensing resolution and spatial segregation contribute to allowing remotely sensed estimate of inequality to capture actual income inequality.

Obviously, in an ideal world, with a sensing resolution to remotely detect each individual separately, indeed no segregation would be needed. Till then, in the near future, with better resolution light data being collected via VIIRS annual products, we would expect the light-based inequality estimates to improve. To avoid comparison across two very different satellite datasets we used the longer albeit coarser NTL time series provided by the older and well used DMSP-OLS products for this study. 
(a)

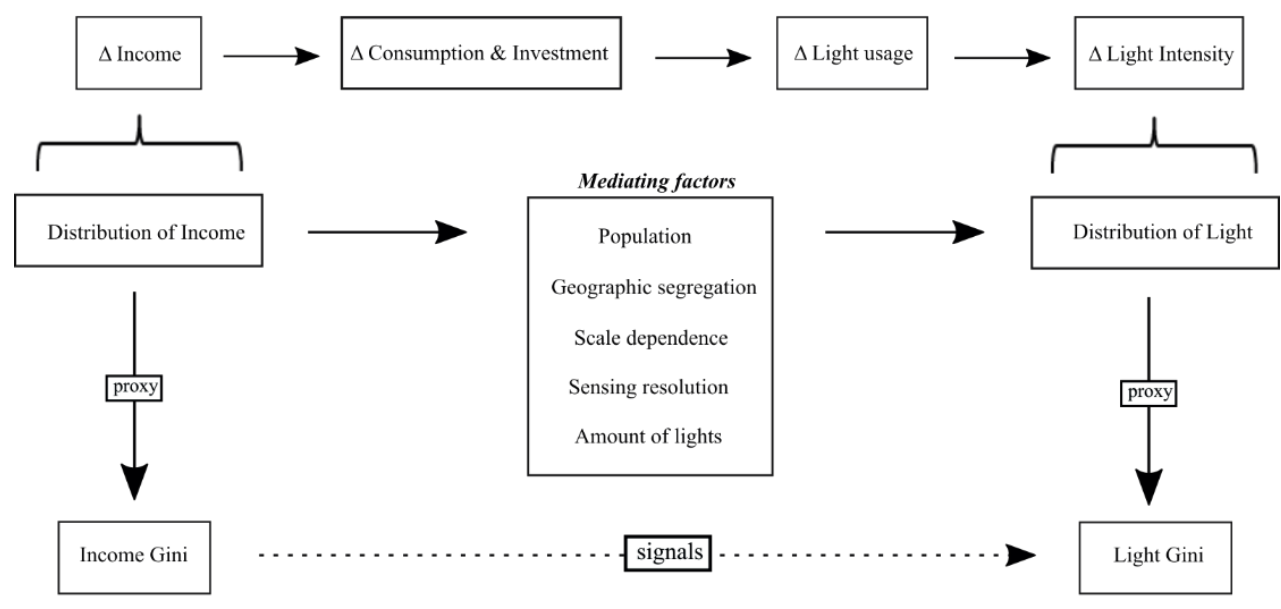

(b)
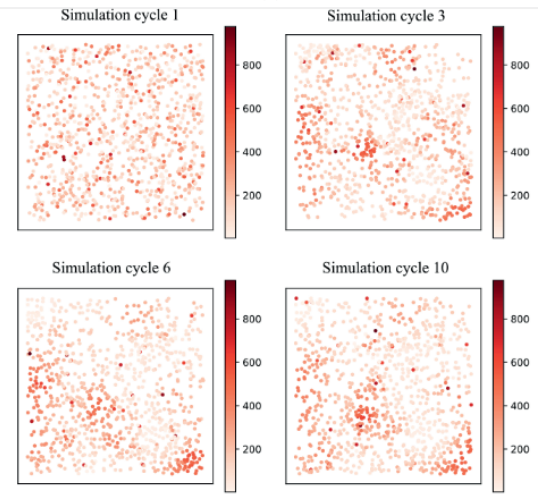

(d)

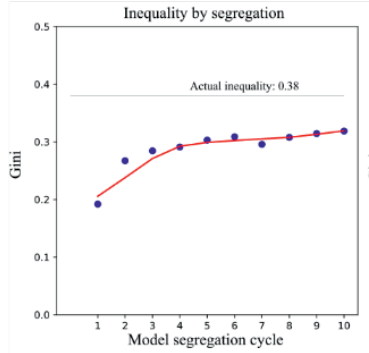

(c)
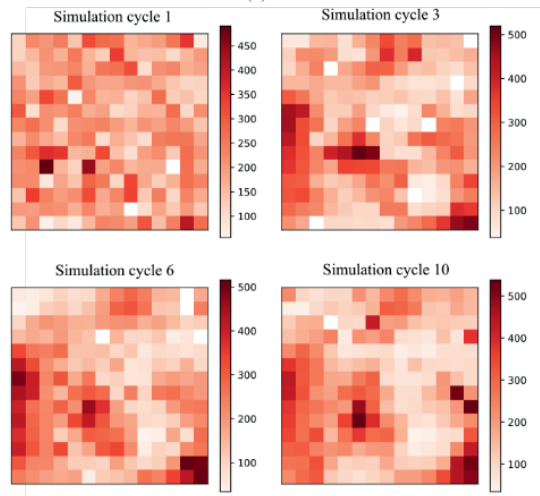

(e)

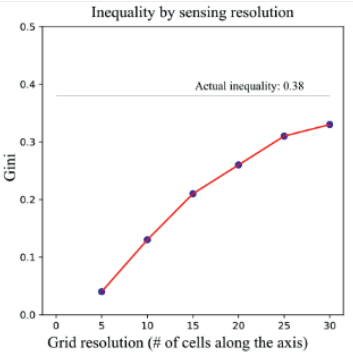

Figure S1: A conceptual visualization of the complex light-income relationship and simulating the effect of segregation and sampling resolution in a light-based estimate of inequality 


\section{References}

1. Piketty, T. Putting Distribution Back at the Center of Economics: Reflections on Capital in the Twenty-First Century. J. Econ. Perspect. 29, 67-88 (2015).

2. Fields, G. S. Data for measuring poverty and inequality changes in the developing countries. J. Dev. Econ. 44, 87-102 (1994).

3. Champernowne, D. G. A Comparison of Measures of Inequality of Income Distribution. Econ. J. 84, 787 (1974).

4. Leigh, A. How closely do top income shares track other measures of inequality? Econ. J. 117, (2007).

5. Meyer, B. D., Mok, W. K. C. \& Sullivan, J. X. Household surveys in crisis. J. Econ. Perspect. 29, 199-226 (2015).

6. Cowell, F. A. Inequality Measurement. in International Encyclopedia of the Social \& Behavioral Sciences: Second Edition (2015). doi:10.1016/B978-008-097086-8.44078-X

7. Ravallion, M. Measuring aggregate welfare in developing countries: How well do national accounts and surveys agree? Rev. Econ. Stat. (2003). doi:10.1162/003465303322369786

8. Rey, S. J. \& Janikas, M. V. Regional convergence, inequality, and space. Journal of Economic Geography 5, 155-176 (2005).

9. Atkinson, A. B. \& Brandolini, A. Promise and pitfalls in the use of 'secondary' data-sets: Income inequality in OECD countries as a case study. J. Econ. Lit. 39, 771-799 (2001).

10. Atkinson, A. B. \& Brandolini, A. On data: A case study of the evolution of income inequality across time and across countries. Cambridge J. Econ. 33, 381-404 (2009).

11. ISSC, IDS \& UNESCO. World social science report 2016: challenging inequalities: pathways to a just world (summary)*. International Social Science Journal 65, (UNESCO Publishing, 2014).

12. Saez, E. \& Zucman, G. Wealth in equality in the United States since 1913: Evidence from capitalized income tax data. Q. J. Econ. 131, 519-578 (2016).

13. Piketty, T. \& Zucman, G. Capital is back: Wealth-income ratios in rich countries 1700-2010. Q. J. Econ. 129, 1255-1310 (2014). 
14. de Miguel, J. M. Global Inequality: A New Approach for the Age of Globalization, de Branko Milanovic. Revista Española de Sociología 26, (Harvard University Press, 2017).

15. Francisco, F. H., Lustig, N. \& Teles, D. Appraising cross-national income inequality databases: An introduction. J. Econ. Inequal. 13, 497-526 (2015).

16. World Bank Group. Taking on Inequality. Poverty Shar. Prosper. 2016 Tak. Inequal. 193 (2016). doi:10.1596/978-1-4648-0958-3

17. Small, C. \& Elvidge, C. D. Night on earth: Mapping decadal changes of anthropogenic night light in asia. Int. J. Appl. Earth Obs. Geoinf. 22, 40-52 (2013).

18. Levin, N. \& Duke, Y. High spatial resolution night-time light images for demographic and socio-economic studies. Remote Sens. Environ. 119, 1-10 (2012).

19. Doll, C. N. H., Muller, J. P. \& Morley, J. G. Mapping regional economic activity from night-time light satellite imagery. Ecol. Econ. 57, 75-92 (2006).

20. Chen, X. \& Nordhaus, W. D. Using luminosity data as a proxy for economic statistics. Proc. Natl. Acad. Sci. (2014).

doi:10.1073/pnas.1408439111

21. Lazar, M. Shedding Light on the Global Distribution of Economic Activity. Open Geogr. J. 3, 147-160 (2011).

22. Henderson, J. V., Storeygard, A. \& Weil, D. N. Measuring economic growth from outer space. American Economic Review 102, 994-1028 (2012).

23. Bischoff, K. \& Reardon, S. Residential Segregation by Income, 1970-2009. Lost Decad. Soc. Chang. U.S. After 2000 (2013). doi:10.1017/CBO9781107415324.004

24. Louf, R. \& Barthelemy, M. Patterns of residential segregation. PLoS One 11, (2016).

25. Schelling, T. C. Dynamic models of segregation. J. Math. Sociol. 1, 143186 (1971).

26. Cheshire, P., Monastiriotis, V. \& Sheppard, S. Income Inequality and Residential Segregation: Labour Market Sorting and the Demand for Positional Goods. in \{Geographies of Labour Market Inequality\} 83-109 
(Routledge, 2003). doi:10.4324/9780203222812-10

27. Reardon, S. F. \& Bischoff, K. Income inequality and income segregation. Am. J. Sociol. 116, 1092-1153 (2011).

28. Watson, T. Inequality and the measurement of residential segregation by income in american neighborhoods. Review of Income and Wealth 55, 820 844 (2009).

29. Smith, B. \& Wills, S. Left in the dark? Oil and rural poverty. J. Assoc. Environ. Resour. Econ. 5, 865-904 (2018).

30. Bureau, U. S. C. 2006 \& 2010 American Community Survey 1-Year GINI Estimates. (2010).

31. Kawachi, I. Income inequality and economic residential segregation. Journal of Epidemiology and Community Health 56, 165-166 (2002).

32. Lessmann, C. \& Seidel, A. Regional inequality, convergence, and its determinants - A view from outer space. Eur. Econ. Rev. (2017). doi:10.1016/j.euroecorev.2016.11.009

33. Korinek, A., Mistiaen, J. A. \& Ravallion, M. Survey nonresponse and the distribution of income. J. Econ. Inequal. 4, 33-55 (2006).

34. Roberts, H. The Spirit Level: Why Equal Societies Almost Always do Better. Children \& Society 24, (Allen Lane, 2010).

35. Helpman, E., Itskhoki, O., Muendler, M. A. \& Redding, S. J. Trade and inequality: From theory to estimation. Rev. Econ. Stud. 84, 357-405 (2017).

36. Mikkelson, G. M., Gonzalez, A. \& Peterson, G. D. Economic inequality predicts biodiversity loss. PLoS One (2007). doi:10.1371/journal.pone.0000444

37. Kahn, M. E. The death toll from natural disasters: The role of income, geography, and institutions. Rev. Econ. Stat. 87, 271-284 (2005).

38. Baland, J. M. \& Platteau, J. P. The ambiguous impact of inequality on local resource management. World Dev. 27, 773-788 (1999).

39. NOAA. Version 4 DMSP-OLS Nighttime Lights Time Series. (2013).

40. Center for International Earth Science Information Network. Gridded Population of the World, Version 4 (GPWv4): Population Count, Revision 11. CIESIN - Columbia University (2018). doi:doi.org/10.7927/H4JW8BX5 
41. Solt, F. The Standardized World Income Inequality Database. Soc. Sci. $Q$. 97, 1267-1281 (2016).

42. Bennett, M. M. \& Smith, L. C. Advances in using multitemporal night-time lights satellite imagery to detect, estimate, and monitor socioeconomic dynamics. Remote Sens. Environ. 192, 176-197 (2017).

43. Nakagawa, S. \& Schielzeth, H. A general and simple method for obtaining R2 from generalized linear mixed-effects models. Methods Ecol. Evol. 4, 133-142 (2013).

44. Fang, Y. Asymptotic Equivalence between Cross-Validations and Akaike Information Criteria in Mixed-Effects Models. J. Data Sci. 9, 15-21 (2011).

45. Salem, A. B. Z. \& Mount, T. D. A Convenient Descriptive Model of Income Distribution: The Gamma Density. Econometrica 42, 1115 (1974).

46. McDonald, J. B. Some Generalized Functions for the Size Distribution of Income. Econometrica (1984). doi:10.2307/1913469 


\section{Chapter 6}

\section{Synthesis: Complex inequality}

\section{(Re)thinking inequality}

Traditionally, economic growth was focused on to strive for the highest aggregate welfare, ignoring how these welfare gains are distributed. The saying "a rising tide lifts all boats", is not always true with economic growth. Evidence suggests that income gains from growth are shared differently between the poor and rich ${ }^{1}$. The resultant widening of income disparities further constraint the poor in harvesting poverty reduction mechanisms, such as credit, investment and access to resources $^{2,3}$. Additionally, inequality also negatively affects key developmental mechanism such as institutional development and educational attainment, thus acting as a major barrier to economic growth and prosperity ${ }^{4}$.

Ensuring inclusive growth, where equal opportunities to grow are available to all, and societal wellbeing require understanding the structure and dynamics of economic inequality. At its core inequality is a quantification of the variance in an individual's or household's wellbeing, where wellbeing can be interpreted principally in two ways. First, wellbeing in material terms, which can either be expressed as income or possessed wealth or second, wellbeing based on access to opportunities linked with social status, ethnicity or gender differences ${ }^{5}$. Both interpretations are fundamental to the notions of fairness and justice, as the former deals with the current standard of living while the latter with having access to potential status or gains. In this thesis, I focus on the first interpretation of individual inequality in material terms i.e. how economic gains in society are distributed.

Inequality is shaped by heterogeneous individuals that interact not only inside an economic system but also across systems, for instance with natural resources and the larger biosphere. For example, the distribution of economic gains depend on market interactions between trading individuals but also how they extract resources and steward the ecosystem that sustains them. Furthermore, these interactions are governed by formal and informal rules, such as institutions, social norms and agreements. Mapping those micro-macro interactions with its intricate interrelations needs a complexity perspective of thinking ${ }^{6}$. More specifically, 
complexity cannot be understood by looking at each interaction in isolation but by considering the adaptive and emergent behaviour of the system as a whole. In this respect, complexity can be thought of as a holistic approach regarding systems with many interacting dimensions, and their emergent and adaptive behaviour ${ }^{7}$. These interactions are usually nonlinear in nature with multiple spatial and/or temporal scales, driven by a combination of positive and negative feedbacks ${ }^{8}$. Positive feedbacks, for example, can trigger a runaway reaction, in the underlying system dynamics, causing a catastrophic shift in response to a small change ${ }^{9}$. Such sudden behaviours, also known popularly as tipping points, make particularly difficult any predictions about interactions involving feedbacks ${ }^{10}$.

\section{Complex inequality}

From a complexity perspective, inequality needs to be studied, measured and understood from a multidimensional point of view, meaning in its relations with other relevant economic, social, technological and ecological systems. Simplifying this complexity by ignoring system-wide interconnections and feedbacks, where only certain relationships in isolation are studied, would lead to a piecemeal understanding of inequality and it's long term dynamics. On the other hand, attempting to model complexity extensively also has its cost in terms of compromising simplicity, tractability and ability to communicate to a broader audience. While striking a balance between complexity and simplicity would be highly valuable, this trade-off is not easy to resolve and is neither the aim of this chapter. Here I synthesis some of the key dimensions, central to achieving a balanced understanding of inequality that I have explored in this thesis, such as resource use, economic growth and institutions.

Inequality is invariably linked to the distribution of, and access to, natural resources, be it biotic or abiotic. Not only is the distribution of resources uneven across countries globally, but access to the resource is also unequal among individuals locally. Evidence suggests that differences in initial endowments (such as wealth, capital and access to resources) lead to significant variation in economic prosperity ${ }^{11}$, though this relationship is anything but straightforward ${ }^{12}$. Access to resource allows income generation, which in turn allows access to better technology and the ability to extract more resources, resulting in a positive feedback that leads to inequality and uneven growth (chapter 2$)^{3}$. Likewise, in an 
open economy, export demand fuels exploitative growth in the resource-abundant sector at the price of more widespread sustainable growth ${ }^{13,14}$.

Similar to economic growth, inequality is also observed as cyclical ${ }^{15}$. While it is well known that rising inequality is a function of economic growth ${ }^{16,17}$, high inequality can also trigger a crisis or possible collapse ${ }^{18}$. Eroding stability in both modern democratic regimes and ancient civilizations are found to follow episodes of high inequality, which triggers turmoil and counteracts any positive impact of growth ${ }^{19,20}$. From ancient Europe, a reconstruction of economic growth, using lead emissions from mining and smelting ${ }^{21}$, and inequality, using archaeological evidence of house $\operatorname{sizes}^{22}$, sheds light into the debilitating nature of high inequality. Inequality in ancient Europe evolved in long-run cycles, with a generally rising trend (Fig 1a). Between -1062 $\mathrm{BC}$ and $79 \mathrm{AD}$, we see a fast rise in inequality, as measured by the reconstructed Gini (green shaded region in Fig 1a). Coinciding with this rise in inequality, economic growth also went up post $-1062 \mathrm{BC}$, as measured with reconstructed data from lead emission (see Fig $1 \mathrm{~b}$ is a zoom-in of the green region in Fig1a). Rising inequality coincides with rising economic performance till the maximum sustained level during the Roman empire in 165 $\mathrm{AD}$, after which the Roman empire collapsed as shown by the red shaded region in (b) top panel, from 165 to $193 \mathrm{AD}$. 
(a)
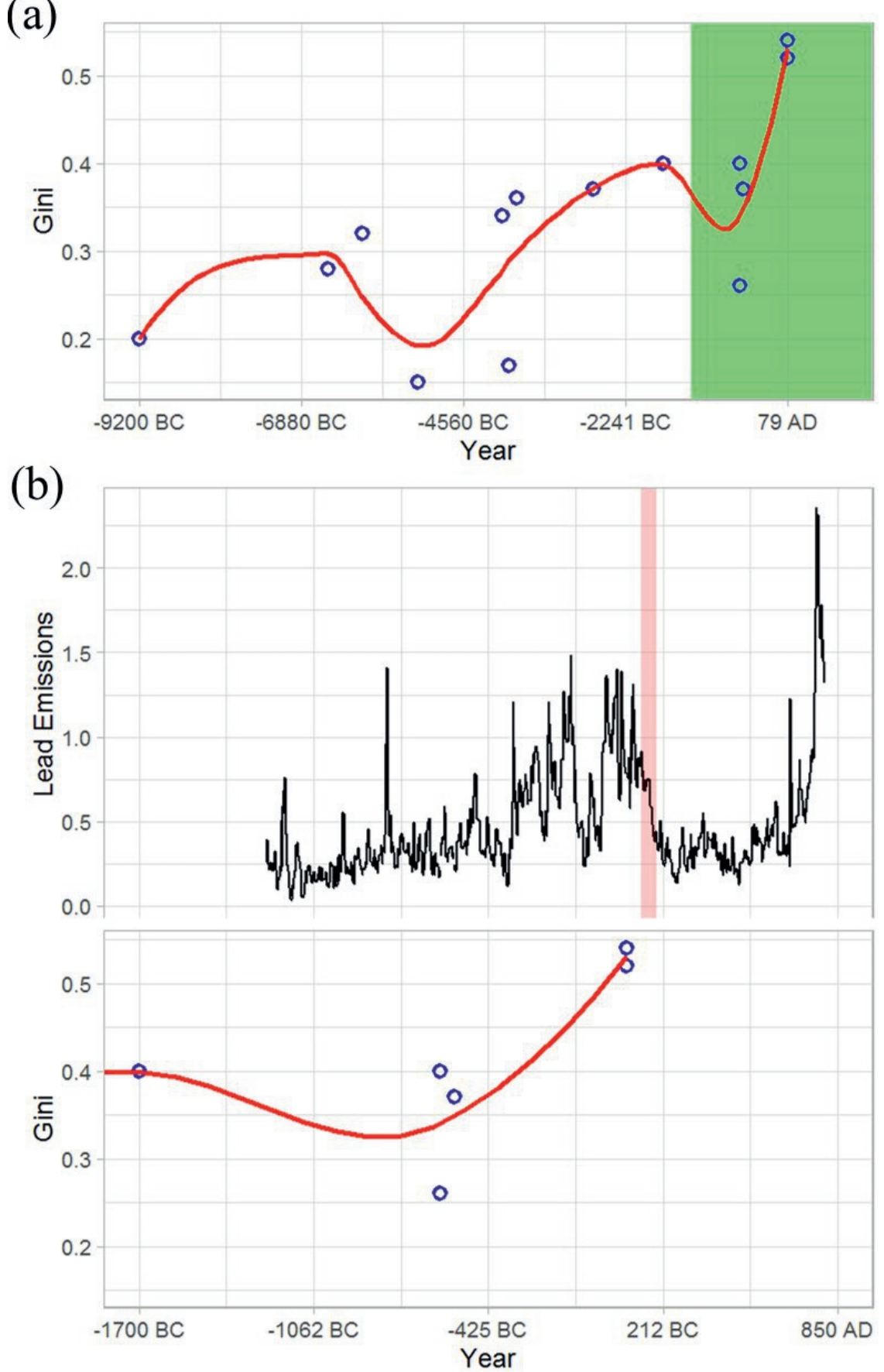

Figure 1: Reconstructed data on economic growth and inequality in ancient Europe. (a) Reconstructed long-run inequality dynamics in ancient Europe. The green 
shaded region shows the steep rise in inequality after -1062 BC. (b) A zoom-in on the green shaded region. Top panel show reconstructed ancient economic growth data from lead emissions. Bottom panel shows reconstructed ancient inequality data from house sizes. The red shaded region in (b) top panel shows the collapse of the Roman empire from 165 to $193 \mathrm{AD}$, coinciding with the rise in inequality from the bottom panel. Source: Reconstructed ancient inequality and economic growth data $^{21,22}$

Alike in both ancient and modern times, the link between inequality and economic growth is crucial for development, but it may not be direct. There is a lively debate on the multiple mediating variables shaping the growth-inequality relationship, and its effects on our fragile biosphere ${ }^{23}$. Foremost among these mediators is institutional strength. Quality of institutions can determine how sustainable economic growth can harness the benefits from natural resources ${ }^{24}$, however at the same time, institutions can lose effectiveness in mitigating the environmental toll of economic growth in regions with high inequality (chapter 3). Exploring these relationships require multivariate data analysis and study of nonlinear relationships.

Institutions constitute a wide set of variables such as cooperation, social norms, agreements and human behaviour, that shapes how individuals interact, drive economic activity and potentially dampen inequality. Each of these has profound implications on the allocation of resources, sharing of economic gains and delivery of services. It is well understood, both theoretically and from experiments, that social groups can rationally choose and sustain an unequal distribution of economic payoffs ${ }^{25-27}$. Some level of inequality is deemed 'fair', as individuals differ with respect to ability, productivity and effort. However, the real problem actualizes when inequality is 'unfairly' high. High inequality has adverse consequences for society such as mistrust, breakdown in cooperation ${ }^{28}$ and less interconnectedness among individuals ${ }^{29}$. In such situations, where cooperation fails and the affluent group disconnects from the rest of the society, wealth redistribution breaks down, thus leading to further inequality.

Unequal distribution of economic gains can be described at the micro individual level through multiple processes. Differentiated access to opportunities, technology and capital ${ }^{3,30,31}$ leading to heterogeneous income growth rates in the population, are some of the most commonly cited factors. Technology-Wealth feedback, for 
example, is seen in both ancient and modern societies as a key driver of inequality ${ }^{22,32}$. Left unchecked such feedbacks can lead to a rapid rise in inequality and can trigger poverty and resource depletion (chapter 2). Such triggers or critical transitions are not often seen due to active government policy with respect to taxation, redistribution or resource protection that can potentially dampen these dynamics.

Another important avenue to understand recent patterns in inequality data is with respect to the dependence between high and low-income groups. Income groups do not evolve independently but depend on the numerous individual interactions within a society. For example, high incomes can control the growth process, effectively casting out low incomes ${ }^{33,34}$. Moreover, income growth can be socially determined by whom you compare yourself with and whether your aspirations inspire or frustrate, in comparison ${ }^{35}$. The dependence relationship between the growth rates and size of these income groups can determine the long term stable distribution of income in a society (chapter 4). For the US, where inequality data per income percentile since 1960 is available, a clear threshold or break exists between high and low-income growth rates (Fig 2). This threshold follows a Ushaped trend over time, with the lowest point at 1980-89 coinciding with the minimum of inequality in the US, over the long-run ${ }^{36}$.

Central to the study of inequality is the need to integrate above-mentioned dimensions, and more such as trade, education or migration, that are not reviewed here. For policy, these multiple dimensions of inequality are not only important to identify leverage points to control inequality but also mechanisms to understand the causal effects, between these dimensions. 
(a)
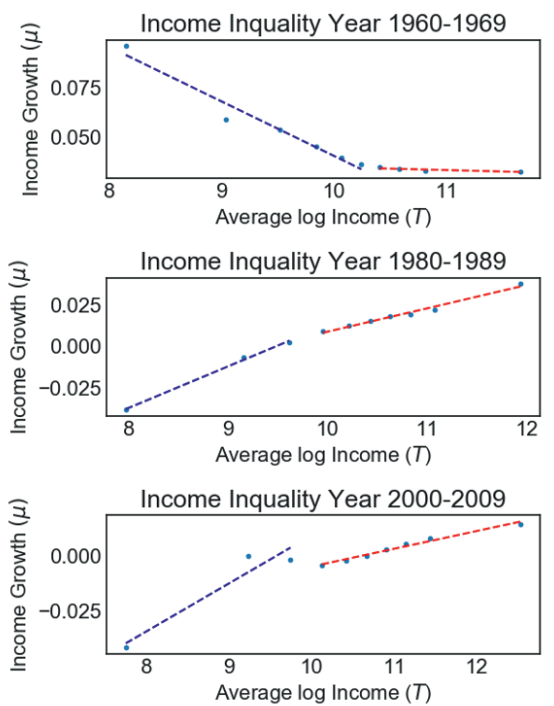
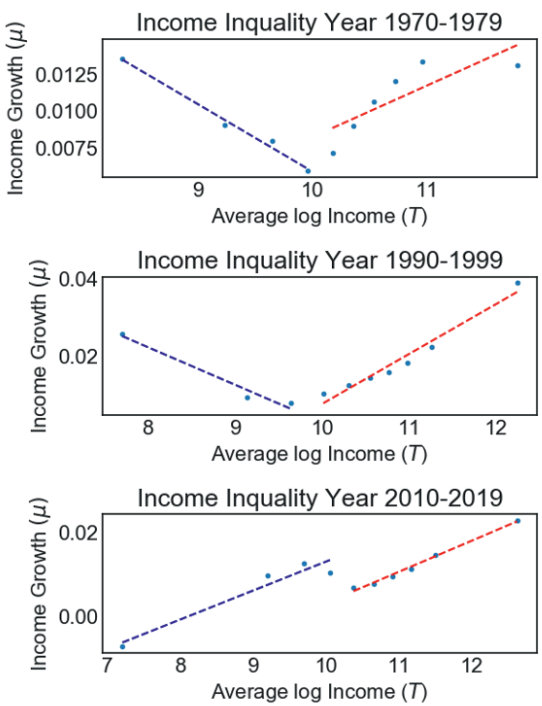

(b)

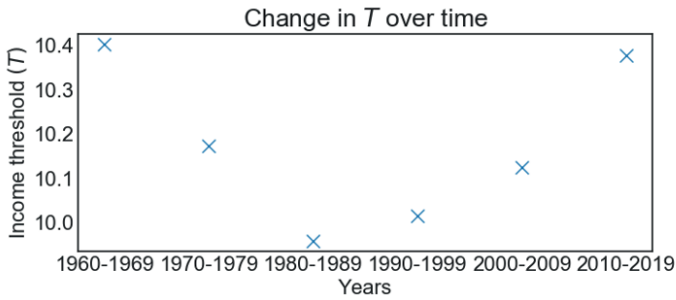

Figure 2: (a) Decade-wise income growth data for the US from 1960 to 2019. (b) Evolution of $T$ in the long-run 1960-2019. Source: World inequality database $(\mathrm{WID})^{37}$

\section{Challenge of inequality measurement}

With complexity in understanding inequality, we also face considerable challenges in reliably measuring it. Income and wealth are the two most popular estimates of economic thriving, but they are fundamentally different. Income is a flow measure, meaning it's a snapshot of your current earning, while wealth is a stock measure representing accumulated earnings or fortune. While economists have long argued that the distribution of wealth has played an important part in the distribution of income ${ }^{38}$, the data present a mixed picture. Wealth inequality tends to vary more and is on average higher than income inequality (see Fig 3 a for US and UK case). Both wealth and income inequality in the US presents the U-shaped curve over 
time, with more variation in wealth than income inequality. The post-1980 increase in inequality is also much more in wealth than in income. For the UK, the difference is more apparent. Wealth inequality kept on decreasing way past the point when income inequality bottomed out and started to increase. In recent years, income inequality in the UK is increasing but wealth inequality is relatively stable.

(a)
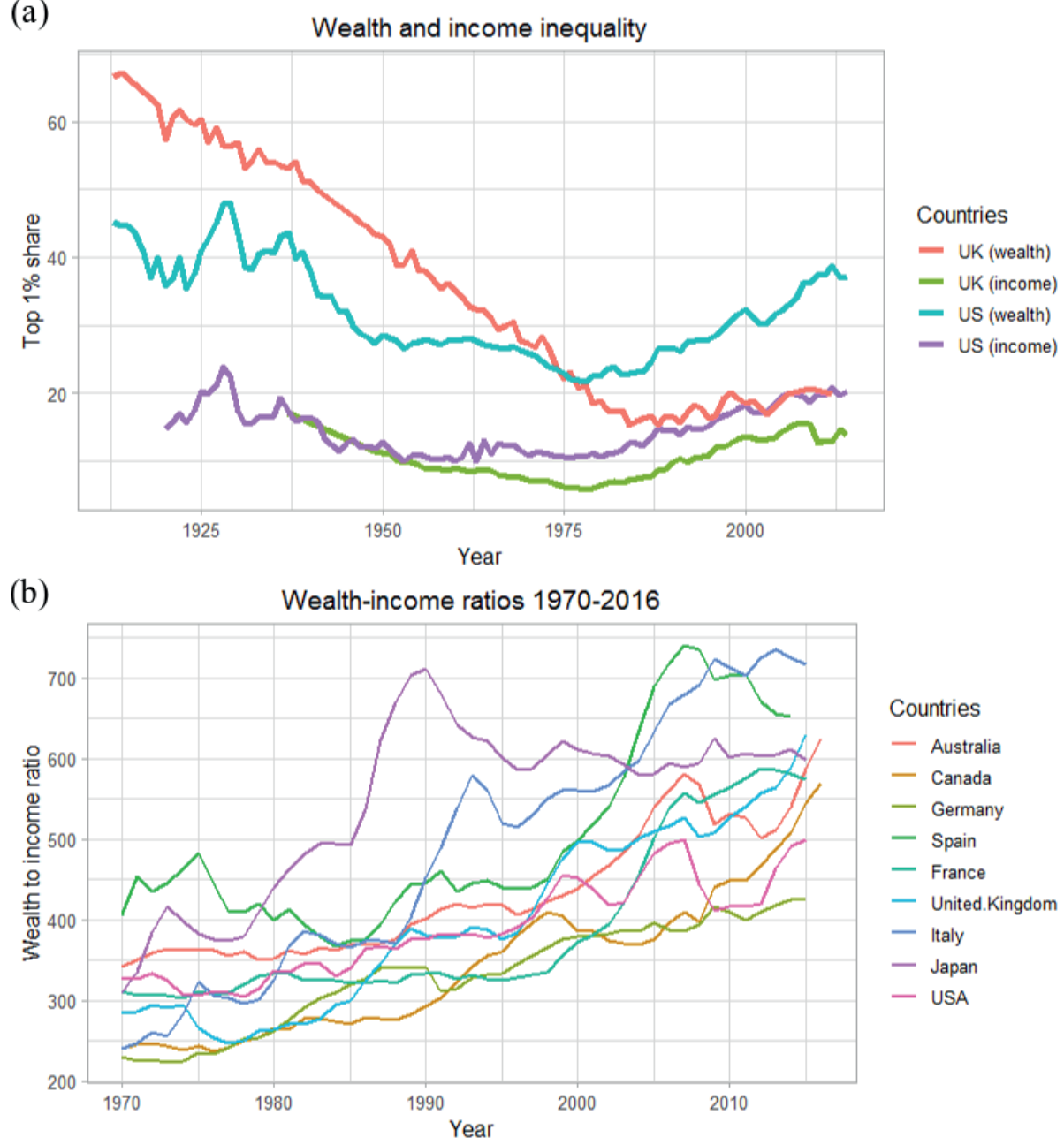

Figures 3: (a) Comparison of wealth and income inequality for the US and UK in the long run. (b) Evolution of wealth-income ratios since 1970 for multiple countries. Source: World inequality report $2018^{39}$

Difference between income and wealth dynamics has partly to do with major wealth components like inheritance and endowments/gifts that are independent of 
base income. Though the contribution of these components is expected to decline with development, as more wealth is accumulated via human capital and rising labour share of income, wealth and income do not seem to move together. This is also evident from data on wealth-income ratios which in general depict a rising trend, but with abundant short-term fluctuations (Fig 3b). Thus measuring economic inequality provides a different picture depending on whether wealth or income base is used.

Assuming we reconcile conceptual differences in wealth and income inequality, there exist serious limiting factors in terms of data availability and collection quality across regions, especially in the developing world ${ }^{40-42}$. We know the least about areas where inequality might present the most serious developmental policy challenge. A possible solution is independently collected data, for example, a remotely sensed measure, which is not dependent on the aforementioned limitations of household surveys or tax records. Remotely sensed data sources such as nigh-time lights (NTL) present us with an exciting and fresh perspective on measuring inequality (chapter 5). Studies show NTL to be a highly consistent indicator of economic activity ${ }^{43-45}$. Furthermore, night-time lights are free of collection or methodological variation across regions and, most importantly, the data is available for high and low developed regions alike. Estimated inequality based on night lights allows us, for the first time, to map inequality globally at a fine resolution (chapter 5).

\section{Limitations}

Work completed under this $\mathrm{PhD}$ thesis, while being ambitious, has a number of limitations that needs to be stated and understood. In modelling feedbacks between technology and wealth in chapter 2 or interactions between high and low-income growth rates in chapter 4, I take the micro-foundations of the income generation process as motivated by relevant literature ${ }^{35,46-50}$, as a simplifying assumption. The aim here is to identify or reveal generalizable patterns at the systems level to gain insights into the dynamics and structure of a macro level process like inequality. These include, in the case of this thesis, feedbacks between wealth and technology to understand the consequences of inequality in a socio-ecological system, and the relationship between low and high-income growth individuals to understand how this interaction leads to rising inequality. 
In chapter 3, institutions are taken in a somewhat restricted sense. Broadly speaking institutions can be both formal (governance and public services) and informal (norms and cooperation). However, restrictions of data availability allowed us to only analyse the interactions between inequality and institutions in the more formal definition, with respect to governance. More information about exactly how the institution's strength data was used is provided in the supplement to chapter 3 , which needs to be considered when interpreting results.

In chapter 5 , in remote sensing of inequality using night-lights data, it is important to note that there is no gold standard measure of income inequality. The popular income Gini is also an imperfect estimate, in terms of capturing the income distribution ${ }^{5}$, and thus the strong association we show with income Gini need to be interpreted with care. Critical here is also the light-income relationship. The lightincome relationship may not be one-to-one because of many factors such as energy savings, lighting habits, more homogenous infrastructural facilities in large urban areas, spatial segregation of residential households and the like. So, the actual relationship may not only be nonlinear but very region-specific in areas where our estimates are relatively weak. However, we do find a reasonable empirical relationship in many parts of the world showing the potential of using the distribution of lights as a measure of income inequality.

\section{Conclusion}

To the modern economist, inequality is primarily about the distribution of economic gains among individuals, and the intrinsic challenges it poses. Drivers and effects of inequality are usually studied in a local disaggregate fashion. Still, there is a pervasive demand from interdisciplinary scientists and policymakers for a multidimensional systems analysis ${ }^{51}$, where micro-dynamics are integrated into a systems analysis. This chapter synthesizes very briefly a new perspective on (re)thinking about inequality, and its multidimensional nature, using a systems complexity perspective.

Complexity science is an established part of the analysis toolbox in many disciplines such as physics, engineering, biology, ecology, environmental and climate sciences. Integration in mainstream economics is slow but ongoing. Nonlinearity and heterogeneity, the two main characteristics of complex systems, are copiously found in the study of inequality, and its long-run dynamics. 
Complexity in inequality, as studied in this thesis sheds light on the existence of multiple feedbacks (chapter 2), direct/indirect effects (chapter 3), adaptive behaviour from heterogeneous interaction (chapter 4) and problem of measurement (chapter 5), that overall may not have even scratched the surface of a potential paradigm shift in perception that complexity science offers. As with most $\mathrm{PhD}$ theses, this is just the beginning and I hope it can contribute to useful policy relevant practical insights in understanding the nature of inequality. 


\section{References}

1. Ravallion, M. Growth, inequality and poverty: Looking beyond averages. World Dev. 29, 1803-1815 (2001).

2. Deininger, K. \& Squire, L. New ways of looking at old issues: Inequality and growth. J. Dev. Econ. (1998). doi:10.1016/S0304-3878(98)00099-6

3. Mirza, M. U., Richter, A., van Nes, E. H. \& Scheffer, M. Technology driven inequality leads to poverty and resource depletion. Ecol. Econ. 160, 215-226 (2019).

4. Easterly, W. Inequality does cause underdevelopment: Insights from a new instrument. J. Dev. Econ. 84, 755-776 (2007).

5. McGregor, T., Smith, B. \& Wills, S. Measuring inequality. Oxford Rev. Econ. Policy 35, 368-395 (2019).

6. Rosser, J. B. On the Complexities of Complex Economic Dynamics. Journal of Economic Perspectives 13, 169-192 (1999).

7. Watkins, N. W. \& Freeman, M. P. Geoscience: Natural complexity. Science 320, 323-324 (2008).

8. Helbing, D. Managing complexity in socio-economic systems. Eur. Rev. 17, 423-438 (2009).

9. Scheffer, M. et al. Early-warning signals for critical transitions. Nature 461, 53-59 (2009).

10. Scheffer, M. et al. Anticipating Critical Transitions. Science (80-. ). 338, 344-348 (2012).

11. Sachs, J. \& Warner, A. Natural Resource Abundance and Economic Growth. NBER Working Paper 5398. NBER 3, (1995).

12. Havranek, T., Horvath, R. \& Zeynalov, A. Natural Resources and Economic Growth: A Meta-Analysis. World Dev. 88, 134-151 (2016).

13. Brander, J. A. \& Taylor, M. S. Open access renewable resources: Trade and trade policy in a two-country model. J. Int. Econ. 44, 181-209 (1998).

14. Stijns, J. P. C. Natural resource abundance and economic growth revisited. Resour. Policy 30, 107-130 (2005).

15. Milanovic, B. Income inequality is cyclical. Nature (2016). doi: $10.1038 / 537479 \mathrm{a}$ 
16. Banerjee, A. V. \& Duflo, E. Inequality and growth: What can the data Say? J. Econ. Growth 8, 267-299 (2003).

17. Forbes, K. J. A reassessment of the relationship between inequality and growth. Am. Econ. Rev. 90, 869-887 (2000).

18. Stockhammer, E. Rising inequality as a cause of the present crisis.

Cambridge J. Econ. 39, 935-958 (2015).

19. Muller, E. N. Economic determinants of democracy. Am. Sociol. Rev. (1995). doi:10.2307/2096435

20. Muller, E. N. Democracy, Economic Development, and Income Inequality. Am. Sociol. Rev. 53, 50 (1988).

21. McConnell, J. R. et al. Lead pollution recorded in Greenland ice indicates European emissions tracked plagues, wars, and imperial expansion during antiquity. Proc. Natl. Acad. Sci. U. S. A. 115, 5726-5731 (2018).

22. Kohler, T. A. et al. Greater post-Neolithic wealth disparities in Eurasia than in North America and Mesoamerica. Nature 24646 (2017). doi:10.1038/nature24646

23. Hamann, M. et al. Inequality and the Biosphere. Annu. Rev. Environ. Resour. 43, 61-83 (2018).

24. Mehlum, H., Moene, K. \& Torvik, R. Institutions and the Resource Curse. 40 Years Res. Rent Seek. 2 116, 245-264 (2006).

25. Starmans, C., Sheskin, M. \& Bloom, P. Why people prefer unequal societies. Nature Human Behaviour (2017). doi:10.1038/s41562-017-0082

26. Dal Bó, P. Social norms, cooperation and inequality. Econ. Theory 30, 89105 (2007).

27. Xie, W., Ho, B., Meier, S. \& Zhou, X. Rank reversal aversion inhibits redistribution across societies. Nat. Hum. Behav. 1, (2017).

28. Hauser, O. P., Hilbe, C., Chatterjee, K. \& Nowak, M. A. Social dilemmas among unequals. Nature 572, 524-527 (2019).

29. Nishi, A., Shirado, H., Rand, D. G. \& Christakis, N. A. Inequality and visibility of wealth in experimental social networks. Nature 526, 426-429 (2015).

30. Vinet, L. \& Zhedanov, A. A 'missing' family of classical orthogonal polynomials. J. Phys. A Math. Theor. 44, 696 (2011). 
31. Guvenen, F. Learning your earning: Are labor income shocks really very persistent? Am. Econ. Rev. 97, 687-712 (2007).

32. Kaymak, B. \& Poschke, M. The evolution of wealth inequality over half a century: The role of taxes, transfers and technology. J. Monet. Econ. 77, 125 (2016).

33. van der Weide, R. \& Milanovic, B. Inequality is bad for growth of the poor (but not for that of the rich). World Bank Econ. Rev. (2018).

doi:10.1093/wber/lhy023

34. Ravallion, M. Income inequality in the developing world. Science (80-. ). 344, 851-855 (2014).

35. Genicot, G. \& Ray, D. Aspirations and Inequality. Econometrica (2017). doi:10.3982/ecta13865

36. Piketty, T. \& Saez, E. Inequality in the long run. Science (80-. ). 344, 838843 (2014).

37. Alvaredo, F., Chancel, L., Piketty, T., Saez, E. \& Zucman, G. World inequality database. URL https//wid.world (2018).

38. Lutz, F. A. \& Kaldor, N. Capital Accumulation and Economic Growth. in The Theory of Capital (1961). doi:10.1007/978-1-349-08452-4_10

39. Alvaredo, F., Chancel, L., Piketty, T., Saez, E. \& Zucman, G. World Inequality Report 2018. Tijdschr. Geneeskd. (2017). doi:10.2143/TVG.70.09.2001601

40. Meyer, B. D., Mok, W. K. C. \& Sullivan, J. X. Household surveys in crisis. J. Econ. Perspect. 29, 199-226 (2015).

41. Cowell, F. A. Inequality Measurement. in International Encyclopedia of the Social \& Behavioral Sciences: Second Edition (2015). doi:10.1016/B978-008-097086-8.44078-X

42. Ravallion, M. Measuring aggregate welfare in developing countries: How well do national accounts and surveys agree? Rev. Econ. Stat. (2003). doi:10.1162/003465303322369786

43. Doll, C. N. H., Muller, J. P. \& Morley, J. G. Mapping regional economic activity from night-time light satellite imagery. Ecol. Econ. 57, 75-92 (2006).

44. Chen, X. \& Nordhaus, W. D. Using luminosity data as a proxy for economic statistics. Proc. Natl. Acad. Sci. (2014). 
doi:10.1073/pnas.1408439111

45. Lazar, M. Shedding Light on the Global Distribution of Economic Activity. Open Geogr. J. 3, 147-160 (2011).

46. Gabaix, X. et al. The Dynamics of Inequality. Econometrica 84, 2071-2111 (2016).

47. Bowles, S. [Ed], Durlauf, S. N. [Ed] \& Hoff, K. [Ed]. Poverty traps. Poverty traps. (2006).

48. Barrett, C. B. \& Carter, M. R. The Economics of Poverty Traps and Persistent Poverty: Empirical and Policy Implications. J. Dev. Stud. 49, 976-990 (2013).

49. Ghatak, M. Theories of poverty traps and anti-poverty policies. World Bank Econ. Rev. 29, S77-S105 (2015).

50. Rosen, S. The Economics of Superstars. Am. Econ. Rev. 71, 845-58 (1981).

51. Aaberge, R. \& Brandolini, A. Multidimensional poverty and inequality. in Handbook of Income Distribution (2015). doi:10.1016/B978-0-444-59428$0.00004-7$ 


\section{Chapter 7}

\section{Summary: Complexity in inequality}

This thesis explores three interrelated research streams. First, I am interested in the very fundamental and ancient question about the functioning of our societies - why are some individuals or countries rich and others poor? Under this broad question, I aim to understand the drivers of inequality, that traverse the artificial boundaries between economic, social and natural sciences. Second, I study inequality, as being complex and governed by highly interconnected processes such as technology, globalization, trade and migration. These processes can be highly nonlinear causing cyclical behaviour and/or critical transitions such as tipping points. Third, using dynamic models and empirical data, I explain the flow of information between heterogeneous agents, including individuals, households or countries, and how these interactions define the emergent dynamics of inequality. Heterogeneous individuals interact not only inside economic systems but also across systems, such as with the environment and climate. Furthermore, these interactions are governed by formal and informal rules, such as institutions, social norms and agreements.

In chapter 1, I discuss that there is no single set of rules which defines the dynamics of inequality. Instead, inequality is complex and governed by highly interconnected processes such as technology, globalization, trade and migration. Complex here refers to processes with many interacting dimensions, and their emergent and adaptive behaviour. These interactions are usually nonlinear in nature with multiple spatial and/or temporal scales.

The rise in inequality is often seen concurrent with resource overuse. In chapter 2, we use a stylised social-ecological model, to illustrate how a positive feedback between wealth and technology may fuel local inequality. Our results show that societies may evolve towards a stable state of few wealthy and many poor individuals, where the distribution of wealth depends on how access to technology is distributed. Overall, we illustrate how access to technology may be a mechanism that fuels resource degradation and consequently pushes most vulnerable members of society into a poverty trap.

Building on the theoretical links with resource use and poverty, inequality can not only be recognized as a key indicator for the welfare of societies but also as a risk 
to the larger biosphere. Biosphere impacts of inequality are inherently complex in nature with intricate interactions and feedbacks. In chapter 3, we use a global country-level dataset to explore how the strength of national institutions and economic inequality in society can mediate the loss of biodiversity worldwide. Our results highlight the complex and nonlinear nature of inequality-institutions interaction. We find both direct and indirect pathways via which economic growth can affect biodiversity loss. Furthermore, in the indirect route, the effectiveness of institutions is conditional on the level of inequality in society, such that biodiversity loss is ameliorated when institutions are strong and inequality low, but in regions with high inequality, institutions tend to lose their efficacy.

Understanding inequality requires unpacking its structure, which comprises income growth rates differing by income groups. Income groups do not evolve independently, but depend on socio-economic relations within a society, between high and low incomes. In chapter 4, we study the long term structure of inequality through modelling the dependence between high and low-income growths and their respective population sizes. First, using dynamic inequality model and income data since 1960, we predict the long term stable distribution of income for the US, France, China and India. Second, we explore the parameter space with respect to the variation in high and low-income growths for these countries, to understand the long term structure of inequality.

Studying inequality from a complexity perspective requires a combination of both computational modelling and empirical data, yet reliable data on income distributions are mostly limited to Northern America and Europe. In chapter 5, we show that this gap may be filled using a remotely sensed proxy for inequality based on nighttime light data. Using the tendency of residential households to spatially segregate on poverty and affluence, we analyse the spatial distribution of light per person as a proxy for variance in economic prosperity. The resulting light-based Gini coefficients relate well to existing estimates of net income inequality at the scale of countries globally, but also for states within the USA. Building on this association, we present the first high-resolution global maps of light-based inequality and its trends over recent years.

From current work, I find nonlinearity, heterogeneity, existence of multiple feedbacks, direct/indirect effects and adaptive behaviour, in the long-run dynamics 
of inequality. Synthesizing this thesis, chapter 6 presents a perspective on thinking about inequality from a complexity point of view. 
This $\mathrm{PhD}$ thesis received funding from the European Union's Horizon 2020 research and innovation programme under the Marie Sklodowska-Curie grant agreement No 643073.

Cover design: Vera van Beek

Cover photo credits: NASA Earth Observatory 



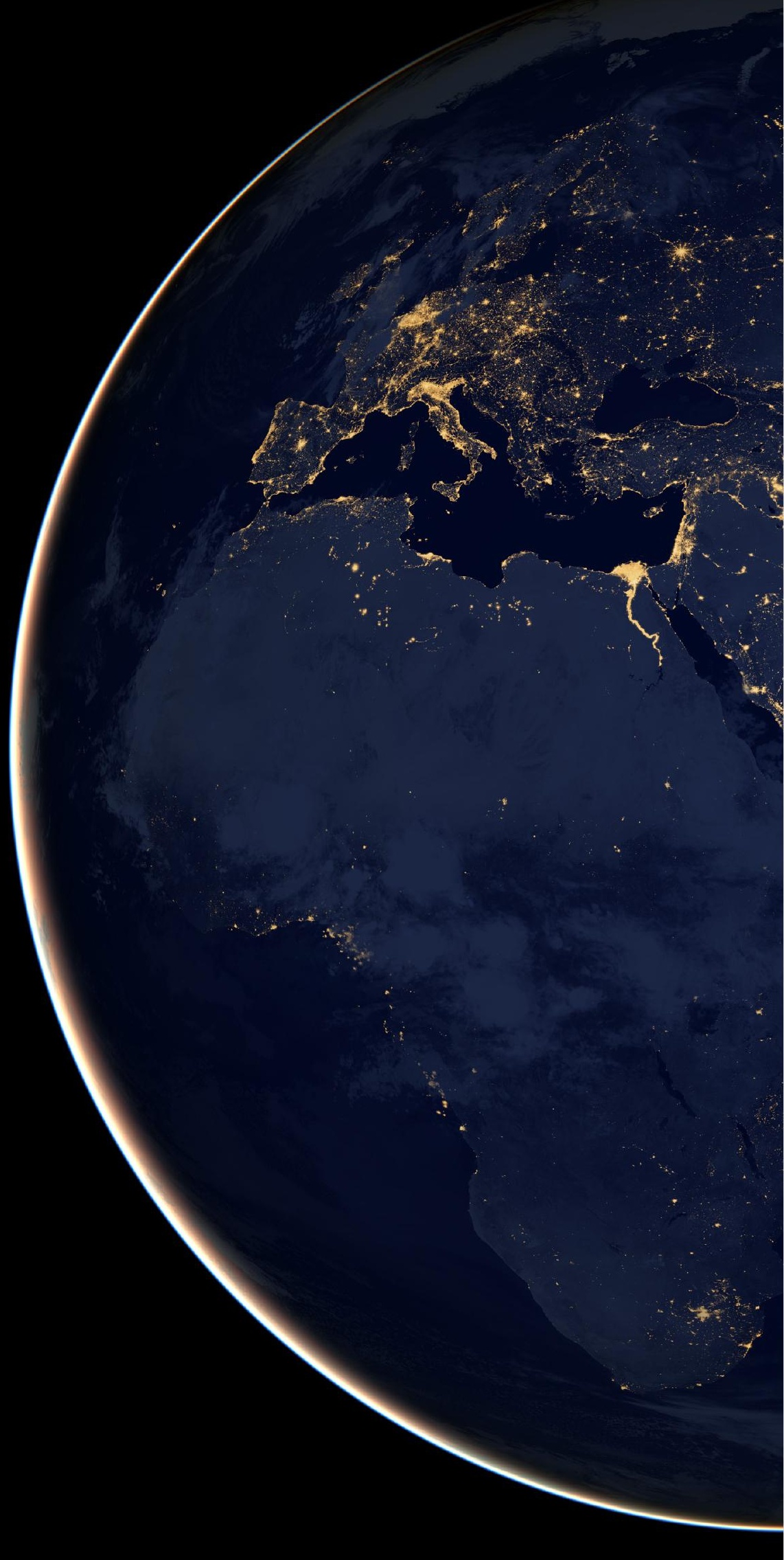

